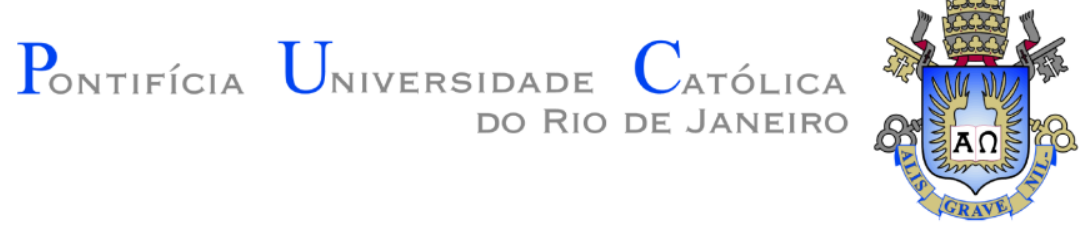

Fabio Marinho da Silva

\title{
Avaliação Probabilística da Estabilidade de uma Barragem de Rejeitos
}

\author{
Dissertação de Mestrado \\ Dissertação apresentada como requisito parcial \\ para obtenção do grau de Mestre pelo Programa \\ de Pós-graduação em Engenharia Civil do \\ Departamento de Engenharia Civil e Ambiental \\ da PUC-Rio
}

Orientador: Alberto de Sampaio Ferraz Jardim Sayão 


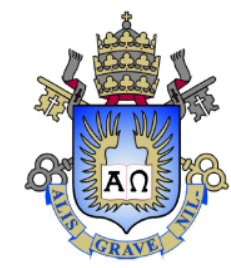

Fabio Marinho da Silva

\section{Avaliação Probabilística da Estabilidade de uma Barragem de Rejeitos}

Dissertação apresentada como requisito parcial para obtenção do grau de Mestre pelo Programa de PósGraduação em Engenharia Civil da PUC-Rio. Aprovada pela Comissão Examinadora abaixo.

Prof. Alberto de Sampaio Ferraz Jardim Sayão Orientador

Departamento de Engenharia Civil e Ambiental - PUC-Rio

Dr. Alessandro Cirone

Departamento de Engenharia Civil e Ambiental - PUC-Rio

Dr. Paulo Roberto Costa Cella

BVP Geotecnia e Hidrotecnia

Rio de Janeiro, 26 de Agosto de 2021. 
Todos os direitos reservados. É proibida a reprodução total ou parcial do trabalho sem autorização da universidade, do autor e do orientador.

Fabio Marinho da Silva

Graduado em Engenharia Civil pela Universidade Estácio de Sá em 2015. Ingressou no mestrado da PUC-Rio em 2019, na área de Geotecnia.

Ficha Catalográfica

Da Silva, Fabio Marinho

Avaliação Probabilística da Estabilidade de uma Barragem de Rejeitos / Fabio Marinho da Silva; orientador: Alberto de Sampaio Ferraz Jardim Sayão. - 2021.

129 f.: il. color. ; $29,7 \mathrm{~cm}$

1. Dissertação (mestrado) - Pontifícia Universidade Católica do Rio de Janeiro, Departamento de Engenharia Civil e Ambiental, 2021.

Inclui bibliografia

1. Engenharia civil e ambiental - Teses. 2. Tensão $x$ Deformação; 3 Probabilidade de Ruptura; 4 Barragem de Rejeito; 5 FOSM; 6 Monte Carlo. I. Sayão, Alberto de Sampaio Ferraz Jardim. II. Pontifícia Universidade Católica do Rio de Janeiro. Departamento de Engenharia Civil e Ambiental. III. Título.

CDD: 624 
À minha família, pelo amor, apoio e compreensão. 


\section{Agradecimentos}

A Deus pela minha saúde e pela força para enfrentar os desafios da vida.

Aos meus pais Almir e Márcia por me proverem educação, pelo exemplo e pelo amor e apoio incondicional em todos os momentos da minha vida. Sei que posso contar com vocês sempre.

Agradeço especialmente à minha companheira, parceira e amor Bruna Julianelli, por acreditar em mim e me levantar nos momentos de dificuldade. Você trouxe luz para a minha vida, como o sol em um dia nublado. Sou muito grato por você ter você ao meu lado.

Aos meus amigos da vida Evandson Freire, Gabriel Medeiros, Helder Pereira, Maycon Wisniewski, Paulo Rodrigues e Tiago Moraes, pela amizade e pelo companheirismo nos momentos bons e pelo apoio nos momentos difíceis.

Ao meu grande amigo Alexandre Schuler, pela amizade e por ter aberto tantas portas na minha vida pessoal e profissional. Sou muito grato pelos ensinamentos e por todo apoio que continua me dando.

Aos ex-colegas de trabalho e agora amigos Ana Rossini, Leidiane Azevedo, Lucas Repsold e Halley Ribeiro pela amizade, pelo apoio e por tornar o dia a dia leve e divertido mesmo nos momentos de pressão.

Ao meu amigo Eng. Nuno Alexandre Silva pelos ensinamentos e pelo exemplo profissional no qual eu me espelho.

Agradeço ao meu orientador Dr. Alberto Sayão por guiar meus estudos e compartilhar comigo sua grande experiência e seus conhecimentos geotécnicos.

Aos meus colegas de mestrado Vitor Guerra Lopes, Vitor Albuquerque, Thiago Ayres, Thiago Schuck, Alessandra Mazon, Tamires Campos, Luiza Fernandes e Gabriel Baldanza pelo apoio e parceria nas incontáveis horas de estudo na PUC. Tenho certeza de que ainda vamos nos encontrar muitas vezes ao longo da carreira profissional.

Ao Dr. Paulo Cella pelos ensinamentos compartilhados e por estimular em mim o apreço pela técnica e pela boa enganharia. 
Ao Dr. Alberto Ortigão pelos muitos anos de ensinamento e pela contribuição efetiva na minha formação como engenheiro geotécnico.

Ao Professor Marcus Bedeschi por acreditar em mim, pelo apoio e pelas diversas cartas de recomendação. Sou muito grato.

À Dra ${ }^{\mathrm{a}}$. Jackeline Castañeda Huertas pela carta de recomendação para ingresso no curso de mestrado.

A empresa BVP pela grande oportunidade profissional e pela disponibilização dos dados utilizados nesta dissertação. É um prazer fazer parte deste time.

À empresa Terratek onde comecei minha carreira e pude me desenvolver profissionalmente com grandes mentores.

Agradeço à mineradora Vale pela disponibilização dos dados necessários para a elaboração deste estudo.

Ao CNPq e à PUC-Rio, pelos auxílios concedidos, sem os quais este trabalho não poderia ter sido realizado.

O presente trabalho foi realizado com apoio da Coordenação de Aperfeiçoamento de Pessoal de Nível Superior - Brasil (CAPES) - Código de Financiamento 001. 


\section{Resumo}

Da Silva, Fabio Marinho; Sayão, Alberto de Sampaio Ferraz Jardim (Orientador). Avaliação Probabilística da Estabilidade de uma Barragem de Rejeitos. Rio de Janeiro, 2021. 129p. Dissertação de Mestrado - Departamento de Engenharia Civil e Ambiental. Pontifícia Universidade Católica do Rio de Janeiro.

Este trabalho apresenta a utilização de métodos de equilíbrio limite em conjunto com métodos numéricos pela abordagem probabilística, para avaliação da estabilidade de uma barragem de rejeitos de mineração de ferro situada no quadrilátero ferrífero, no Estado de Minas Gerais. Foram conduzidas análises fazendo uso dos métodos de Bishop Simplificado (1955) e Morgenstern \& Price (1965), além de análises numéricas de tensão vs deformação pelo método dos elementos finitos. Os campos de poropressão gerados no modelo numérico em dois momentos distintos da obra foram exportados para os modelos de equilíbrio limite, de forma que ambas análises fossem realizadas em condições piezométricas similares. Para as análises probabilísticas foram adotados os métodos FOSM (First Order Second Moment) e Monte Carlo. São apresentandos os conceitos básicos de análises de estabilidade determinísticas e probabilísticas, abrangendo os métodos de cálculo de FS, fundamentos de probabilidade e estatística e conceitos de modelagem numérica. Este estudo aborda também os princípios construtivos de barragens de rejeito de mineração, além da aplicação dos métodos probabilísticos para avaliação da estabilidade de uma barragem de rejeitos, construída pelo método de jusante. Os resultados indicaram que a consideração de uma superfície de ruptura livre foi fator preponderante na influência dos parâmetros na PR (Probabilidade de Ruptura). Concluiu-se também que os método de cálculo de FS teve maior influência no valor da PR do que as condições piezométricas da fundação.

\section{Palavras-chave}

Tensão vs Deformação; Probabilidade de Ruptura; Barragem de Rejeito; FOSM; Monte Carlo. 


\section{Abstract}

Da Silva, Fabio Marinho; Sayão, Alberto de Sampaio Ferraz Jardim (Advisor). Probabilistic Stability Evaluation of a Tailings Dam. Rio de Janeiro, 2021. 129p. Dissertação de Mestrado - Departamento de Engenharia Civil e Ambiental. Pontifícia Universidade Católica do Rio de Janeiro.

This work presents the use of limit equilibrium (LEM) and numerical methods by the probabilistic approach, in order to evaluate the stability of an iron ore tailings dam located in Minas Gerais's iron quadrangle. LEM analyzes were carried out using the Simplified Bishop (1955) and Morgenstern \& Price (1965) methods, in addition to stress vs strain analyzes with the finite element method. The pore pressure fields generated in the numerical model at two distinct construction stages were exported to the limit equilibrium models in order to guarantee that both analyzes were performed on the same piezometric conditions. For the probabilistic analyzes the FOSM (First Order Second Moment) and Monte Carlo methods were applied. The basic concepts of deterministic and probabilistic stability analysis are presented together with the fundamentals of statistics and probability, FoS (Factor of Safety) calculation methods, as well as numerical modeling concepts. This work also addresses the definition and construction principles of tailings dams. This study presents an application of probabilistic methods to assess the stability of a tailings dam built and heightened by the downstream method. The results indicate that the consideration of a free failure surface was the decisive factor to the magnitude of the influence of each parameter on the PF (Probability of Failure). It was also concluded that the FoS calculation methods had a greater influence on the PF than the foundation's piezometric conditions.

\section{Keywords}

Stress-strain; Probability of Failure; Tailings Dam; FOSM; Monte Carlo 


\section{Sumário}

1 Introdução 16

1.1. Relevância do Tema 16

$\begin{array}{ll}\text { 1.2. Objetivo } & 18\end{array}$

$\begin{array}{ll}\text { 1.3. Estrutura da Dissertação } & 19\end{array}$

2 Revisão Bibliográfica $\quad 21$

2.1. Análises Determinísticas de Estabilidade - Métodos de Equilíbrio Limite $\quad 21$

2.1.1. Cálculo de FS 22

2.1.2. Métodos Aproximados 25

2.1.3. Métodos Rigorosos 26

2.2. Análises Probabilísticas de Estabilidade 29

2.2.1. Fundamentos de Estatística e Probabilidade 30

2.2.2. Probabilidade de Ruptura e Confiabilidade 34

$\begin{array}{ll}\text { 2.2.3. Método FOSM } & 37\end{array}$

2.2.4. Método das Estimativas Pontuais 39

2.2.5. Método de Monte Carlo 40

2.2.6. Amostragem por Hipercubo Latino 42

2.2.7. Variabilidade Espacial de Parâmetros Geotécnicos 44

2.2.8. Estudos Anteriores 48

2.3. Análises Numéricas $\quad 51$

2.3.1. Método das Diferenças Finitas 51

2.3.2. Método dos Elementos Finitos 54

2.3.3. Modelos Constitutivos $\quad 57$

2.4. Geração e Caracterização do Rejeito de Ferro 74

$\begin{array}{ll}\text { 2.4.1. Barragens de Rejeito } & 77\end{array}$

3 Estudo de Caso - Barragem de Rejeito de Mineração de Ferro 82

3.1. Histórico da Barragem 82 
3.2. Aspectos Geológico-Geotécnicos

3.3. Comportamento Tensão x Deformação 91

3.3.1. Construção do Modelo Numérico 91

3.4. Avaliação de Segurança 97

3.4.1. Metodologia 97

4 Análise dos Resultados 101

4.1. Aplicação do Método FOSM 101

4.2. Aplicação do Método de Monte Carlo 113

4.3. Comparação dos Resultados 114

5 Conclusões 117

6 Recomendações para Estudos Futuros 119

7 Referências Bibliográficas $\quad 120$

$\begin{array}{ll}\text { Apêndices } & 125\end{array}$ 


\section{Lista de Figuras}

Figura 2-1 - Fator de segurança e probabilidade de ruptura (Adaptado de Lacasse, 2016) .22

Figura 2-2 - Método das fatias (Craig, 2004) ...................................................... 23

Figura 2-3 - Forças atuantes em uma fatia genérica ........................................ 24

Figura 2-4 - Método de Morgenstern \& Price - Forças aplicadas sobre uma fatia 27

Figura 2-5 - Forças atuantes na base das fatias pelo método de Spencer ............. 28

Figura 2-6 - Distribuição de forças em uma fatia (Sarma, 1973) ......................... 29

Figura 2-7 -Distribuição normal de probabilidades (Wackerly et al., 2007).......... 31

Figura 2-8 - Distribuição normal gaussiana padrão ……………………….............. 32

Figura 2-9 -Curva da função de densidade da distribuição probabilística log-normal

Figura 2-10 - Distribuição normal e log-normal de resistência não drenada, $S u$, com média de $100 \mathrm{kPa}$ e desvio padrão de $50 \mathrm{kPa}$ (Chok, 2009) 34

Figura 2-11 - Conceito de probabilidade de ruptura quando: a solicitação e a resistência são variáveis aleatórias a); quando somente a resistência é conhecida $b$ ) 35

Figura 2-12 - Relação entre índice de confiabilidade e probabilidade de ruptura (Dell'Avanzi e Sayão, 1998) 37

Figura 2-13 - Nuvem de pontos gerada pela distribuição puramente aleatória de pontos (Hurtado e Barbat, 1998) 41

Figura 2-14 - Amostragem estratificada (Hurtado e Barbat, 1998) 42

Figura 2-15 - Hipercubo latino para duas variáveis e 5 eventos, onde a matriz $5 \times 2$ (a) determina o plano ilustrado em (b) (adaptado de Olsson et al., 2003)..... 43 Figura 2-16 - Amostragem por hipercubo latino (Hurtado e Barbat, 1998) ......... 44

Figura 2-17 - Variabilidade inerente dos solos (Phoon e Kulhawy, 1999)........... 45 Figura 2-18 - Medidas estatísticas de $\boldsymbol{c u}$. (a) $\boldsymbol{c u}$ variando com a profundidade (b) função de densidade de probabilidade de $\boldsymbol{c u}$ (Hicks e Samy, 2002) 46 
Figura 2-19 - Ilustração geométrica de aproximações de primeira ordem utilizando o método das diferenças finitas 53

Figura 2-20 - Convenção de coordenadas de uma malha de pontos discretos com localização do ponto central e pontos adjacentes

Figura 2-21 - Posição dos nós e pontos de integração para diferentes tipos de elemento finito (Adaptado de PLAXIS, 2020) ….........................................55

Figura 2-22 - Etapas de construção de um modelo elementos finitos ...................56

Figura 2-23 - Solução numérica versus solução exata (PLAXIS, 2020) ...............57

Figura 2-24 -Exemplos de curvas tensão vs deformação para o estado 1D de tensão: (a) típico resultado de ensaio de laboratório em solo; (b) material rígido perfeitamente plástico; (c) material elasto-perfeitamente plástico; (d) material plástico com endurecimento - hardening; (e) material plástico com amolecimento - softening (Romanel, 2018) ................................................58

Figura 2-25 - Lei de fluxo não associada (adaptado de Naylor et al., 1981) .........60

Figura 2-26 - Superfície de escoamento de Mohr-Coulomb no plano das tensões principais para $\mathrm{c}^{\prime}=0$ (PLAXIS, 2020) 63

Figura 2-27 - Relação hiperbólica de tensão x deformação formulada por Kondner e Zelasko (1963) (a), e sua modificação conforme Duncan e Chang (1970) (b) (Adaptado de Benz, 2007) 65

Figura 2-28 - Sucessivas envoltórias de escoamento para vários valores do parâmetro de plasticidade $\gamma^{\mathrm{p}}$ (Schanz; Vermeer e Bonnier 1999) 66

Figura 2-29 - Superfície de escoamento por compressão e cisalhamento (Benz, 2007) 69

Figura 2-30 - Representação da superfície de escoamento completa do modelo HS no espaço das tensões principais, para um solo não coesivo (PLAXIS. 2020) 70

Figura 2-31 - Variação do módulo $E_{50}$ com os parâmetros $m, \phi \phi^{\prime}$ e c' (Obrzud, 2016)

Figura 2-32 - Representação pelo modelo HS do comportamento de solos - ativação das superfícies de escoamento por carregamentos desviadores $f s$ e

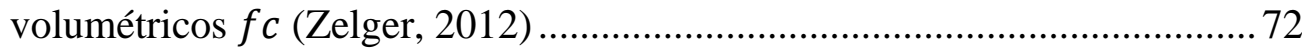

Figura 2-33 -Seção transversal da superfície de escoamento do critério de Mohr Coulomb no plano octaédrico 72 
Figura 2-34 - Lúnula de tensões para carregamentos do tipo drenado e não drenado (A) 73

Figura 2-35 - Fluxograma típico de tratamento de minério (Luz et al., 2010) ..... 76 Figura 2-36 -Seção típica de uma barragem alteada para montante (Vick, 1990) 78 Figura 2-37 - Alteamento sequencial de barragem construída pelo Método de Jusante (Vick, 1990) .79

Figura 2-38 - Alteamento sequencial de barragem construída pelo Método de Linha de Centro (Vick, 1990) 81

Figura 3-1 - Desenho esquemático da configuração da barragem na época de sua construção..... 82

Figura 3-2 - Desenho esquemático da barragem após o primeiro alteamento...... 83 Figura 3-3 - Desenho esquemático da configuração da barragem após o $2^{\circ}$ alteamento...... 84

Figura 3-4 - Desenho esquemático da configuração da barragem após a paralisação do $3^{\circ}$ alteamento .84

Figura 3-5 - Histórico de alteamentos da barragem de rejeitos estudada .86

Figura 3-6 - Localização da seção de análise A-A (fonte: Google Earth, 2021) .. 88

Figura 3-7 - Modelo geotécnico do maciço da Seção A-A.................................... 89

Figura 3-8 - Modelo geotécnico da fundação da seção A-A ................................. 90

Figura 3-9 - Malha de elementos finitos da Seção A-A......................................... 91

Figura 3-10 - Distribuição de poropressões no maciço e na fundação da barragem, ao final da construção das bancadas de alteamento e após a dissipação total dos excessos de poropressão construtivos .93

Figura 3-11 - Envoltórias de resistência efetiva das camadas SAC e SSG no plano p'-q .94

Figura 3-12 - Coeficientes de variação das variáveis aleatórias .98

Figura 3-13 - Cálculo da derivada parcial de FS em relação ao ângulo de atrito do $\mathrm{SAC}$ 100

Figura 4-1 - a) superfície de ruptura crítica no cenário pós construtivo b) escalar dos excessos de poropressão na fundação no cenário pós construtivo 102

Figura 4-2 - Influência relativa dos parâmetros variáveis na variância do FS Método Phi-c Reduction - Final de Construção 103

Figura 4-3 - Tensão cisalhante relativa a) cenário pós construtivo b) cenário pós dissipação dos excessos de poropressão. 104 
Figura 4-4 - a) superfície de ruptura crítica no cenário pós dissipação de poropressão b) escalar dos excessos de poropressão na fundação no cenário pós dissipação de poropressão 106

Figura 4-5 - Variação da influência dos parâmetros na variância de FS entre cenários de análise pelo método Phi-c Reduction 107

Figura 4-6 - Análise de estabilidade considerando parâmetros médios no cenário pós construtivo 108

Figura 4-7 - Influência relativa dos parâmetros na variância de FS nos métodos de equilíbrio limite no cenário pós construtivo 109

Figura 4-8 - Análise de estabilidade considerando parâmetros médios no cenário pós dissipação de poropressão 110

Figura 4-9 - Influência relativa dos parâmetros na variância de FS nos métodos de equilíbrio limite no cenário pós dissipação de poropressão

Figura 4-10 - Comparação da influência dos parâmetros na variância do FS para os três métodos no cenário pós construtivo 112

Figura 4-11 - Comparação da influência dos parâmetros na variância do FS para os três métodos no cenário pós dissipação de poropressão.

Figura 4-12 - Probabilidade de ruptura nos dois cenários de análise pelo método de FOSM 113

Figura 4-13 - Probabilidade de ruptura nos dois cenários de análise pelo Método de Monte Carlo 114

Figura 4-14 - Comparação das probabilidades de ruptura e índices de confiabilidade entre métodos 116 


\section{Lista de Tabelas}

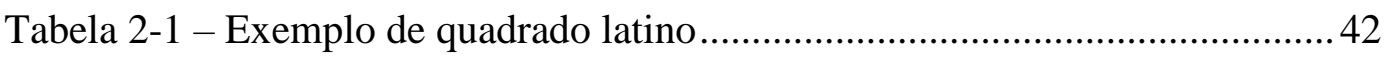

Tabela 2-2 - Coeficientes de variação e distribuições típicas de parâmetros de solo (Adaptado de Lacasse e Nadim, 2007) ........................................................46

Tabela 2-3 - Coeficientes de variação para propriedades geotécnicas e ensaios in

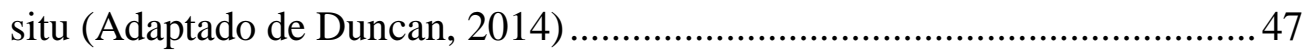

Tabela 2-4 - Resumo de escalas de flutuação de algumas propriedades geotécnicas (Adaptado de Phoon e Kulhawy, 1999) 48

Tabela 2-5 - Parâmetros do modelo elástico perfeitamente plástico de MohrCoulomb 64

Tabela 2-6 - Parâmetros de entrada do modelo constitutivo Hardening Soil ....... 74

Tabela 3-1 - Histórico construtivo da barragem de rejeitos analisada.................. 85

Tabela 3-2 - Parâmetros geotécnicos adotados nas análises (BVP, 2020) ........... 95

Tabela 3-3 - Parâmetros de deformabilidade dos materiais simulados no modelo

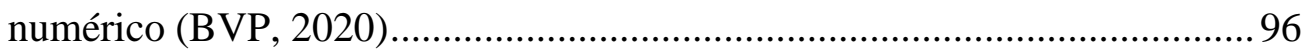

Tabela 3-4 - Distribuições probabilísticas das variáveis aleatórias (BVP, 2021). 98

Tabela 4-1 - Resultados das análises probabilísticas pelo Método FOSM .........112

Tabela 4-2 -Resultados das análises probabilísticas pelo Método de Monte Carlo 114

Tabela 4-3 - Resumo dos resultados das análises probabilísticas 115 


\section{Introdução}

\section{1.}

\section{Relevância do Tema}

O avanço da produção mineral tem demandado a utilização de áreas cada vez maiores para disposição dos rejeitos e estéreis oriundos do processo de extração e beneficiamento de minério. Trata-se de uma demanda crescente em escala global, que vem exigindo estudos cada vez mais complexos acerca do comportamento de estruturas de contenção, submetidas à diferentes tipos de carregamentos e fenômenos geotécnicos.

Em geral, os fenômenos a serem estudados dependem de condições geométricas do meio físico, dos materiais de construção utilizados, dos métodos construtivos e de características geomecânicas do material armazenado.

Recentemente a discussão do tema de segurança de barragem tem ganhado força no Brasil, na sombra das tragédias desencadeadas pela ruptura da Barragem de Fundão, em Mariana, e da Barragem do Córrego do Feijão, em Brumadinho, nos anos de 2015 e 2019.

Cada vez mais a comunidade acadêmica e as empresas vem percebendo que os métodos e critérios utilizados atualmente como referência para a avaliação de estabilidade de barragens de rejeito carecem de revisão e complementação.

Atualmente, a forma mais usual de avaliação da estabilidade de barragens de rejeito é feita por meio de análises pelo Método de Equilíbrio Limite (MEL), no qual a razão entre a mobilização de resistência e a solicitação imposta à estrutura é quantificada na forma de um quociente conhecido como fator de segurança.

As normas vigentes adotam fatores de segurança mínimos para diversos cenários, visando assegurar uma margem de segurança quanto às incertezas na determinação de um conjunto único de parâmetros para simulação das envoltórias resistência de cada material, além de incertezas inerentes aos próprios métodos de cálculo adotados. Em geral estas avaliações são feitas por meio da chamada abordagem determinística, a qual considera que os parâmetros de resistência dos 
materiais são conhecidos e não variam dentro de uma mesma massa de solo. Esta abordagem não leva em consideração as incertezas envolvidas na determinação individual de cada parâmetro, nem a variabilidade espacial dos parâmetros dos solos.

O impacto das incertezas na confiabilidade das análises de estabilidade é significativo. Análises convencionais baseadas em fatores de segurança não são capazes de representar devidamente as incertezas, comprometendo a adequação de projeções feitas com base nelas (El-Ramly et al., 2002).

A principal desvantagem das análises determinísticas reside na consideração de que a resistência do solo é representada por um único conjunto de parâmetros obtido por meio de ensaios geotécnicos, quando na realidade as propriedades do solo são inerentemente variáveis de um ponto para o outro, mesmo em depósitos relativamente homogêneos (Vanmarcke, 1977a).

A abordagem probabilística surge como uma alternativa mais precisa para quantificar o risco de ruptura de estruturas geotécnicas. Nesta abordagem, definemse variáveis aleatórias cujos possíveis valores estão inseridos em uma função probabilística a elas atribuída. Além do fator de segurança determinístico, a análise probabilística fornece a Probabilidade de Ruptura (PR) de um dado sistema, que é quantificada pela probabilidade de que a solicitação imposta exceda a resistência do sistema. Em uma análise probabilística, as variáveis aleatórias são atribuídas de forma independente, conforme a função de distribuição de probabilidade, ou função de densidade de probabilidade atribuída a elas. Esta abordagem permite que as incertezas sejam quantificadas à análise de forma racional, além de permitir a verificação da sensibilidade de um determinado parâmetro para a estabilidade do sistema como um todo.

As análises de estabilidade probabilísticas têm como finalidade a avaliação da condição de estabilidade de uma estrutura e a admissibilidade do risco desta estrutura, quando analisado de forma conjunta com o dano potencial de uma eventual ruptura.

A contribuição das análises probabilísticas para o campo da geotecnia é inquestionável, no entanto, em se tratando de barragens de rejeito, a constatação de que a estrutura se encontra estável pode não ser suficiente para garantir que não haja risco de instabilização por alterações, lentas ou abruptas, nas condições de contorno do meio físico. Fenômenos como compressibilidade da fundação, 
liquefação de rejeitos, formação de zonas de cisalhamento no maciço ou abertura de trincas de tração, podem levar uma estrutura aparentemente estável ao colapso, caso atuem como gatilhos para uma instabilização global. Nestes casos, a análise de tensão-deformação é uma ferramenta importante para verificação do desempenho da estrutura em função do tempo, de alterações geométricas e de variações no estado de tensões impostas ao longo da vida útil da obra.

As análises de tensão deformação permitem a simulação do comportamento de materiais submetidos a diferentes estados de tensão e trajetórias de carregamento.

À relação entre as tensões e deformações sofridas por um corpo, dá-se o nome de lei constitutiva, ou modelo constitutivo.

Uma vez que solos não apresentam a mesma resposta mecânica quando submetidos a variados estados de tensão, diferentes relações constitutivas podem ser aplicadas para a solução de problemas de natureza não linear. O principal método numérico para solução de problemas geotécnicos é o Método dos Elementos Finitos, ou MEF. Este método, já consolidado e amplamente utilizado na engenharia, consiste na divisão dos materiais em diversos elementos menores que são conectados entre si por nós.

A abordagem numérica permite a simulação de comportamentos geomecânicos complexos com características elasto-plásticas associadas a diferentes critérios de ruptura.

Este trabalho apresenta como estudo de caso o alteamento de uma barragem de rejeito de mineração de ferro que foi construída sobre um depósito de colúvio e solos residuais compressíveis. A barragem apresentou recalques, além da formação de trincas transversais e longitudinais em diversos pontos, durante algumas das etapas construtivas do maciço. Fenômenos que se intensificaram à medida que a barragem sofreu novos alteamentos. Recentemente, a barragem teve suas obras de alteamento paralisadas até que se identificasse o fenômeno originador da formação das trincas e suas implicações para a estabilidade da estrutura.

\section{2.}

\section{Objetivo}

O estudo tem como objetivo apresentar uma análise crítica comparativa dos métodos de avaliação de estabilidade e desempenho de uma barragem de rejeitos, 
adotando a abordagem probabilística com auxílio de análises de tensão vs deformação por MEF. O estudo adota como metodologia de integração entre os modelos MEL e MEF, o compartilhamento dos campos de distribuição de poropressão gerados nas análises numéricas por MEF para os modelos do MEL, com o objetivo de tornar seus resultados comparáveis e obter o melhor de cada abordagem. Adotou-se o software Slide 2.0, da Rocscience, como ferramenta para as análises de estabilidade determinísticas e probabilísticas. Para as análises de tensão vs deformação, adotou-se o software de elementos finitos PLAXIS 2D 2021.

A partir da implementação da metodologia descrita acima, buscou-se os seguintes objetivos:

- Comparar resultados da aplicação dos métodos MEL e MEF em análises de estabilidade probabilísticas;

- Avaliar a variação da probabilidade de ruptura da barragem entre os cenários de final de construção e após a dissipação total dos excessos de poropressão;

- Estudar a influência relativa dos parâmetros geotécnicos na variância de FS pelo método FOSM;

- Comparar as probabilidades de ruptura obtidas através dos diferentes métodos de análise;

- Avaliar influência das diferenças intrínsecas entre os métodos MEL e MEF nos resultados obtidos.

\section{3.}

\section{Estrutura da Dissertação}

Este trabalho foi estruturado da seguinte forma:

- Capítulo 1: contextualização do tema, objetivos, métodos e estrutura do estudo;

- Capítulo 2: revisão bibliográfica contendo fundamentos de estatística e probabilidade, análises de estabilidade pelo método de equilíbrio limite adotando as abordagens determinística, probabilística e de variabilidade espacial, além de análises de tensão x deformação. A revisão apresenta, também, a definição e os princípios construtivos das barragens de rejeito de mineração.

- Capítulo 3: apresentação do estudo de caso contendo o histórico da estrutura, aspectos geológico-geotécnicos, construção dos modelos de tensão x deformação e 
equilíbrio limite e metodologia de implementação dos métodos probabilísticos para análise da barragem.

- Capítulo 4: apresentação dos resultados obtidos por meio da implementação dos métodos probabilísticos FOSM e Monte Carlo na avaliação de segurança da barragem, assim como a comparação e análise dos resultados obtidos pelo estudo.

- Capítulo 5: discussão das principais conclusões obtidas a partir da análise dos resultados do estudo, comentários e críticas do autor.

- Capítulo 6: apresentação das lições e recomendações para estudos futuros dentro do tema apresentado na dissertação. 


\section{2 Revisão Bibliográfica}

\section{1. Análises Determinísticas de Estabilidade - Métodos de Equilíbrio Limite}

As análises de estabilidade determinísticas constituem a principal e mais utilizada forma de avaliação de segurança de taludes naturais e antrópicos. O processo de elaboração de uma análise de estabilidade determinística consiste tipicamente das seguintes etapas:

1. Determinação do perfil geotécnico do terreno;

2. Identificação das seções críticas para a estabilidade em termos geométricos, hidrogeológicos e geotécnicos;

3. Modelamento geométrico do problema (análise 3D) ou construção das seções de análise (análise 2D);

4. Definição dos parâmetros geotécnicos de cada camada;

5. Cálculo do FS considerando diferentes hipóteses;

6. Verificação da admissibilidade do FS obtido conforme preceitos das normas técnicas.

O método determinístico tem como principais vantagens a agilidade e a simplicidade de execução, permitindo uma avaliação rápida da estabilidade de uma encosta pelo fator de segurança, ou mesmo a avaliação da viabilidade técnica de projetos de barragens e pilhas de estéril.

Embora amplamente utilizada, a abordagem determinística desconsidera incertezas acerca de fatores relevantes, como a possível não representatividade dos parâmetros obtidos, devido às limitações de amostragem, ou mesmo devido aos erros na medição ou nos procedimentos adotados em ensaios geotécnicos.

Em uma análise determinística, as incertezas são muitas vezes compensadas pelo julgamento de engenharia, que é uma prática cujo sucesso depende muito da experiência do projetista. 
Não é incomum que o julgamento de engenharia tenha um papel importante em análises determinísticas, entretanto, não é incomum que o julgamento de engenharia leve a previsões insatisfatórias do comportamento geotécnico de estruturas de terra (Chok, et al., 2007).

Por não considerar a influência das incertezas, um fator de segurança elevado obtido por meio de uma análise determinística, não garante uma probabilidade de ruptura aceitável. A Figura 2-1, apresentada em Lacasse (2016), ilustra o conceito apresentado, por meio da comparação do fator de segurança de uma estrutura offshore construída nos anos 1970, com dados limitados e métodos antigos de interpretação de ensaios geotécnicos, reanalisada 20 anos depois com dados acumulados ao longo do tempo e métodos de análise mais avançados. As novas análises resultaram em um fator de segurança menor, entretanto o novo conjunto de dados apresentou menor variabilidade nos parâmetros de resistência, provocando um estreitamento da função de densidade de probabilidade e consequente redução da probabilidade de ruptura.

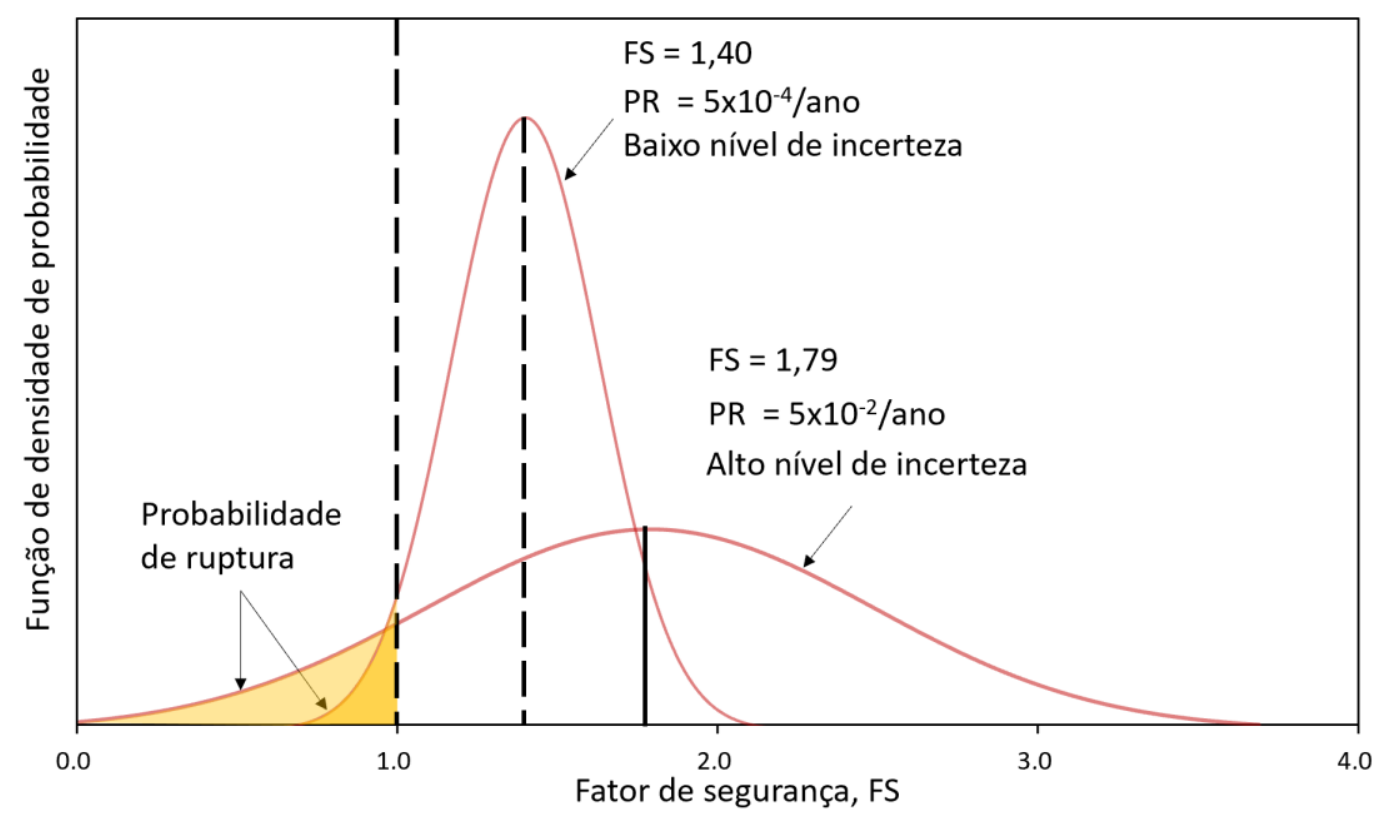

Figura 2-1 - Fator de segurança e probabilidade de ruptura (Adaptado de Lacasse, 2016)

\subsection{1.}

\section{Cálculo de FS}

A avaliação convencional da segurança de um talude consiste no equilíbrio entre as forças solicitantes, isto é, as forças que contribuem para o escorregamento, 
e as forças resistentes ao escorregamento. Fatores como: estratigrafia, ângulo de inclinação, posição no nível d'água e resistência ao cisalhamento são preponderantes em uma avaliação de estabilidade.

O fator de segurança é o valor que quantifica a razão entre os esforços mobilizados e a resistência ao cisalhamento na superfície de ruptura analisada, o que pode ser expresso matematicamente como:

$$
F S=\frac{\text { Resistência }}{\text { Solicitação }}
$$

O método mais usual para avaliação do fator de segurança de taludes é o Método das Fatias.

Introduzido por Fellenius (1936) e reformulado por diversos autores ao longo dos anos. Neste método a massa de solo é dividida em fatias verticais ao longo de uma superfície de cisalhamento, em seguida, são calculadas as forças e momentos atuantes em cada fatia e o equilíbrio estático é verificado. (Figura 2-2).
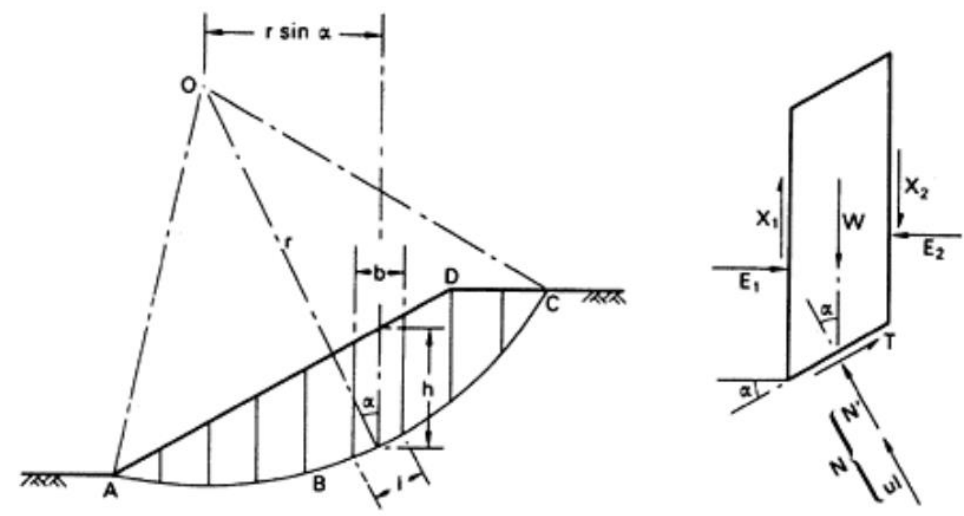

Figura 2-2 - Método das fatias (Craig, 2004)

A Figura 2-3 apresenta um perfil esquemático das forças atuantes em uma fatia genérica. 


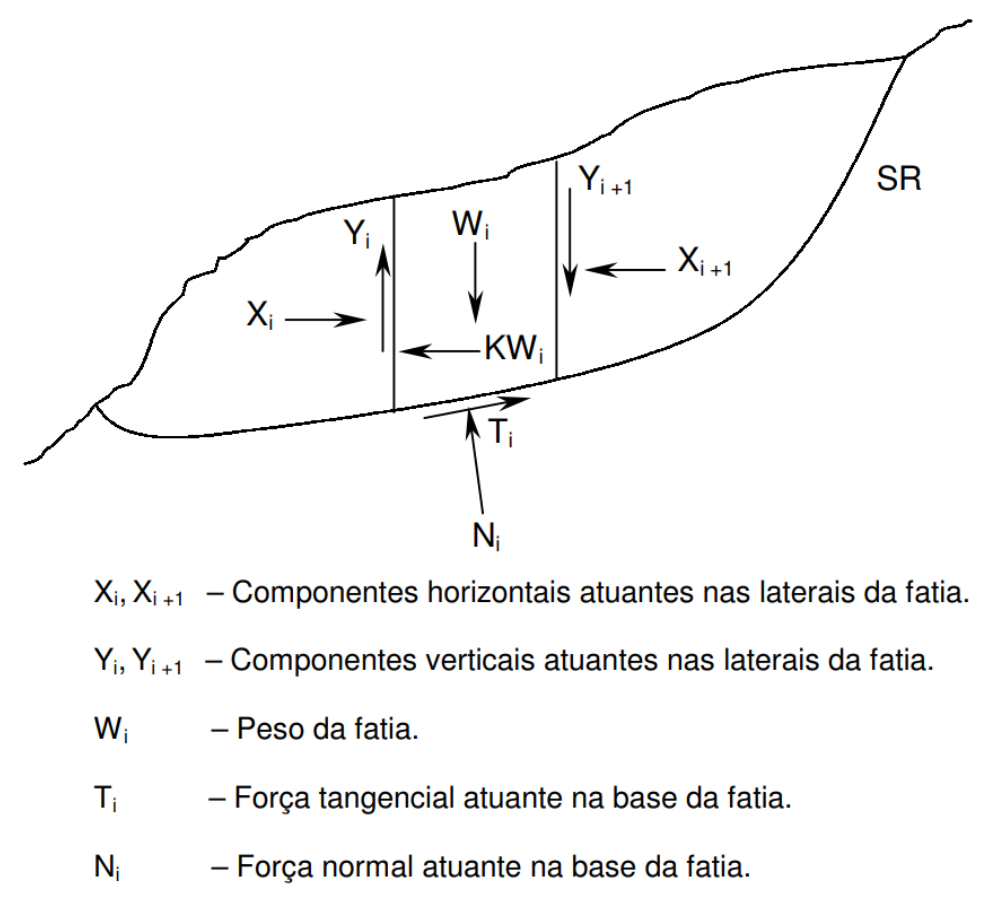

Figura 2-3 - Forças atuantes em uma fatia genérica

Nos métodos derivados do método das fatias, adota-se uma superfície de ruptura potencial como ponto de partida para a verificação do fator de segurança. Este é obtido por meio da aplicação de uma ou mais das equações de equilíbrio estático de corpos:

$$
\begin{gathered}
\sum \text { Forças verticais }=0 \\
\sum \text { Forças horizontais }=0 \\
\sum \text { Momentos }=0
\end{gathered}
$$

Aplicando-se simultaneamente as três equações de equilíbrio estático, obtêmse um sistema cujo número de incógnitas é maior do que o número de equações, logo, para resolver as equações de equilíbrio para cada fatia, algumas hipóteses simplificadoras devem ser adotadas. Estas hipóteses diferenciam os vários métodos existentes. São classificados como métodos rigorosos aqueles que satisfazem todas as equações de equilíbrio estático, enquanto aqueles que não atendem são chamados de métodos simplificados, ou aproximados. 


\subsection{2. \\ Métodos Aproximados}

\subsubsection{Método de Fellenius (1936)}

Aplicando-se o equilíbrio de momentos em relação à origem da superfície de ruptura circular e o equilíbrio de forças na direção perpendicular à superfície de ruptura, é possível determinar o fator de segurança por meio da eq. (5).

$$
F S=\frac{\sum c^{\prime}(b / \cos \alpha)+(W \cos \alpha-u(b / \cos \alpha)) * \operatorname{tg} \varphi^{\prime}}{\sum W \operatorname{sen} \alpha}
$$

Onde:

$u$ - Poropressão média na base da fatia;

c' - Coesão efetiva do solo;

$\phi$ ' - Ângulo de atrito efetivo do solo.

A eq. (5) é aplicada para diversas superfícies potenciais de ruptura, até que seja encontrada a superfície que apresente o menor fator de segurança, ou superfície crítica de ruptura.

O método satisfaz apenas o equilíbrio de momentos, considerando que a resultante das forças entre fatias é paralela à suas bases, fazendo com que se anulem. Devido a esta hipótese simplificadora, o método subestima o fator de segurança.

\subsubsection{Método de Bishop Simplificado (1955)}

Assim como o método de Fellenius (1936), o método de Bishop Simplificado adota como premissa que a resultante das forças horizontais entre fatias é nula na direção vertical. A tensão normal é aplicada no ponto central da base de cada fatia.

Partindo da equação de Fellenius, o método acrescenta a parcela que impõe o equilíbrio das forças verticais (eq. (6)).

$$
F S=\frac{1}{\sum W \operatorname{sen} \alpha} \sum\left(c^{\prime} b+(W-u b) \operatorname{tg} \varphi^{\prime}\right) / m_{\alpha}
$$

Onde o parâmetro $m_{\alpha}$ é calculado pela eq. (7).

$$
m_{\alpha}=\cos \alpha\left(\frac{1+\operatorname{tg} \alpha * \operatorname{tg} \varphi^{\prime}}{F S_{i}}\right)
$$


$\mathrm{O}$ método exige que seja arbitrado um valor de $\mathrm{FS}_{\mathrm{i}} \mathrm{e}$, em seguida, realiza diversas iterações até que $F S$ se iguale ao valor arbitrado para $F S_{i}$.

O Método de Bishop Simplificado apresenta resultados comparáveis aos métodos mais rigorosos e possui alta confiabilidade.

\subsection{3.}

\section{Métodos Rigorosos}

\subsubsection{Método de Morgenstern \& Price (1965)}

O Método de Morgenstern \& Price é um método rigoroso, no qual todas as condições de equilíbrio devem ser satisfeitas. O método permite a construção de superfícies de ruptura circulares e não circulares. Devido à necessidade de realização de processos iterativos, este método exige a utilização de computadores.

A seguir são apresentadas as equações de equilíbrio assumidas pelo método e as forças atuantes nas fatias:

Equações de Equilíbrio:

- A equação para a superfície de ruptura assumida é y = y(x);

- Equação para a superfície do talude, assumida como conhecida y = z(x);

- Equação para a posição da ação dos impulsos efetivos horizontais, i.e., linha de empuxo, y = yt'(x), sendo que esta função é desconhecida;

- A linha de impulso da pressão de água é y = h(x);

Forças atuantes em uma fatia:

- E', empuxo lateral na face da fatia em termos de tensões efetivas;

- $\mathrm{X}$, força vertical tangencial nas faces da fatia;

- $\mathrm{dW}$, peso da fatia;

- $\quad$ dN', pressão normal efetiva;

- dT, força tangencial atuante ao longo da base da fatia;

- $\alpha$, inclinação que a fatia faz com a horizontal;

A condição para que não haja rotação da fatia é satisfeita se a soma dos momentos no centro da base da fatia for igual a zero, igualmente neste ponto, estão aplicadas as forças dN', dN e dW, pelo que os seus momentos serão nulos em relação a este (Freitas, 2011). A Figura 2-4 ilustra a distribuição de forças em cada fatia. 

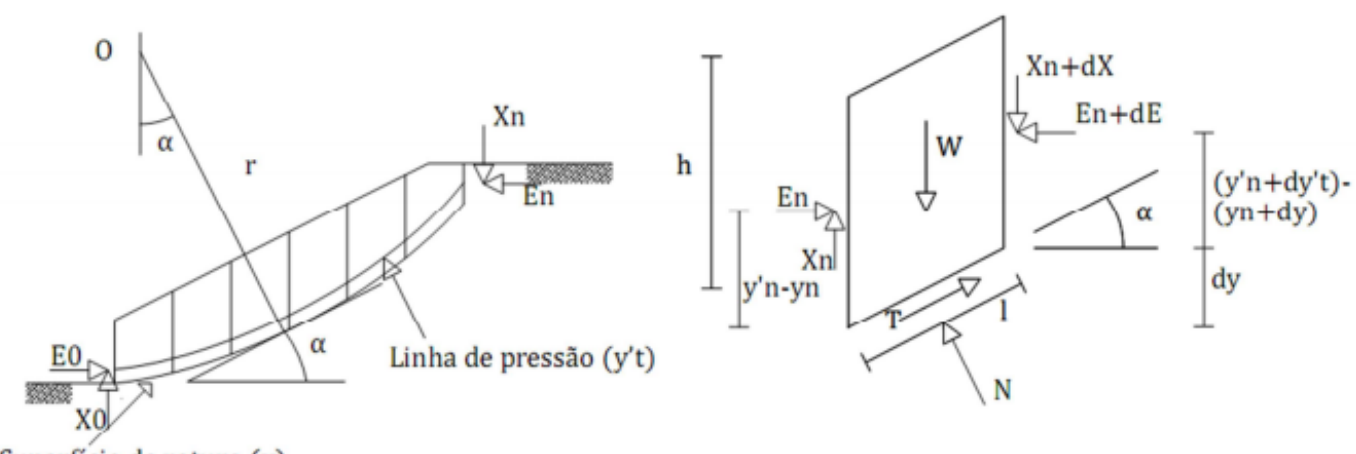

Superfície de rotura $(y)$

Figura 2-4 - Método de Morgenstern \& Price - Forças aplicadas sobre uma fatia

O método é resolvido para a obtenção de um fator de segurança pelo somatório das forças tangenciais e normais à base de uma fatia e o somatório de momentos em relação ao centro de cada fatia infinitesimal. As equações de equilíbrio de forças e momentos são então combinadas e modificadas.

\subsubsection{Método de Spencer (1967)}

Originalmente desenvolvido para superfícies de ruptura circulares, porém adaptado para considerar, também, superfícies não circulares, este método é rigoroso, satisfazendo as condições de equilíbrio de forças, vertical, horizontal e de momento.

O Método de Spencer considera dois fatores de segurança, um para o equilíbrio de momentos em relação à um determinado ponto e outro baseado no equilíbrio de forças paralelas à direção das forças entre fatias. Neste método as forças Xi e Yi atuantes nos planos entre fatias são substituídas por uma resultante $\mathrm{Q}$, que atua no centro da base de cada fatia (Figura 2-5). 


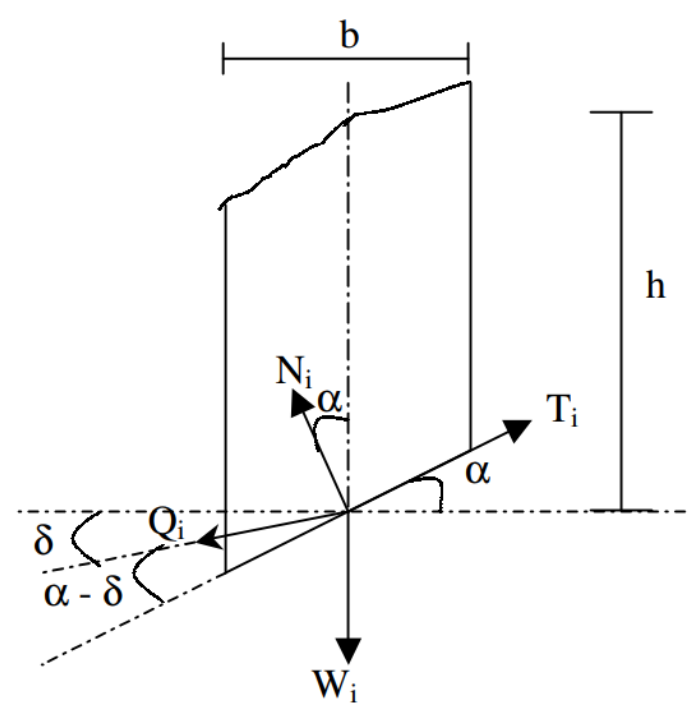

Figura 2-5 - Forças atuantes na base das fatias pelo método de Spencer

Somando as forças em direções perpendiculares e paralelas à base da fatia obtêm-se as seguintes equações de equilíbrio:

$$
\begin{aligned}
& N+F_{v} \cos \alpha-F_{h} \operatorname{sen} \alpha-Q \operatorname{sen}(\alpha-\theta)=0 \\
& S+F_{v} \operatorname{sen} \alpha+F_{h} \cos \alpha+Q \cos (\alpha-\theta)=0
\end{aligned}
$$

Combinando as duas equações de equilíbrio de forças com a equação da envoltória de resistência de Mohr-Coulomb, solucionando-a para obtenção de Q, têm-se:

$$
\frac{-F_{v} \operatorname{sen} \alpha-F_{h} \cos \alpha-\left(c^{\prime} \frac{\Delta l}{F}\right)+\left(F_{v} \cos \alpha-F_{h} \operatorname{sen} \alpha+u \Delta l\right)\left(\tan \varphi^{\prime} / F\right)}{\cos (\alpha-\theta)+\left[\operatorname{sen}(\alpha-\theta) \tan \varphi^{\prime} / F\right]}
$$

\subsubsection{Método de Sarma (1973 e 1979)}

O Método de Sarma se difere dos demais, pois assume a existência de uma aceleração horizontal fictícia denominada $\mathrm{k}_{\mathfrak{c}}$, que representa o coeficiente sísmico capaz de induzir um estado de equilíbrio limite na massa deslizante. Admite-se um fator de segurança igual a 1 e, em seguida, calcula-se o coeficiente de aceleração necessário para que essa condição se torne verdadeira. $\mathrm{O}$ fator de segurança estático é obtido pela redução dos parâmetros de resistência ao cisalhamento, até que o coeficiente sísmico crítico seja nulo. Na atualização do método de 1979, lamelas 
inclinadas são permitidas, o que possibilita a realização de análises de maciços rochosos com presença de descontinuidades.

O Método de Sarma é considerado um método rigoroso, pois satisfaz ao equilíbrio de forças e momentos.

A principal vantagem do método reside na simplicidade de solução das equações de equilíbrio, podendo ser realizada sem o auxílio de computadores. A Figura 2-6 apresenta a distribuição de forças nas fatias, pelo método de Sarma (1973).
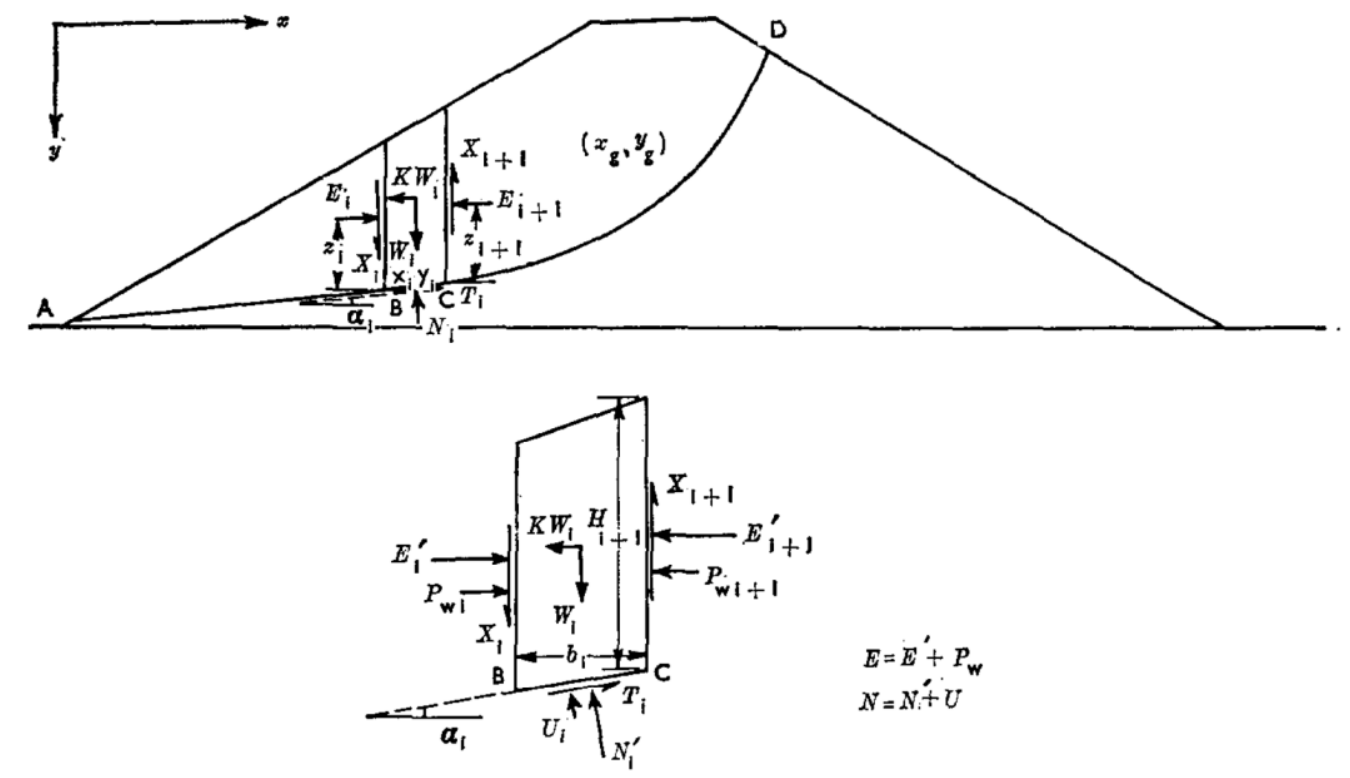

Figura 2-6 - Distribuição de forças em uma fatia (Sarma, 1973)

\section{2.}

\section{Análises Probabilísticas de Estabilidade}

No campo da geotecnia a estabilidade de taludes é talvez um dos tópicos mais dominados por incertezas. Alguns dos fatores que contribuem para a incerteza em uma análise de estabilidade de taludes, são: anomalias geológicas, variabilidade espacial de parâmetros geotécnicos, escassez de dados representativos, variação das condições do meio físico, além das simplificações de cálculo e erro humano no dimensionamento (El-Ramly et al., 2002).

$\mathrm{Na}$ abordagem probabilística as incertezas inerentes a cada parâmetro são consideradas por meio da adoção de variáveis aleatórias, as quais possuem distribuições probabilísticas independentes, de modo que os efeitos das incertezas do problema podem ser considerados de forma individual e simultânea. 


\subsection{1.}

\section{Fundamentos de Estatística e Probabilidade}

A probabilidade, que pode ser definida como a ciência da incerteza, fornece regras matemáticas para o entendimento e análise da nossa própria ignorância (Evans \& Rosenthal, 2009).

O entendimento da probabilidade começa pela definição do conjunto de resultados possíveis para um dado experimento. Um exemplo clássico, usualmente adotado, para estes possíveis resultados é o lançamento de uma moeda ao ar. O resultado possível para este experimento se limita à qual dos dois lados da moeda estará virado para cima após o lançamento. Por outro lado, no lançamento de um dado, o número de resultados possíveis é igual ao número de faces que o dado apresenta. Ao conjunto de todos os possíveis eventos resultantes de um experimento dá-se o nome de espaço amostral, que é representado pela letra $\mathrm{S}$.

Um modelo probabilístico inclui um conjunto de eventos, representado pelo espaço amostral S, para os quais são atribuídas probabilidades de ocorrência. À esta probabilidade é atribuída a letra $\mathrm{P}$, que indica a probabilidade de um determinado evento ocorrer, dentro do espaço amostral S. Em outras palavras, um modelo probabilístico consiste em um grupo de dados representados pelo espaço amostral, um conjunto de eventos que são subdivisões do espaço amostral e uma medida de probabilidade entre 0 e 1 para cada evento, onde 0 significa um evento impossível e 1 um evento garantido (Evans \& Rosenthal, 2009).

A distribuição probabilística mais comumente utilizada é a distribuição normal. Este modelo é representado por uma curva em forma de sino, que depende de duas variáveis estatísticas, a média aritmética dos dados $(\mu)$ e o desvio padrão $(\sigma)$. A eq. (11) define a função de densidade de probabilidades na distribuição normal.

$$
f(y)=\frac{1}{\sigma \sqrt{2 \pi}} e^{-(y-\mu)^{2} /\left(2 \sigma^{2}\right)},-\infty<\mathrm{y}<\infty
$$

Quando plotada em função de $\mu$ e $\sigma$, a curva da distribuição normal apresenta o aspecto da Figura 2-7. 


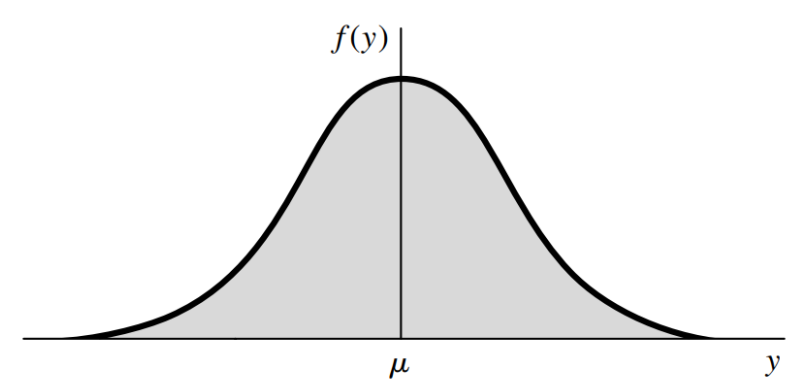

Figura 2-7 -Distribuição normal de probabilidades (Wackerly et al., 2007)

Considerando que a variável aleatória $x$ tem uma função de densidade dada pela eq. (12), para $-\infty<\mathrm{a}<\mathrm{b}<\infty$, a probabilidade da variável $x$ estar entre a e b é dada pela área sob a curva da distribuição normal no intervalo entre a e b. Essa área pode ser obtida a partir da integração numérica apresentada na eq. (12).

$$
P(a \leq \mathrm{x} \leq \mathrm{b})=\int_{a}^{b} \varphi(x) d x=\int_{a}^{b} \frac{1}{\sqrt{2 \pi}} e^{-x^{2} / 2} d x
$$

Quando a função de densidade apresenta média igual a 0 e desvio padrão igual a 1, tem-se uma distribuição normal padrão. A normalização é feita subtraindo a média aritmética da variável aleatória e, em seguida, dividindo o resultado da subtração pelo desvio padrão, conforme apresentado na eq. (13), onde Z é a variável aleatória $x$, na distribuição normal padrão.

$$
Z=(x-\mu) / \sigma
$$

Quando uma variável aleatória $x$ apresenta distribuição normal, a notação convencional é apresentada pela eq. (14), enquanto na distribuição normal padrão a função toma a forma apresentada pela eq. (15).

$$
\begin{gathered}
X \sim N\left(\mu, \sigma^{2}\right) \\
Z \sim N(0,1)
\end{gathered}
$$

Quando uma variável aleatória $x$ apresenta função de densidade representada pela eq. (11), tem-se uma distribuição cujas probabilidades de ocorrência de eventos podem ser obtidas pela integração da função de densidade de probabilidade no intervalo desejado. A Figura 2-8 apresenta a distribuição normal padrão com 
destaque para a distribuição percentual das áreas sob a curva da função de densidade, para diferentes intervalos de desvio padrão.

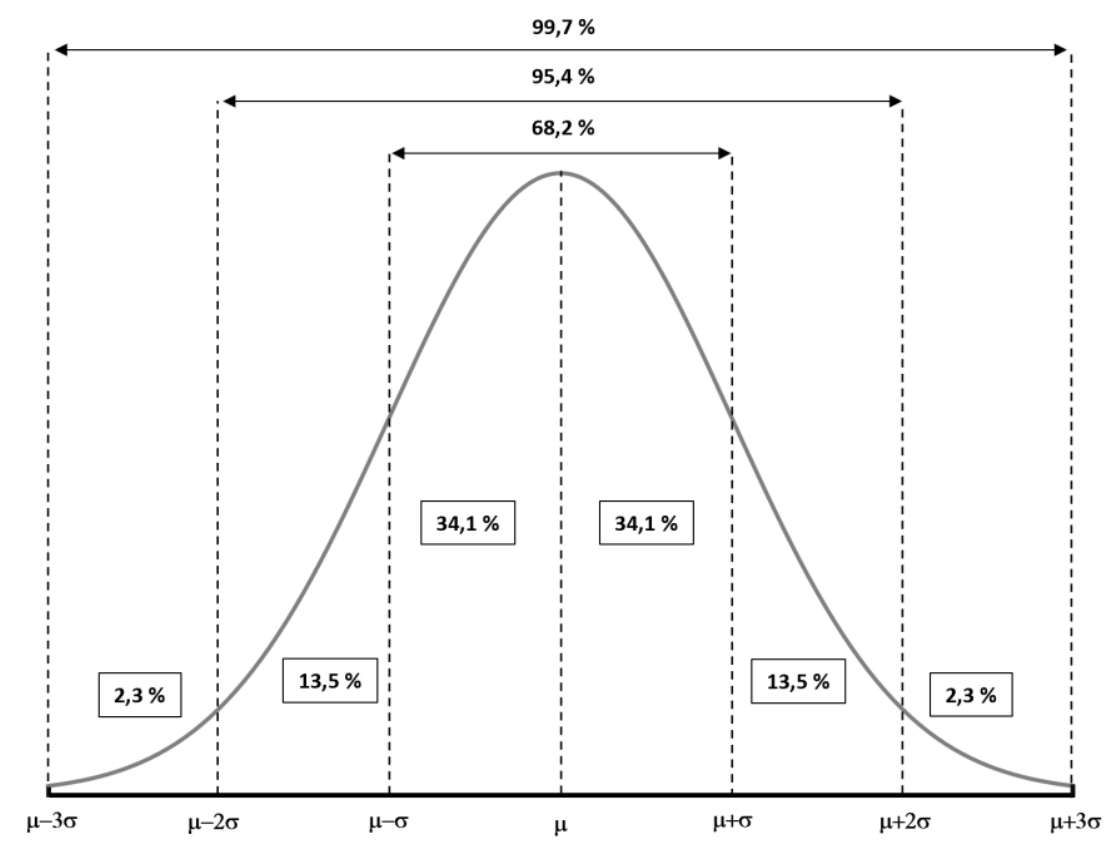

Figura 2-8 - Distribuição normal gaussiana padrão

A variância relaciona os desvios em torno de uma média, representando a média aritmética dos quadrados dos desvios, conforme apresentado na eq. (16).

$$
s^{2}=\frac{1}{n-1} \sum_{i-1}^{n}\left(y_{i}-\bar{y}\right)^{2}
$$

Sendo a variância calculada a partir dos quadrados dos desvios, ela é um número em unidade quadrada em relação à variável em questão, o que, sob o ponto de vista prático, é um inconveniente, por isso, tem pouca utilidade na estatística descritiva (Correa, 2003).

O desvio-padrão é uma ferramenta mais precisa na comparação de diferenças entre conjuntos de dados do que a variância. O desvio padrão determina a dispersão dos valores em relação à média e é calculado por meio da raiz quadrada da variância:

$$
\sigma=\sqrt{S^{2}}
$$

Outra ferramenta útil no tratamento de dados estatísticos é o coeficiente de variação. Esta medida representa o desvio padrão em proporção à média amostral, e é definida pela eq. (18), onde $S$ é o desvio padrão amostral, e $\bar{x}$ a média amostral. 


$$
C V=\frac{S}{\bar{x}} \times 100 \%
$$

Considera-se que uma distribuição tem baixa dispersão quando $\mathrm{CV} \leq 15 \%$; média dispersão quando $15 \%<\mathrm{CV}<30 \%$; e alta dispersão quando $\mathrm{CV} \geq 30 \%$ (Correa, 2003).

$\mathrm{Na}$ geotecnia existem muitos casos nos quais os parâmetros não podem assumir valores negativos, ou apresentam distribuição assimétrica. Coesão, ângulo de atrito, resistência não drenada e a resistência de ponta do piezocone são alguns exemplos típicos de parâmetros que não podem assumir valores negativos. Para estes casos, a distribuição log-normal pode ser uma alternativa mais adequada, uma vez que despreza valores negativos, que são fisicamente impossíveis.

A distribuição log-normal é uma distribuição probabilística de uma variável, na qual o logaritmo desta variável apresenta distribuição normal, variando entre 0 e $\infty$, desta forma, não há possibilidade de se obter valores negativos.

A distribuição log-normal de uma variável aleatória $x$, com média $\mu$ e desvio padrão $\sigma$, é representada matematicamente pela eq. (19). A curva da função de densidade da distribuição log-normal é apresentada na Figura 2-9.

$$
f(y)=\frac{1}{\sigma \sqrt{2 \pi} \sigma} e^{-\frac{1}{2}\left(\frac{\ln (x)-\mu_{\ln x}}{\sigma \ln x}\right)^{2}}, 0<x<\infty
$$

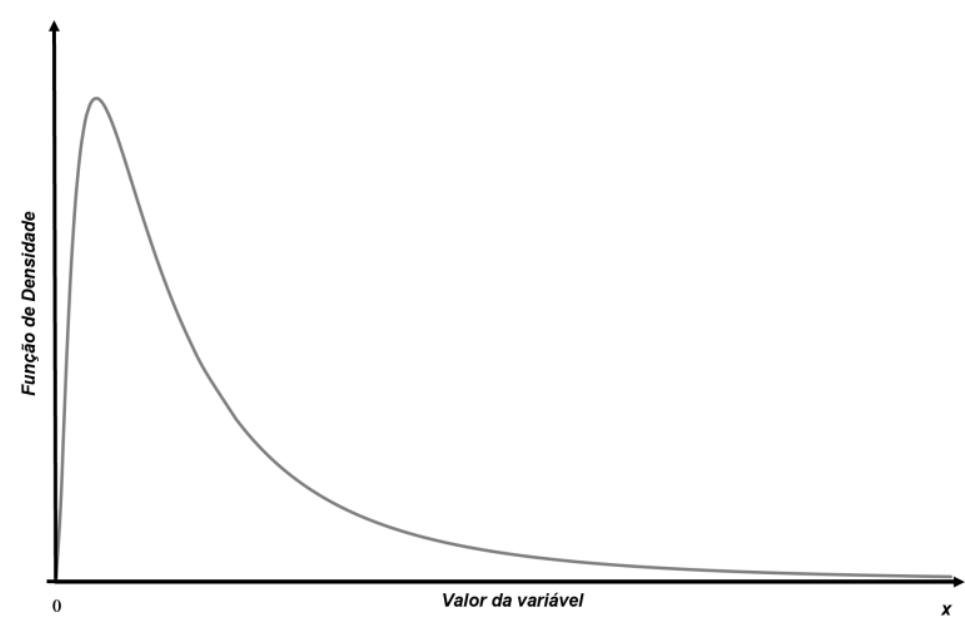

Figura 2-9 -Curva da função de densidade da distribuição probabilística lognormal

Chok (2009) apresenta uma distribuição log-normal típica de resistência não drenada, $S_{u}$, com média de $100 \mathrm{kPa}$ e desvio padrão de $50 \mathrm{kPa}(\mathrm{CV}=50 \%)$, 
juntamente com a distribuição normal do parâmetro, utilizando a mesma média e desvio padrão (Figura 2-10).

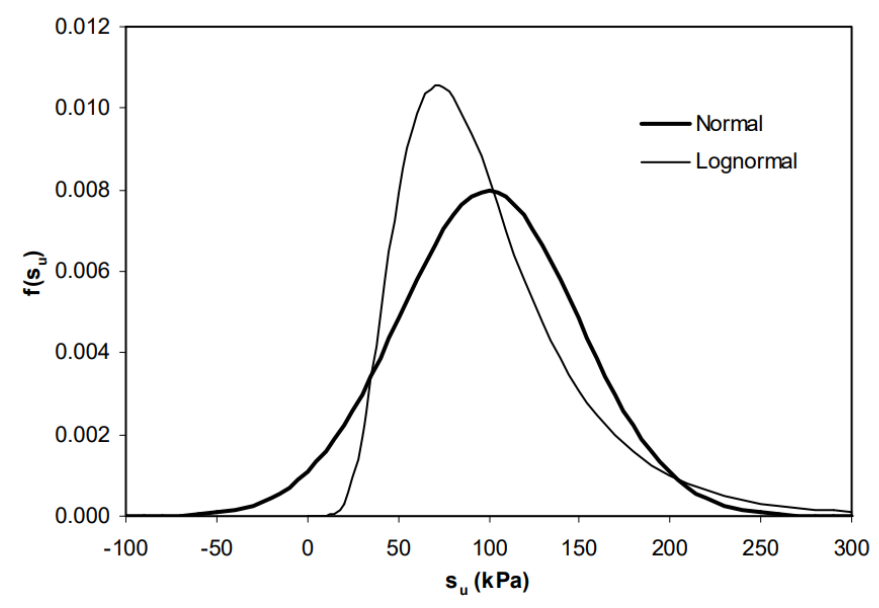

Figura 2-10 - Distribuição normal e log-normal de resistência não drenada, Su, com média de $100 \mathrm{kPa}$ e desvio padrão de $50 \mathrm{kPa}$ (Chok, 2009)

Observa-se que na distribuição normal, no intervalo inferior à $\mu-2 \sigma$ a resistência não drenada assume valores negativos, o que é fisicamente impossível. Neste caso, a utilização da distribuição log-normal é mais adequada.

\subsection{2. \\ Probabilidade de Ruptura e Confiabilidade}

Em se tratando de análises probabilísticas, é comum o uso de termos como probabilidade de ruptura, confiabilidade e índice de confiabilidade.

Harr (1987) define confiabilidade como a probabilidade de um sistema realizar sua função adequadamente por um período específico, sob condições especificas. Trazendo esta afirmação para contexto da estabilidade de taludes, podese afirmar que a confiabilidade de um talude é a probabilidade dele se manter estável sob as condições consideradas em projeto, que podem incluir, por exemplo, final de construção, fluxo permanente, rebaixamento rápido e sismos (Duncan et al., 2014). Matematicamente, a definição de confiabilidade é dada pela eq. (20).

$$
\text { Reliability }=1-P R
$$

Onde PR é a probabilidade de ruptura do talude dentro das condições consideradas em projeto. 
A definição matemática mais abrangente de probabilidade de ruptura é apresentada na eq. (21), que representa a violação de um estado limite último.

$$
P R=P(R-S<0)
$$

Onde:

$\mathrm{R}$ - Parcela resistente do sistema;

$\mathrm{S}$ - Parcela referente a solicitação sofrida pelo sistema.

A Figura 2-11 demonstra graficamente o conceito de probabilidade de ruptura para dois cenários: a) quando a solicitação e a resistência são variáveis aleatórias, isto é, quando tanto a parcela resistente quanto a parcela solicitante possuem incertezas; b) quando a resistência do sistema é conhecida, porém há incerteza quanto à parcela da solicitação.

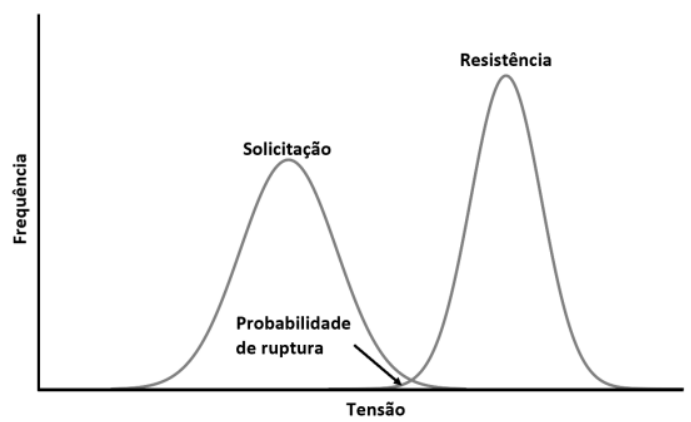

a)

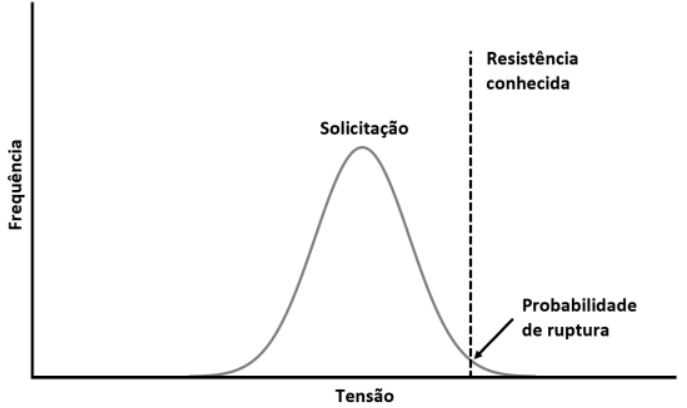

b)

Figura 2-11 - Conceito de probabilidade de ruptura quando: a solicitação e a resistência são variáveis aleatórias a); quando somente a resistência é conhecida b).

O conceito também pode ser expresso da seguinte forma, no cenário a) a PR do sistema é a probabilidade dos valores de ambas as variáveis aleatórias estarem situados nas extremidades das funções de densidade, convergindo no ponto central do gráfico. No cenário b) a PR representa a probabilidade de a solicitação ser superior ao valor conhecido da resistência do sistema, neste caso apenas a solicitação contribui para a incerteza do sistema.

O índice de confiabilidade, representado pela letra $\beta$, é um parâmetro que define o número de desvios padrão entre a condição de ruptura, definida por FS = 1, e a média da distribuição dos fatores de segurança $\left(F S_{m}\right)$.

Por definição, o índice de confiabilidade permite a seguinte interpretação: 
- Se $\beta>1$ - o fator de segurança médio está mais de 1 desvio padrão acima da condição de ruptura;

- Se $\beta=0$ - o fator de segurança médio é igual ao fator se segurança na ruptura $F S_{m}=1,0$;

- Se $\beta<0-$ o fator de segurança médio é menor do que 1,0 .

A eq. (22) apresenta a definição geral do índice de confiabilidade.

$$
\beta_{\text {Normal }}=\frac{F S_{m}-1,0}{\sigma}
$$

Quando a distribuição de FS é log-normal, o índice de confiabilidade pode ser obtido pela eq. (23).

$$
\beta_{L N}=\frac{\ln \left(F S_{m} / \sqrt{1+C V^{2}}\right)}{\sqrt{\ln \left(1+C V^{2}\right)}}
$$

A avaliação de estabilidade de taludes pela probabilidade de ruptura é uma forma de avaliar os efeitos combinados das incertezas e de fornecer meios de distinção entre casos em que o efeito das incertezas é particularmente alto ou baixo (Duncan et al., 2014).

A probabilidade de ruptura é função direta do índice de confiabilidade, sendo obtida pela relação:

$$
P R=1-\Phi \beta
$$

Onde $\Phi$ representa a distribuição gaussiana padrão.

Observa-se pela eq. (24) que a probabilidade de ruptura depende da distribuição probabilística adotada para o índice de confiabilidade. Dell'Avanzi e Sayão (1998), apresentam um ábaco que fornece a relação entre $\beta$ e PR para distribuições normal e log-normal e para diferentes valores de CV do FS (Figura 2-12). 


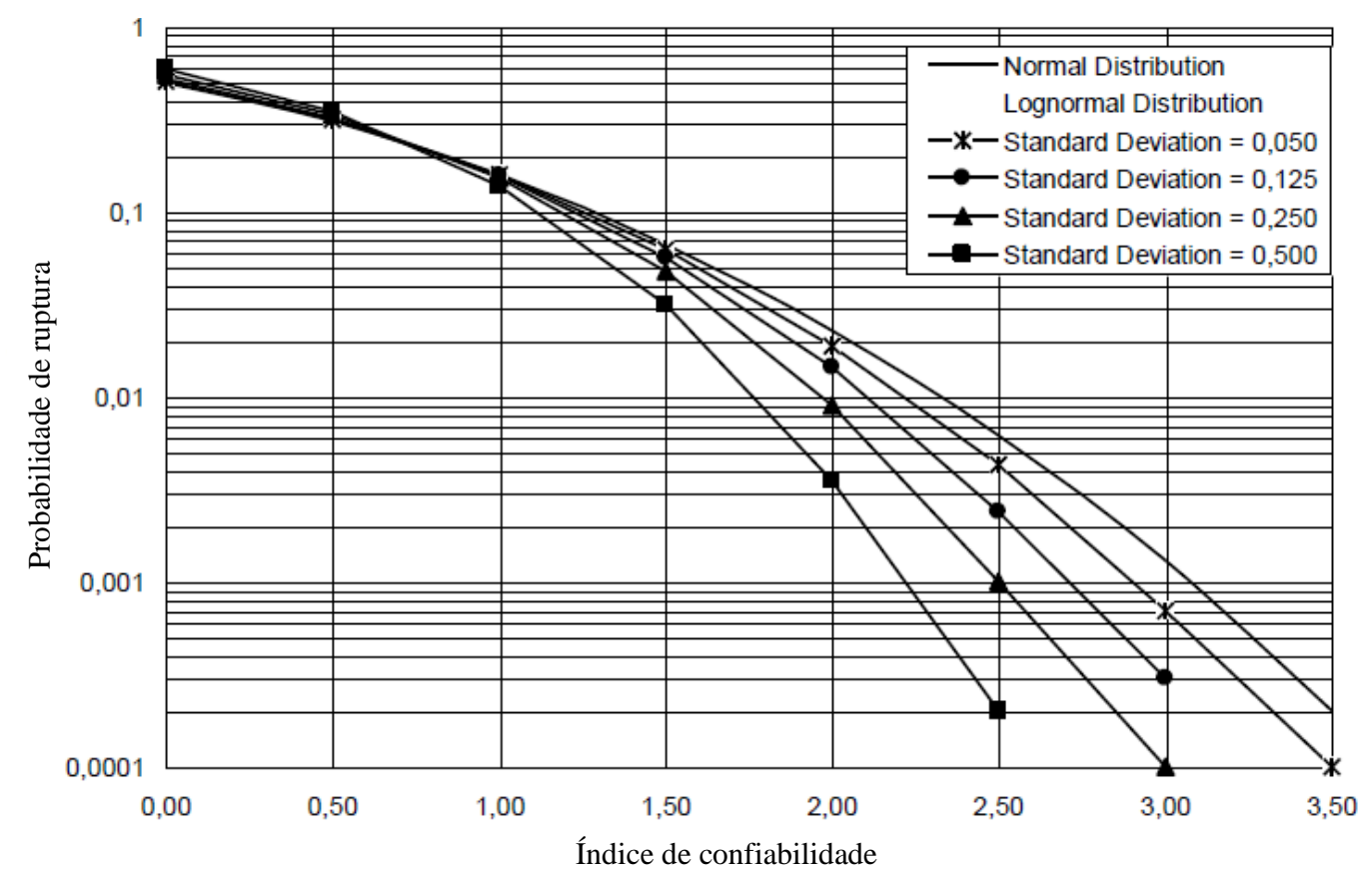

Figura 2-12 - Relação entre índice de confiabilidade e probabilidade de ruptura (Dell'Avanzi e Sayão, 1998)

\subsection{3.}

\section{Método FOSM}

O FOSM (First-Order Second-Moment) é um método probabilístico que consiste na aplicação de uma aproximação de primeira ordem da série de Taylor com informação estatística limitada ao segundo momento, em torno dos valores médios das variáveis do problema. Este método expressa a função de densidade de probabilidade do fator de segurança, como uma função de variação das diferentes variáveis aleatórias consideradas no problema.

No campo da estatística, o primeiro momento é a média enquanto o segundo momento é a variância.

Se $\left(x_{1}, x_{2}, x_{3}, \ldots, x_{n}\right)$ representam as variáveis aleatórias que influenciam no valor de FS e $\left(\bar{x}_{1}, \bar{x}_{2}, \bar{x}_{3}, \ldots, \bar{x}_{n}\right)$ definem seus valores médios, a função de desempenho $f(x)$ expressa na forma da série de Taylor é representada pela Expressão:

$$
f(x)=f(\bar{x})+\frac{f^{\prime}(\bar{x})}{1 !}(x-\bar{x})+\frac{f^{\prime \prime}(\bar{x})}{2 !}(x-\bar{x})^{2}+\cdots
$$

Na qual $f^{\prime}(\bar{x})$ é a derivada de primeira ordem e $f^{\prime \prime}(\bar{x})$ é a derivada de segunda ordem, em torno de $\bar{x}$. Os termos subsequentes da série de Taylor tornamse progressivamente menos relevantes para a precisão da solução, por esta razão, a 
série é cortada na primeira derivada, ou seja, no segundo momento da série, tomando a seguinte forma:

$$
f(x)=f(\bar{x})+f(\bar{x})(x-\bar{x})
$$

Manipulando a equação por álgebra elementar, obtêm-se:

$$
f(x)-f(\bar{x})=f(\bar{x})(x-\bar{x})
$$

Observa-se que os termos $f(x)-f(\bar{x})$ e $(x-\bar{x})$ representam desvios em torno de uma média, logo, ao elevar-se os dois lados da equação ao quadrado, obtêm-se as variâncias dos termos. Assim, considerando que a variável de interesse é o fator de segurança, a eq. (27) toma a seguinte forma:

$$
V[F S]=\left(\frac{\delta F S}{\delta x_{i}}\right)^{2} \cdot V(x)
$$

A eq. (28) expressa a relação da variância do fator de segurança em relação à derivada parcial de uma única variável aleatória. Sabendo-se que análises probabilísticas de estabilidade envolvem diversas variáveis independentes, entende-se que a variância do fator de segurança é correlata ao somatório do produto das derivadas parciais da função $f(x)$ e da variância de $x_{i}$ em relação a cada parâmetro. Neste caso, a variância de FS pode ser obtida por meio da eq. (29):

$$
V[F S]=\sum_{i=1}^{n}\left(\frac{\delta F S}{\delta x_{i}}\right)^{2} \cdot V\left(x_{i}\right)
$$

Onde n é o número de parâmetros simulados como variáveis aleatórias no problema.

O método tem como principal vantagem a simplicidade de aplicação, que possibilita o cálculo da probabilidade de ruptura de um talude sem o conhecimento da função de densidade de probabilidade de FS. Além disso, o método também permite a determinação da influência de cada parâmetro considerado variável, na estabilidade da obra geotécnica (Vecci, 2018).

A média e a variância obtidas pelo método FOSM podem ser utilizadas para cálculo do Índice de Confiabilidade e da Probabilidade de Ruptura, por intermédio das eq. (22), (23) e (24). 


\subsection{4. \\ Método das Estimativas Pontuais}

Desenvolvido por Rosenblueth (1975), o Método das Estimativas Pontuais, ou EP é um método indireto que permite a estimativa dos dois primeiros momentos de uma função estatística, $\mu$ e $\sigma$, por meio de uma aproximação numérica.

Pelo método de Rosenblueth, considerando uma função de desempenho FS dependente de dois parâmetros admitidos como variáveis aleatórias, a média desta função será dada por:

$$
E(F S)=P_{++} * F S_{++}+P_{+-} * F S_{+-}+P_{-+} * F S_{-+}+P_{--} * F S_{--}
$$

Onde:

$P_{++}$é a probabilidade de que os valores das duas variáveis sejam acrescidos de seus desvios padrão simultaneamente;

$P_{+_{-}}$e $P_{-}$é a probabilidade de que uma variável seja acrescida de seu desvio padrão e a outra variável seja decrescida de seu desvio padrão, na ordem imposta pelos símbolos de adição e subtração;

$P_{-}$é a probabilidade de que os valores das duas variáveis sejam decrescidos de seus desvios padrão simultaneamente;

$F S_{++}$é o valor do fator de segurança obtido quando as duas variáveis são acrescidas de seus desvios padrão;

$F S_{+_{-}} F S_{+}+$são os fatores de segurança obtidos quando uma variável é acrescida e a outra decrescida de seus respectivos desvios padrão, na ordem imposta pelos símbolos de adição e subtração;

FS_- é o fator de segurança obtido quando as duas variáveis são decrescidas de seus desvios padrão.

Considerando que as funções de densidade de probabilidade sejam simétricas e que as variáveis não possuem correlação, as probabilidades de que as variáveis sejam acrescidas ou decrescidas do desvio padrão serão todas iguais. Na mesma linha de raciocínio, para duas variáveis aleatórias, entende-se que:

$$
P_{++}=P_{ \pm}=P_{\mp}=P_{--}=0,25 \text { ou } \frac{1}{4}
$$

Logo, 


$$
(F S)=\frac{F S_{++}+F S_{ \pm}+F S_{\mp}+F S_{--}}{4}
$$

A eq. (32) torna evidente a necessidade da elaboração de uma análise de estabilidade determinística para cada hipótese de acréscimo ou decréscimo e para cada variável aleatória do problema. Substituindo-se alternadamente as estimativas pontuais para cada variável, atinge-se um número mínimo de $2^{\mathrm{n}}$ análises determinísticas para aplicação do método, onde n é o número de variáveis aleatórias.

Obtendo-se os valores de FS correspondentes a todas as combinações possíveis dos acréscimos e decréscimos estimados para cada variável aleatória, é possível calcular a variância pela subtração do quadrado da média aritmética dos valores de FS do somatório dos quadrados de FS, conforme indicado na eq. (33):

$$
V[F S]=p_{++} \cdot F S_{++}{ }^{2}+p_{+_{-}} \cdot F S_{+_{-}}{ }^{2}+p_{-_{+}} \cdot F S_{-_{+}}{ }^{2}+p_{--} \cdot F S_{--}{ }^{2}-[E(F S)]^{2}
$$

Deste modo, o desvio padrão é calculado pela raiz da variância obtida na eq. (34):

$$
\sigma[F S]=\sqrt{V[F S]}
$$

O número de análises determinísticas necessárias para aplicação do método das estimativas pontuais aumenta exponencialmente com o número de variáveis aleatórias adicionadas problema, o que torna o método não recomendável para análises com muitos parâmetros variáveis.

De forma semelhante ao método FOSM, a média e o desvio padrão obtidos pelo método das Estimativas Pontuais podem ser usados no cálculo do Índice de Confiabilidade e da Probabilidade de Ruptura do talude, por meio das eq. (22), (23) e (24).

\subsection{5. \\ Método de Monte Carlo}

O método de Monte Carlo, desenvolvido por Von Newmann e Staniaslaw Ulam (Metropolis e Ulam, 1949) e nomeado com base no cassino de Monte Carlo, utiliza sequências de números aleatórios para desenvolver simulações numéricas.

Primeiramente o método exige a definição das variáveis aleatórias do problema, em seguida, de acordo com a função de densidade de probabilidade atribuída a cada variável, é definido aleatoriamente um valor. Quando aplicado à 
estabilidade de taludes, cada combinação de valores obtidos para as variáveis representa uma amostra, para a qual será calculado o valor de FS. O processo é então repetido $\mathrm{N}$ vezes, gerando um histograma das frequências dos fatores de segurança. A assertividade de uma análise pelo método de Monte Carlo é fortemente influenciada pelo número de amostras adotado, podendo se aproximar de uma solução exata quando $\mathrm{N}$ tende ao infinito, entretanto, quanto mais próximo da solução exata, menor será o benefício do incremento do número de amostras para a precisão da solução.

Uma vez que a estabilidade de um talude está diretamente condicionada ao equilíbrio entre a força cisalhante mobilizada e a força cisalhante resistente, em uma análise pelo método de Monte Carlo, a probabilidade de ruptura funciona como uma medida relativa do número de vezes no qual as força cisalhante mobilizada foi superior à resistente.

Apesar de ter sido um grande avanço no campo dos estudos de probabilidade, o método de Monte Carlo tradicional possui uma ineficiência relevante. $\mathrm{Na}$ amostragem puramente aleatória, a distribuição de frequências dos eventos tende a ficar muito concentrada nos pontos centrais da curva de distribuição, deixando as extremidades com poucos eventos. A Figura 2-13 exemplifica o conceito exposto por meio de uma distribuição bivariada, isto é, uma distribuição conjunta de duas variáveis aleatórias, na qual, utilizando a simulação de Monte Carlo, ocorre uma concentração de eventos na região central representada pelos topos das gaussianas.

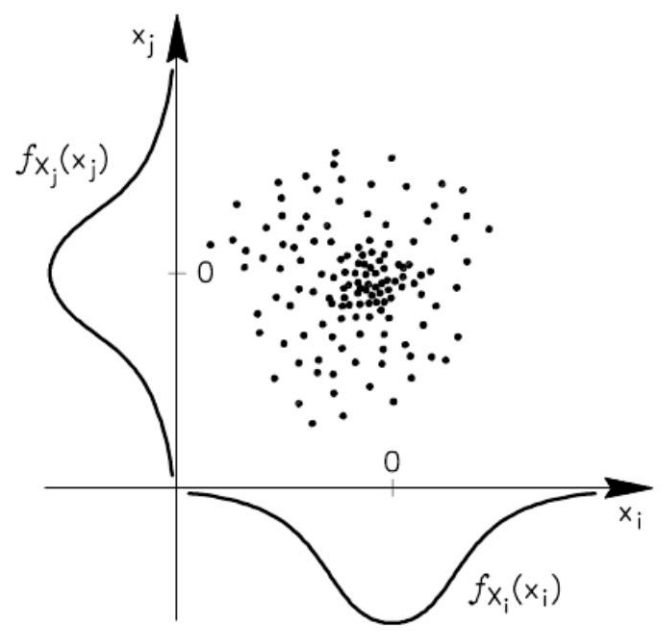

Figura 2-13 - Nuvem de pontos gerada pela distribuição puramente aleatória de pontos (Hurtado e Barbat, 1998) 


\subsection{6.}

\section{Amostragem por Hipercubo Latino}

Introduzido por Mckay et al., (1979), o método de amostragem conhecido como hipercubo latino aplica o princípio da amostragem estratificada como solução para o problema da ineficiência do método de Monte Carlo com amostragem puramente aleatória.

A amostragem estratificada consiste na segmentação do espaço amostral em $\mathrm{N}$ fatias de igual probabilidade, $1 / \mathrm{N}$, seguida da realização de amostragens em cada segmento (Mckay et al., 1979). Esta abordagem tem como objetivo homogeneizar a distribuição de eventos. A Figura 2-14 ilustra a distribuição de eventos em uma amostragem estratificada com duas variáveis.

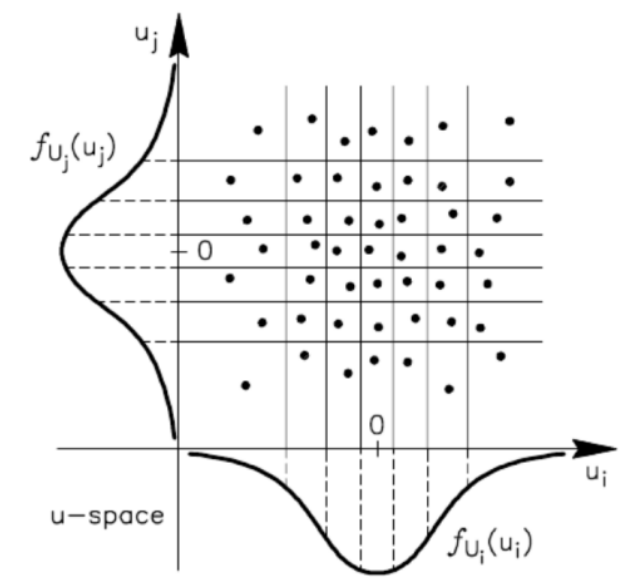

Figura 2-14 - Amostragem estratificada (Hurtado e Barbat, 1998)

O quadrado latino é uma matriz $n \times n$ com valores que ocorrem apenas uma vez em cada linha e em cada coluna, conforme apresentado na Tabela 2-1.

Tabela 2-1 - Exemplo de quadrado latino

\begin{tabular}{|l|c|c|c|c|}
\hline & $\mathbf{1}$ & $\mathbf{2}$ & $\mathbf{3}$ & $\mathbf{4}$ \\
\hline $\mathbf{1}$ & A & B & C & D \\
\hline $\mathbf{2}$ & B & A & D & C \\
\hline $\mathbf{3}$ & C & D & B & A \\
\hline $\mathbf{4}$ & D & C & A & B \\
\hline
\end{tabular}

O termo hipercubo é utilizado na geometria para definir um quadrado de $n$ dimensões, logo, subentende-se que o hipercubo latino é uma combinação do conceito do quadrado latino com as $n$ dimensões do hipercubo. 
Se $N$ for o número de eventos e $K$ o número de variáveis aleatórias, o espaço amostral terá $K$ dimensões. Imaginando uma matriz $\mathrm{P}$ de dimensões $N$ x $K$, na qual cada coluna $K$ é uma permutação aleatória de $1, . ., n$, e uma matriz $\mathrm{R}$ de dimensões $N$ x $K$, composta por números aleatórios de distribuição $(0,1)$ uniforme. Estas matrizes formam o plano de amostragem representado pela matriz $\mathrm{S}$, apresentada na eq. (35) (Olsson et al., 2003). A Figura 2-15 exemplifica o processo descrito acima.

$$
\begin{aligned}
& S=\frac{1}{N}(P-R) \\
& \left|\begin{array}{ll}
1 & 2 \\
2 & 4 \\
3 & 3 \\
4 & 1 \\
5 & 5
\end{array}\right|-\left|\begin{array}{cc}
0,6 & 0,83 \\
0,42 & 0,11 \\
0,69 & 0,51 \\
0,32 & 0,58 \\
0,83 & 0,32
\end{array}\right|=\left|\begin{array}{cc}
0,4 & 1,17 \\
1,58 & 3,89 \\
2,31 & 2,50 \\
3,68 & 0,42 \\
4,17 & 4,68
\end{array}\right|
\end{aligned}
$$

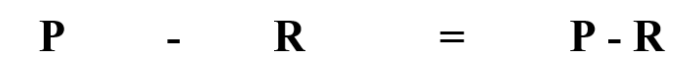

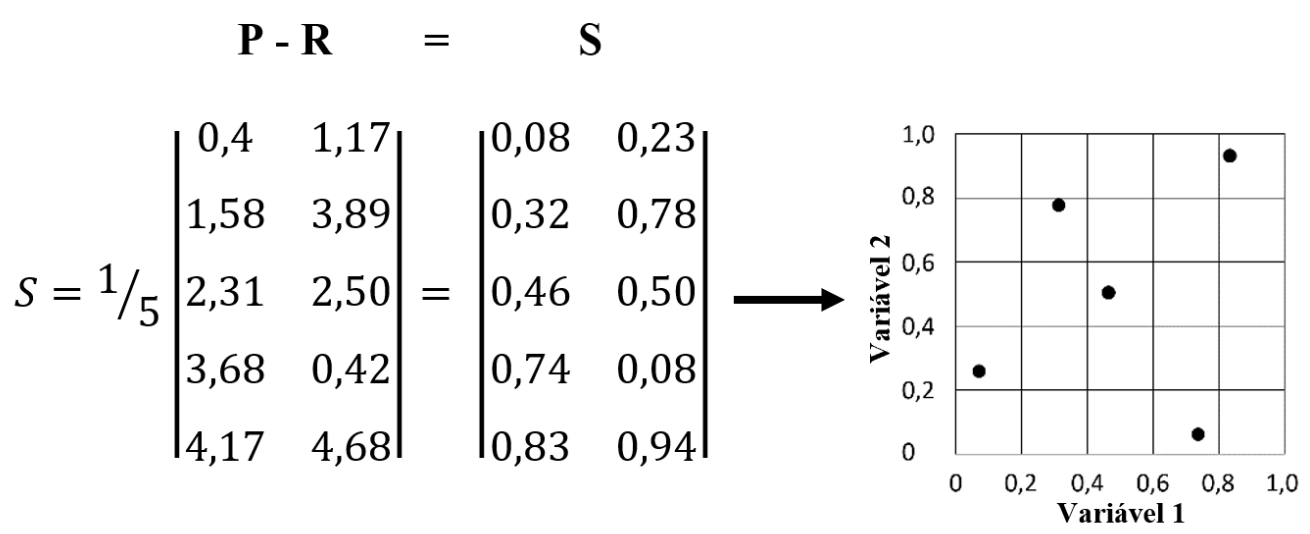

Figura 2-15 - Hipercubo latino para duas variáveis e 5 eventos, onde a matriz 5x2 (a) determina o plano ilustrado em (b) (adaptado de Olsson et al., 2003)

A Figura 2-16 exemplifica o método de amostragem por hipercubo latino para uma distribuição bivariada de duas variáveis aleatórias. Observa-se que a distribuição de eventos ocorre em todos os seguimentos estratificados, apenas uma vez em cada coluna e uma vez em cada linha. 


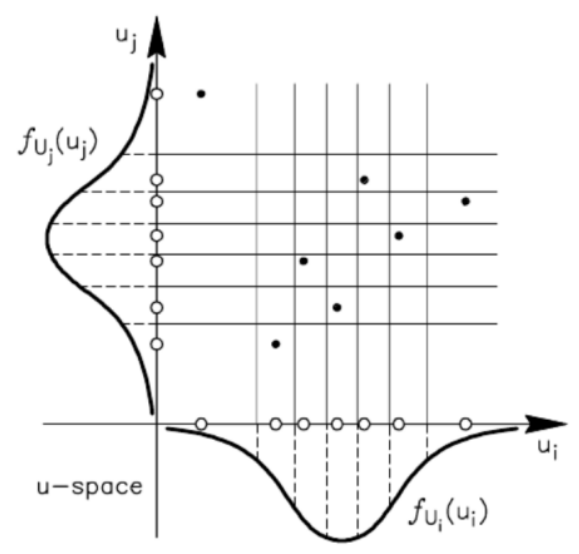

Figura 2-16 - Amostragem por hipercubo latino (Hurtado e Barbat, 1998)

\subsection{7. \\ Variabilidade Espacial de Parâmetros Geotécnicos}

Nas análises de estabilidade probabilísticas os parâmetros do solo variam de forma simultânea e valores são obtidos de acordo com a função de densidade de probabilidade atribuída a cada variável. No entanto, este tipo de análise ainda pressupõe distribuição homogênea de parâmetros dentro de cada camada de solo. Na realidade, a composição e as propriedades do solo variam de um ponto para outro, dentro de uma mesma camada. Lacasse e Nadim (1996) atribuem a variabilidade espacial de propriedades dos solos a fatores como composição mineralógica, condições climáticas durante a deposição, história de tensões e processos intempéricos.

Além dos fatores naturais já apresentados, Phoon e Kulhawy (1999) apontam outros três fatores que se somam às incertezas geológicas na modelagem de solos, os erros devido a equipamentos, ensaios e procedimentos adotados nas medições de campo e de laboratório; as incertezas estatísticas por limitação de dados; as incertezas de transformação que ocorrem quando os parâmetros obtidos experimentalmente são convertidos em parâmetros de projeto.

Devido aos fatores geológicos apresentados em Lacasse e Nadim (1996) solos apresentam variabilidade tanto na direção horizontal quanto na direção vertical. Esta variação espacial pode ser decomposta em uma função de tendência $t(z)$ e uma componente de flutuação $w(z)$, matematicamente expressa pela eq. (36).

$$
\xi(z)=t(z)+w(z)
$$


Onde $\xi$ representa a propriedade do solo in situ, e $z$ a profundidade, conforme ilustrado na Figura 2-17.

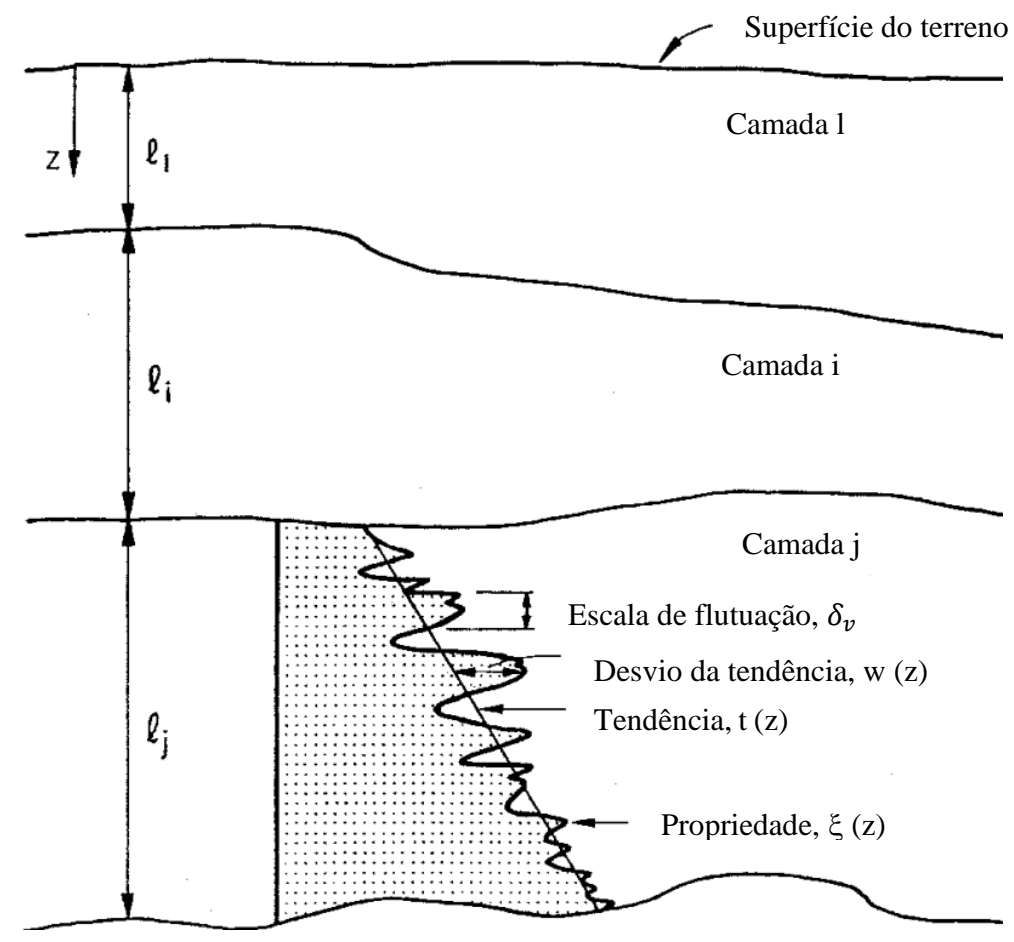

Figura 2-17 - Variabilidade inerente dos solos (Phoon e Kulhawy, 1999)

A análise de variação espacial é um tipo de análise probabilística na qual os parâmetros variam conforme sua posição espacial dentro da massa de solo. Neste tipo de análise, diferentes parâmetros são atribuídos para cada ponto dentro da camada formando um campo escalar, cuja distribuição de valores é probabilística, porém segue diretrizes pré-definidas. Em seguida, a busca pela superfície de ruptura com menor fator de segurança é realizada. Idealmente, o processo deve ser repetido $n$ vezes até que a variação do fator de segurança médio se aproxime de zero.

A Figura 2-18 exemplifica a construção do campo de distribuição de parâmetros de uma análise de variação espacial, onde (a) representa a variação do parâmetro $c_{u}$ com a profundidade e (b) representa a função de densidade que define a variabilidade do parâmetro ponto a ponto. 

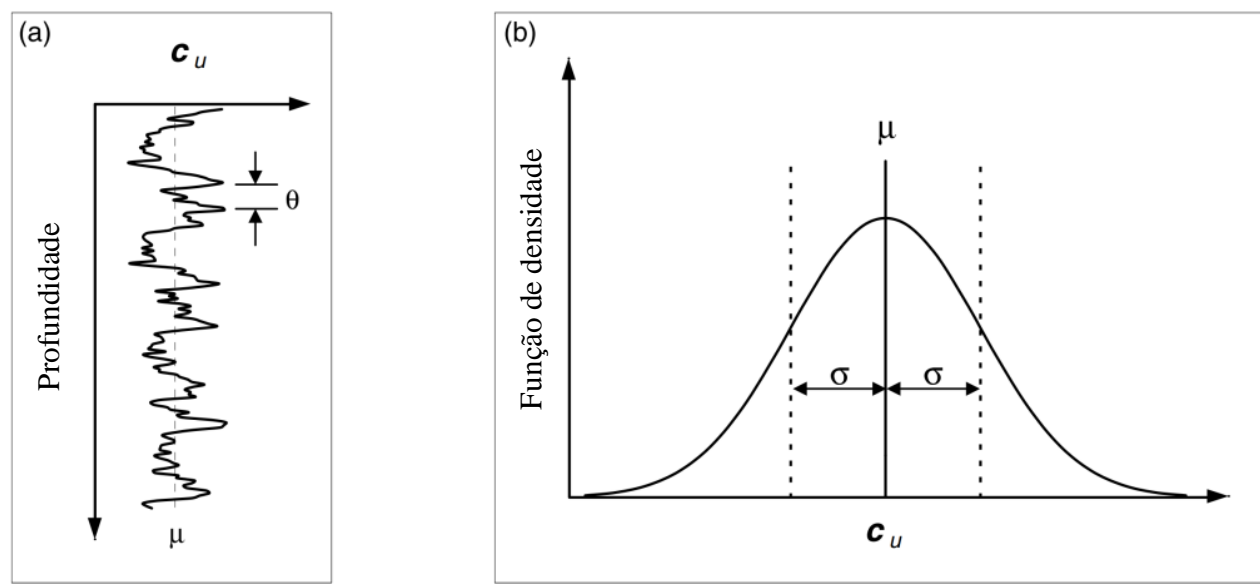

Figura 2-18 - Medidas estatísticas de $\boldsymbol{c}_{\boldsymbol{u}}$. (a) $\boldsymbol{c}_{\boldsymbol{u}}$ variando com a

profundidade (b) função de densidade de probabilidade de $\boldsymbol{c}_{\boldsymbol{u}}$ (Hicks e Samy, 2002)

Na maioria das vezes o principal fator limitador para a utilização de análises de variação espacial é o desconhecimento das funções de densidade de probabilidade e coeficientes de variação mais adequados para representar cada propriedade do solo. Por esta razão, diversos autores têm conduzido estudos visando um melhor entendimento a respeito da variabilidade típica de cada parâmetro geotécnico.

Lacasse e Nadim (2007) publicaram uma lista de valores obtidos para coeficientes de variação e funções de densidade de probabilidade mais apropriadas para diversos parâmetros e diferentes tipos de solo (

Tabela 2-2). Duncan (2014) compilou os intervalos de coeficiente de variação obtidos em Harr (1987), Lacasse e Nadim (1997), Kulhawy (1992) e Duncan (2000) (Tabela 2-3).

Tabela 2-2 - Coeficientes de variação e distribuições típicas de parâmetros de solo (Adaptado de Lacasse e Nadim, 2007)

\begin{tabular}{llll}
\hline \multicolumn{1}{c}{ Propriedades do solo } & Tipo de solo & FDP & \multicolumn{1}{c}{ CV } \\
\hline Resistência de ponta & Areia & LN & $\begin{array}{l}\text { Varia de local } \\
\text { para local }\end{array}$ \\
\hline \multirow{2}{*}{ Resistência de ponta } & Argila & N e LN & $\begin{array}{l}\text { Varia de local } \\
\text { para local }\end{array}$ \\
\hline \multirow{3}{*}{ Resistência não drenada } & Argila (triaxial) & LN & $5-20 \%$ \\
\cline { 2 - 4 } & Argila (Indice $\mathrm{S}_{\mathrm{u}}$ ) & LN & $10-35 \%$ \\
\cline { 2 - 4 } & Silte argiloso & N e LN & $10-30 \%$ \\
\hline
\end{tabular}




\begin{tabular}{llll} 
Razão $S_{\mathrm{u}} / \sigma_{\text {vo }}^{\prime}$ & Argila & $\mathrm{N} / \mathrm{LN}$ & $5-15 \%$ \\
\hline Limite de plasticidade & Argila & $\mathrm{N}$ & $3-20 \%$ \\
\hline Peso específico submerso & Todos & $\mathrm{N}$ & $1-8 \%$ \\
\hline Ângulo de atrito & Areia & $\mathrm{N}$ & $2-5 \%$ \\
\hline Índice de vazios, porosidade & Todos & $\mathrm{N}$ & $7-30 \%$ \\
\hline Razão de sobreadensamento & Argila & $\mathrm{N} / \mathrm{LN}$ & $10-35 \%$ \\
\hline
\end{tabular}

Tabela 2-3 - Coeficientes de variação para propriedades geotécnicas e ensaios in situ (Adaptado de Duncan, 2014)

\begin{tabular}{lcl}
\hline Propriedade ou ensaio de campo & CV (\%) & \multicolumn{1}{c}{ Referências } \\
\hline Peso específico $(\gamma)$ & $3-7$ & Harr (1987), Kulhawy (1992) \\
\hline Peso específico submerso $\left(\gamma_{\text {sub }}\right)$ & $0-10$ & $\begin{array}{l}\text { Lacasse e Nadim (1997), Duncan } \\
(2000)\end{array}$ \\
\hline Ângulo de atrito efetivo $\left(\phi^{\prime}\right)$ & $2-13$ & $\begin{array}{l}\text { Harr }(1987), \text { Kulhawy (1992), } \\
\text { Duncan (2000) }\end{array}$ \\
\hline Resistência não drenada $\left(S_{u}\right)$ & $13-40$ & $\begin{array}{l}\text { Kulhawy (1992), Harr (1987), } \\
\text { Lacasse e Nadim (1997) }\end{array}$ \\
\hline Razão de resistência $\left(S_{u} / \sigma_{v}\right)$ & $5-15$ & $\begin{array}{l}\text { Lacasse e Nadim (1997), Duncan } \\
(2000)\end{array}$ \\
\hline $\begin{array}{l}\text { Número de golpes de ensaio SPT } \\
(N)\end{array}$ & $15-45$ & Harr (1987), Kulhawy (1992) \\
\hline $\begin{array}{l}\text { Ensaio de penetração de cone } \\
\text { elétrico }\left(q_{c}\right)\end{array}$ & $5-15$ & Kulhawy (1992) \\
\hline $\begin{array}{l}\text { Ensaio de penetração de cone } \\
\text { mecânico }\left(q_{c}\right)\end{array}$ & $15-37$ & Harr (1987), Kulhawy (1992) \\
\hline $\begin{array}{l}\text { Resistência de ponta do dilatômetro } \\
\left(q_{D}\right)\end{array}$ & $5-15$ & Kulhawy (1992) \\
\hline $\begin{array}{l}\text { Resistência ao cisalhamento da } \\
\text { palheta }\left(S_{u}\right)\end{array}$ & $10-20$ & Kulhawy (1992) \\
\hline
\end{tabular}

A distribuição de parâmetros na massa de solo é influenciada também pela distância de correlação $\theta$, que representa a distância para a qual os parâmetros possuem magnitude similar. Uma grande distância de correlação reflete em uma variação sutil de parâmetros dentro da massa de solo, enquanto uma pequena distância representa uma variabilidade errática de parâmetros no espaço (Chakraborty e Dei, 2018).

Phoon e Kulhawy (1999) realizaram extensa revisão bibliográfica a fim de encontrar valores típicos para escalas de flutuação de diversos parâmetros 
geotécnicos. O resumo dos resultados obtidos pelos autores é apresentado na Tabela $2-4$.

Tabela 2-4 - Resumo de escalas de flutuação de algumas propriedades geotécnicas (Adaptado de Phoon e Kulhawy, 1999)

\begin{tabular}{|c|c|c|c|c|}
\hline \multirow{2}{*}{ Propriedades } & \multirow{2}{*}{ Tipo de solo } & \multirow{2}{*}{$\begin{array}{c}\mathbf{N}^{\mathbf{o}} \text { de } \\
\text { estudos }\end{array}$} & \multicolumn{2}{|c|}{ Escala de flutuação $(\mathrm{m})$} \\
\hline & & & Intervalo & Média \\
\hline \multicolumn{5}{|c|}{ Flutuação vertical } \\
\hline$S_{u}$ & Argila & 5 & $0,8-6,1$ & 2,5 \\
\hline$q_{c}$ & Areia, argila & 7 & $0,1-2,2$ & 0,9 \\
\hline$q_{T}$ & Argila & 10 & $0,2-0,5$ & 0,3 \\
\hline$S_{u}(V S T)$ & Argila & 6 & $2,0-6,2$ & 3,8 \\
\hline$N$ & Areia, argila & 1 & - & 2,4 \\
\hline$w_{n}$ & Argila & 3 & $1,6-12,7$ & 5,7 \\
\hline$w_{\mathrm{L}}$ & Argila & 2 & $1,6-8,7$ & 5,2 \\
\hline $\bar{\gamma}$ & Argila & 1 & - & 1,6 \\
\hline$\gamma$ & Argila & 2 & $2,4-7,9$ & 5,2 \\
\hline \multicolumn{5}{|c|}{ Flutuação horizontal } \\
\hline$q_{c}$ & Areia, argila & 11 & $3,0-80,0$ & 47,9 \\
\hline$q_{T}$ & Argila & 2 & $23,0-66,0$ & 44,5 \\
\hline$S_{u}(V S T)$ & Argila & 3 & $46,0-60,0$ & 50,7 \\
\hline$w_{n}$ & Argila & 1 & - & 170,0 \\
\hline
\end{tabular}

Su e Su (VST), resistência não drenada obtidos em testes de laboratório e ensaios de palheta, respectivamente; $\bar{\gamma}$, peso específico efetivo.

A distância de correlação pode atuar em ambos os eixos do plano cartesiano, de forma que permite a simulação de campos aleatórios de distribuição paramétrica definidos de acordo com as escalas de flutuação espacial atribuídas a cada material. A distância de correlação permite, por exemplo, a simulação de materiais com anisotropia ortogonal, por meio da variação de parâmetros em apenas uma direção.

\subsection{8.}

\section{Estudos Anteriores}

Dell’ Avanzi (1995) apresentou o estudo de caso da Barragem Santa Branca, localizada no Estado de São Paulo, como exemplo da aplicação de métodos probabilísticos para avaliação da confiabilidade de análises de estabilidade. $\mathrm{O}$ autor compara as probabilidades de ruptura e índices de confiabilidade obtidos mediante 
a aplicação de diferentes métodos de equilíbrio limite, pelo método FOSM. O autor realiza dois estudos paralelamente. O primeiro, conforme descrito anteriormente, visa avaliar a influência do método de estabilidade adotado na composição da confiabilidade do talude da barragem. O segundo, por sua vez, tem por objetivo a definição do valor relativo de variação dos parâmetros mais adequado para aproximação das derivadas parciais do método FOSM, de forma a assegurar a linearidade da aproximação. Ao final do estudo, o autor conclui que o valor da probabilidade de ruptura, assim como do FS, é consideravelmente dependente do método de estabilidade adotado, tendo os métodos rigorosos apresentado os maiores índices de confiabilidade e, consequentemente, as menores probabilidades de ruptura.

A conclusão da segunda parte do estudo é de que houve constância na aproximação da derivada parcial para variações de até $15 \%$, sejam elas incrementais ou decrementais. Essa conclusão vai de encontro à recomendação de Sayão et al. (2012) de se adotar variações de 10\% para parâmetros assumidos como variáveis aleatórias do problema.

Vecci (2018) aplicou métodos probabilísticos e determinísticos para averiguar a estabilidade de um talude de $200 \mathrm{~m}$ de altura da Mina do Cauê, em Itabira, MG. A autora adota cinco conhecidos métodos de equilíbrio limite, fazendo uso dos métodos probabilísticos FOSM, Estimativas Pontuais e Monte Carlo. O estudo tem como objetivo complementar os estudos pré-existentes de Sayão et al. (2012), Guedes (1997) e Farias e Assis (1998) com métodos e abordagens não exploradas pelos autores citados. O estudo busca principalmente avaliar o efeito da fixação, ou não, da superfície crítica de ruptura obtida nas análises determinísticas, para as análises probabilísticas. A autora conclui que os métodos FOSM e Monte Carlo apresentaram insensibilidade à variação da superfície de ruptura, não apresentando diferenças relevantes nos valores de $\beta$ e PR com superfícies fixas ou livres. Ademais, o estudo relata que o método de Monte Carlo apresentou valores de $\beta$ relativamente maiores do que aqueles obtidos pelos métodos FOSM e Estimativas Pontuais.

Silva (2015) utiliza como estudo de caso para aplicação de métodos probabilísticos a Mina Alegria. O estudo adota os métodos de Monte Carlo, FOSM e Estimativas Pontuais para determinação da PR. Como ponto central, o estudo reforça que a PR deve ser analisada conjuntamente com as consequências de uma 
ruptura, para determinação do risco de uma obra. O autor também afirma que o método FOSM pode ser utilizado como forma de exclusão dos parâmetros que possuem pouca contribuição para a variância do FS, antes da aplicação dos demais métodos como Monte Carlo e Estimativas Pontuais.

De Oliveira (2018) aplica a abordagem probabilística para avaliação de estabilidade de um quebra-mar construído sobre argila mole no Terminal Portuário de Sergipe, em outubro de 1989. O estudo adota os métodos probabilísticos FOSM, Monte Carlo e Estimativas Pontuais para a avaliação dos valores de b e PR. A autora compara os resultados de três cenários de análise distintos. O primeiro em termos de tensão totais, utilizando parâmetros de resistência obtidos por ensaios de campo e laboratório, um segundo cenário no qual os parâmetros de resistência, obtidos por ensaios, são apresentados em termos tensões efetivas, e um terceiro cenário, também em termos de tensões efetivas, no qual o ângulo de atrito da camada argilosa de fundação é obtido mediante retroanálise de uma ruptura pré-existente. Nos 3 cenários abordados, os valores de $\beta$ e PR calculados pela metodologia FOSM foram similares aos calculados por Estimativas Pontuais. A autora conclui ainda que, considerando os métodos rigorosos de Morgenstern \& Price (1965) e Spencer (1967), as análises em tensões totais e tensões efetivas, com $\phi$ ' obtido por meio de retroanálise, apresentaram resultados similares. Por outro lado, as análises em tensões efetivas com parâmetros oriundos de ensaios apresentaram valores de PR muito inferiores aos outros dois cenários analisados.

Assim como Dell' Avanzi (1995), Araujo (2018) analisa o caso da Barragem Santa Branca, situada no Estado de São Paulo, através da abordagem probabilística. A Barragem, que faz parte do complexo da hidrelétrica Santa Branca, possui altura máxima de 55 metros e foi construída na década de 1950. Na década de 1980 a estrutura sofreu obras de reforço devido a sucessivos processos de instabilidade no talude de jusante. A autora conduziu análises de estabilidade probabilísticas pelos métodos FOSM, Monte Carlo e Estimativas Pontuais, em um cenário no qual foi considerada a condição da barragem após as obras de reforço, assumindo a inoperância do sistema de drenagem interna da estrutura.

Os resultados das análises se mostraram coerentes entre si, apontando para fatores e segurança determinísticos da ordem de 2,2, com PR inferior a $1 \times 10^{\wedge-10}$ para todos os métodos. É interessante ressaltar que a autora obteve PR nula pelo Método de Monte Carlo, o que é algo recorrente em estruturas com valores elevados 
de $\beta$ e ocorre quando não há valores de FS inferiores a 1 em nenhuma das amostras analisadas.

Braga (2019) apresenta a aplicação de métodos probabilísticos na avaliação da PR da Barragem I da Mina Córrego do Feijão, a qual sofreu ruptura no ano de 2019. O autor aplica o método probabilístico FOSM para o estudo de dois cenários pelos métodos de estabilidade de Morgenstern \& Price (1965) e Spencer (1967). O primeiro em termos de tensões totais, para o qual a resistência não drenada do rejeito foi obtida pelos ensaios de campo (palheta e piezocone) e laboratório (triaxiais). No segundo cenário a resistência do rejeito é simulada em termos de tensões efetivas, com parâmetros obtidos pelos ensaios de laboratório. O resultado do estudo indica que a estrutura apresentava PR próxima de 1:4, o que equivale a um nível de confiabilidade inadequado para uma barragem. Ademais, nas análises em tensões totais, a razão de resistência não drenada $\left(s_{u} / \sigma^{\prime}{ }_{v}\right)$ do rejeito saturado se destacou como o parâmetro de maior influência na PR, enquanto nas análises em tensões efetivas, o parâmetro tan $\phi^{\prime}$ sobressai aos demais.

\section{3. \\ Análises Numéricas}

\subsection{1. \\ Método das Diferenças Finitas}

O método das diferenças finitas consiste na discretização do problema em um número finito de passos, por meio da geração de uma malha formada por pontos discretos, ou pontos nodais. A solução destes pontos discretos é aproximada por meio da taxa de variação dos pontos adjacentes. $\mathrm{O}$ método estima a solução das equações diferenciais por uma Série de Taylor, que aproxima a solução das equações diferenciais por um sistema de equações algébricas ordinárias.

Considerando que $h$ representa o espaço entre pontos adjacentes de uma malha, pode-se aproximar a função $f(x+h)$, mediante aproximação para frente, o que resulta na seguinte expansão da Série de Taylor no ponto adjacente $\mathrm{x}+\mathrm{h}$ :

$$
f(x+h)=f(x)+h \frac{d_{f}}{d_{x}}+\frac{h^{2}}{2 !} \frac{d_{f}^{2}}{d^{2}{ }_{x}}+\cdots \frac{h^{n}}{n !} \frac{d_{f}^{n}}{d_{x}^{n}}
$$

Adotando-se o mesmo método com aproximação para trás, pode-se aproximar a função $f(x-h)$, da forma seguinte: 


$$
f(x-h)=f(x)-h \frac{d_{f}}{d_{x}}+\frac{h^{2}}{2 !} \frac{d^{2}{ }_{f}}{d^{2}{ }_{x}}-\cdots \frac{h^{n}}{n !} \frac{d_{f}^{n}}{d_{x}^{n}}
$$

Truncando-se as Séries de Taylor apresentadas na eq. (37) e na eq. (38) na primeira derivada, obtém-se:

$$
\frac{d_{f}}{d_{x}}=\frac{f(x+h)-f(x)}{h} e \frac{d_{f}}{d_{x}}=\frac{f(x)-f(x-h)}{h}
$$

Geometricamente, o resultado destas divisões equivale à aproximação do gradiente da derivada entre o ponto $\mathrm{x}$ e o ponto $\mathrm{x}+\mathrm{h}$ ou $\mathrm{x}-\mathrm{h}$.

Também é possível aproximar o resultado utilizando os valores da função nos pontos em ambos os lados do ponto derivado, este método é conhecido como aproximação central:

$$
\frac{d_{f}}{d_{x}}=\frac{f(x+h / 2)-f(x-h / 2)}{h}
$$

$\mathrm{Na}$ aproximação com truncamento na primeira derivada, são desprezados os termos de ordem superior. Desta forma, denota-se que o erro de truncamento é de ordem $O\left(\Delta \mathrm{x}^{2}\right)$.

A Figura 2-19 ilustra geometricamente as abordagens de aproximação de primeira ordem pelo método das diferenças finitas. A linha azul (1) representa uma aproximação para a frente, a linha vermelha (2) representa uma aproximação para trás, enquanto a linha verde (3) ilustra uma aproximação central. Observa-se que a qualidade da aproximação é inversamente proporcional ao espaçamento entre os pontos. 


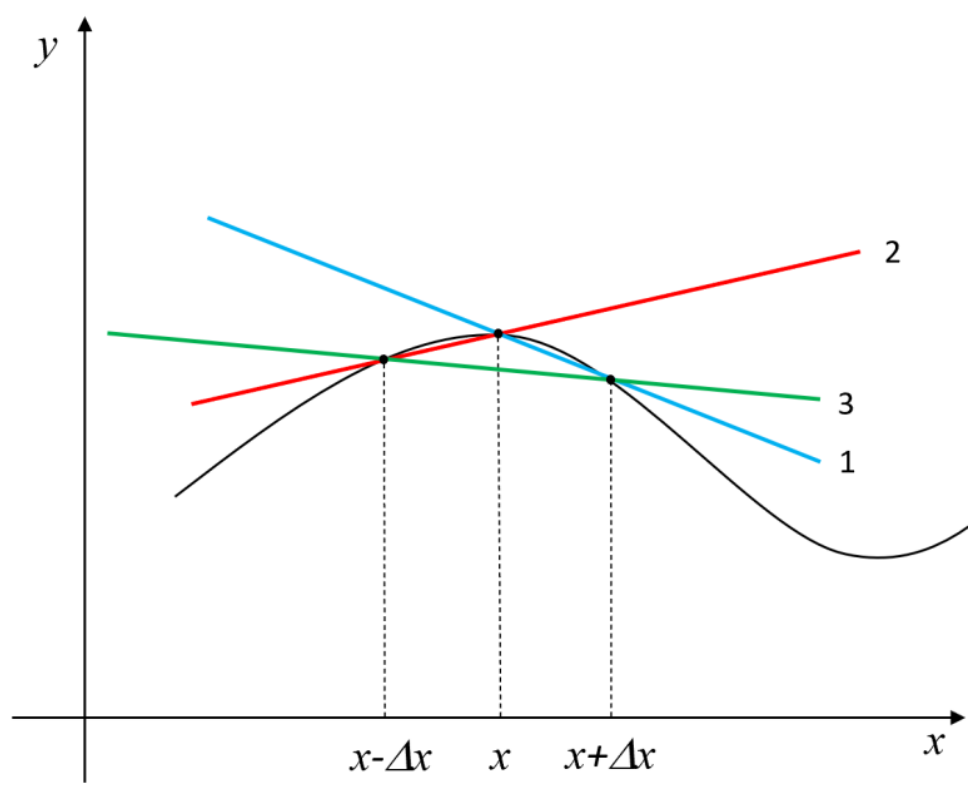

Figura 2-19 - Ilustração geométrica de aproximações de primeira ordem utilizando o método das diferenças finitas

A Figura 2-20 exemplifica a utilização do método das diferenças finitas para a solução de problemas bidimensionais.

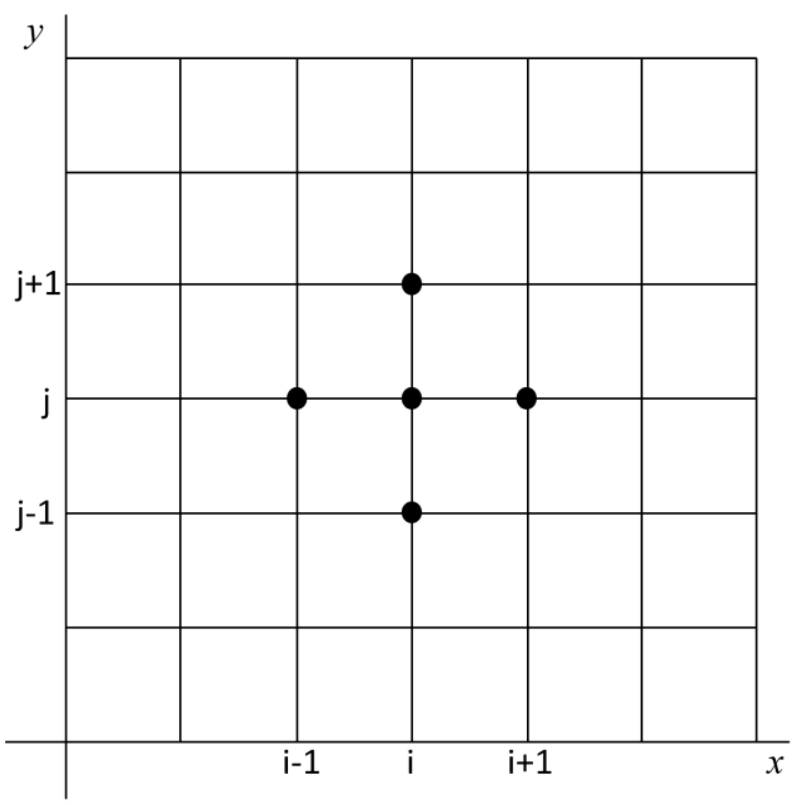

Figura 2-20 - Convenção de coordenadas de uma malha de pontos discretos com localização do ponto central e pontos adjacentes

O Método das Diferenças Finitas é muito utilizado na geotecnia para a aproximação de problemas de tensão vs deformação e fluxo 2D e 3D.

Este método não foi utilizado no âmbito deste estudo. 


\subsection{2. Método dos Elementos Finitos}

O método dos elementos finitos (MEF) é um método numérico aplicado na solução de diversos problemas de engenharia. No campo geotécnico, o método é utilizado na simulação do comportamento tensão vs deformação de solos para análises não lineares.

O método consiste na divisão dos corpos (áreas ou volumes) que compõem o problema em pequenos elementos conectados entre si por nós, formando uma malha. Esse processo, conhecido como discretização, permite a solução das equações equilíbrio dos elementos de forma individual, simplificando a solução para corpos com geometrias ou carregamentos complexos. Os elementos finitos são divididos em elementos lineares, elementos de superfície e elementos sólidos, podendo assumir diferentes formas a depender da geometria dos corpos discretizados.

Cada elemento possui um vetor $\{\mathrm{u}\}$ que contém todos os deslocamentos possíveis para seus nós. A cada um destes deslocamentos, dá-se o nome de grau de liberdade. Quanto maior for o número de graus de liberdade dos nós de um elemento, maior será sua matriz de rigidez [k], que associa o vetor das forças nodais $\{f\}$ ao vetor dos deslocamentos $\{u\}$. Na solução por elementos finitos, as matrizes de rigidez de cada elemento individual são montadas dentro de uma única matriz global que relaciona os deslocamentos do modelo com as forças aplicadas (eq. (41)).

$$
\{F\}=[K]\{U\}
$$

A solução da matriz de rigidez global exige a definição de condições de contorno, geralmente representadas por nós com graus de liberdade restritos nas extremidades do modelo numérico.

Com a solução da matriz de rigidez global, obtém-se os deslocamentos nodais do modelo, o que permite ao software calcular as tensões e deformação resultantes destes deslocamentos.

A definição das tensões, deformações e deslocamentos no interior dos elementos finitos é feita por meio de funções de forma. Estas funções são conjuntos de equações que definem os valores das propriedades no espaço entre os nós dos 
elementos finitos. As funções de forma são definidas para cada ponto de integração, representado por pares de coordenadas referenciados a um eixo local do elemento.

No software de elementos finitos PLAXIS, elementos triangulares utilizam dois eixos de coordenada locais ( $\xi$ e $\eta$ ), além de uma coordenada auxiliar $\zeta$.

A Figura 2-21 exemplifica a distribuição de nós e pontos de integração para diferentes tipos de elemento finito.

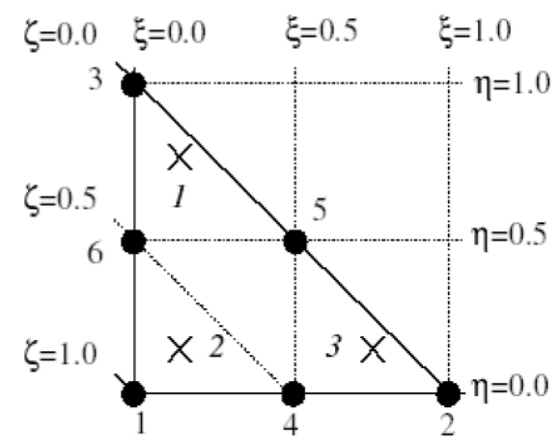

a) Elemento triangular de 6 nós

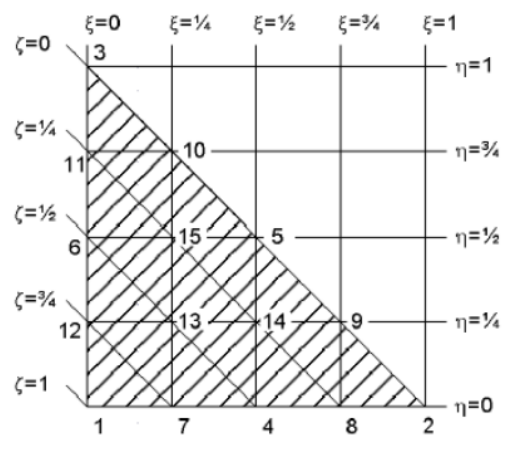

b) Elemento triangular de 15 nós

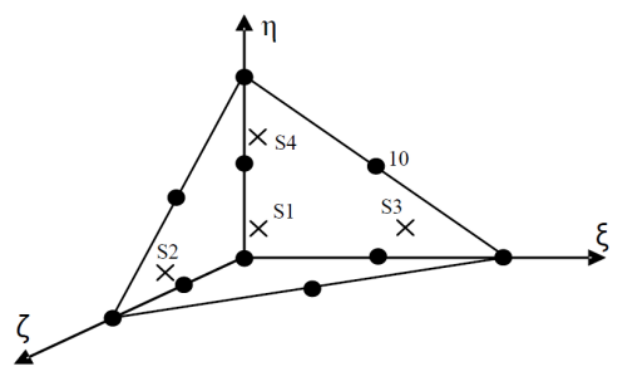

c) Elemento tetraédrico de 10 nós

Figura 2-21 - Posição dos nós e pontos de integração para diferentes tipos de elemento finito (Adaptado de PLAXIS, 2020)

A primeira etapa para construção de um modelo numérico pelo método dos elementos finitos é a assimilação do problema físico, o qual será objeto da modelagem. A segunda etapa, aqui chamada de pré-processamento, pode ser dividida em duas fases, onde a primeira consiste na reprodução da geometria do problema dentro do software de elementos finitos, na definição das leis constitutivas que regem o comportamento dos materiais, assim como dos carregamentos a serem aplicados e da sequência construtiva da simulação. A segunda fase do pré-processamento consiste na discretização do modelo numérico. Nesta fase, é definido o tipo de elemento finito mais adequado para representação 
do problema físico, a distribuição de densidade destes elementos dentro da malha e as condições de contorno do problema.

A terceira etapa é comandada pelo algoritmo do software de elementos finitos, que constrói a matriz de rigidez global do problema unindo as matrizes de rigidez individuais dos elementos finitos. A solução da matriz de rigidez global pode ser aproximada por meio de diferentes métodos. O Software PLAXIS, por exemplo, adota o Método de Resíduos Ponderados de Galerkin.

A Figura 2-22 sintetiza as etapas do processo de construção de um modelo numérico de elementos finitos para solução de problemas de engenharia.

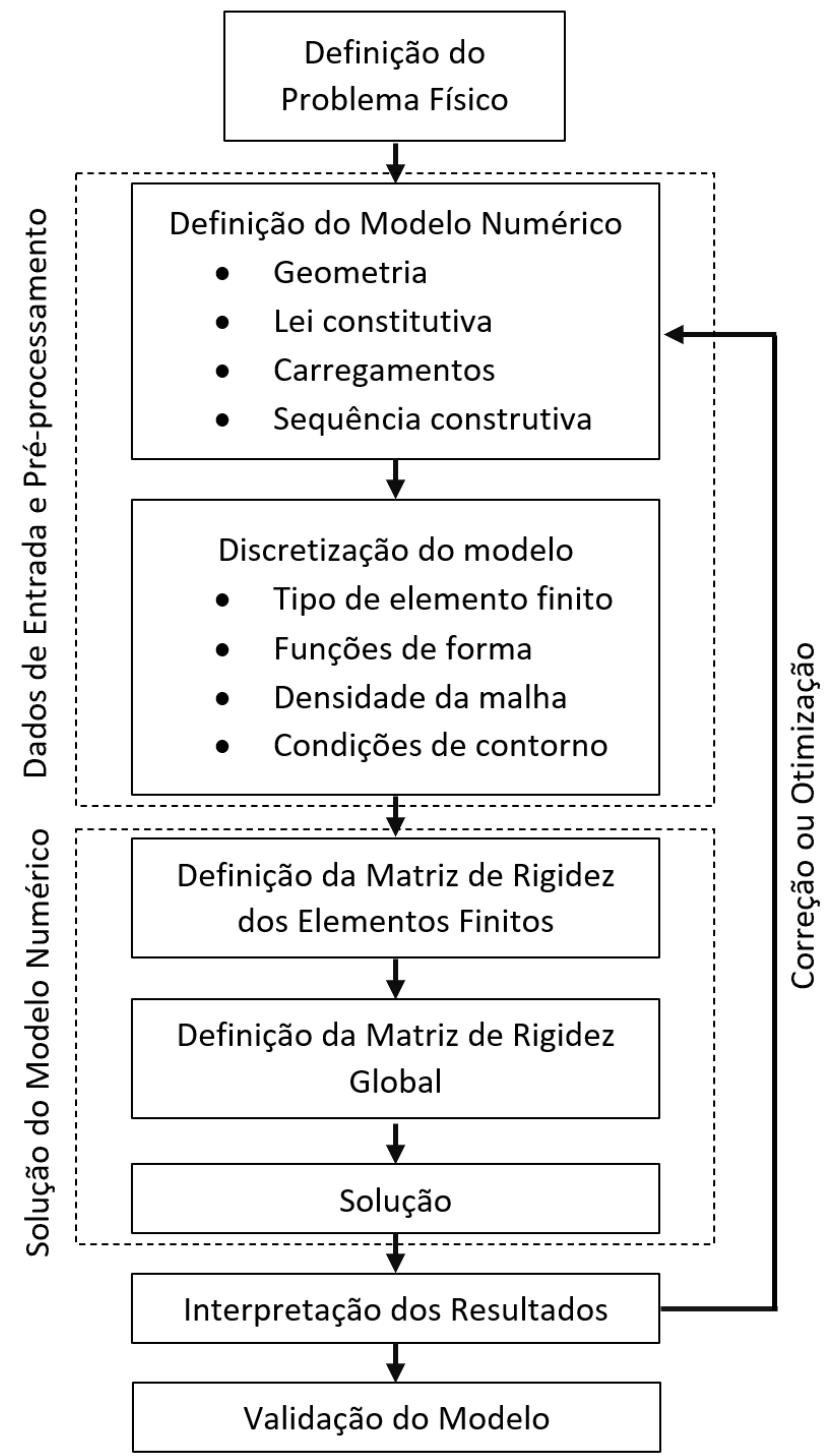

Figura 2-22 - Etapas de construção de um modelo elementos finitos

Como solos apresentam comportamento não linear, a solução do problema é realizada mediante uma série de etapas iterativas de cálculo, para as quais são 
verificadas as condições de equilíbrio. Durante cada etapa, o erro de equilíbrio global é reduzido sucessivamente, até convergir para o nível de carregamento desejado (PLAXIS, 2020). A Figura 2-23 ilustra a convergência de uma solução numérica para a solução exata do problema.

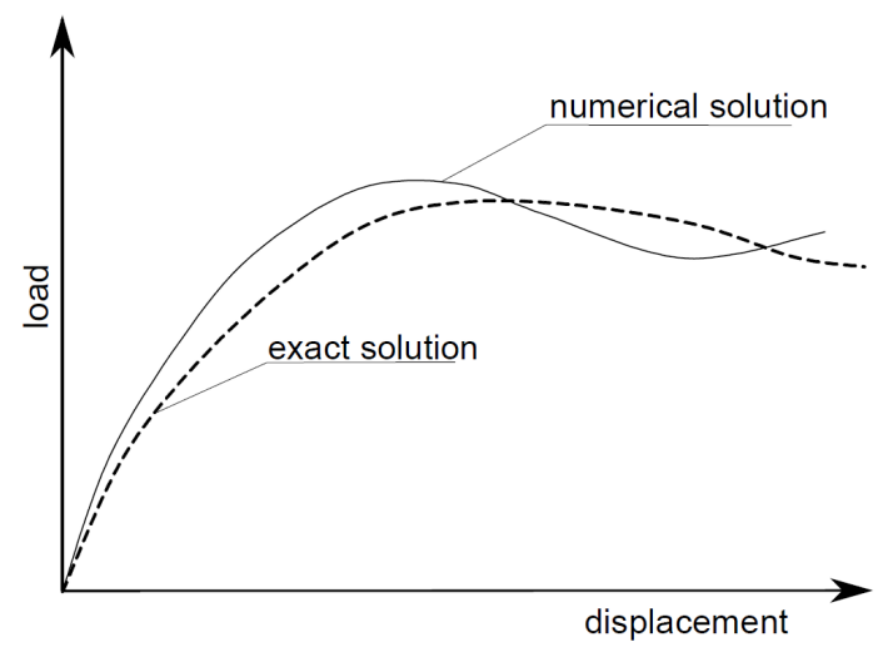

Figura 2-23 - Solução numérica versus solução exata (PLAXIS, 2020)

A aderência entre a solução exata do problema e a solução numérica é controlada pelo parâmetro conhecido como "tolerated error", ou erro tolerado. Para isto, dentro de cada etapa de cálculo, o software conduz uma série de iterações até que os erros de equilíbrio sejam inferiores ao erro tolerado estabelecido para a análise.

\subsection{3.}

\section{Modelos Constitutivos}

Solos são materiais porosos e particulados que podem apresentam diferentes comportamentos quando submetidos a variados estados de tensão. A resposta mecânica de solos submetidos a tensões é altamente dependente de fatores como: forma dos grãos, cementação, intemperismo, história de tensões e mineralogia.

Uma lei constitutiva pode ser definida como um conjunto de relações matemáticas entre componente de tensão e componentes de deformação de materiais.

Os modelos constitutivos de solos tipicamente descrevem a resposta mecânica do conjunto formado por grãos e pelos vazios existentes entre eles, quando submetido a forças atuantes nos contornos de elementos infinitesimais formados por esse conjunto (Carter, 2006). É importante ressaltar que os vazios 
podem conter água, ar ou uma combinação dos dois, o que afeta o comportamento mecânico do material.

A modelagem de solos pode ser feita mediante a adoção de um modelo tensão vs deformação capaz de representar de forma satisfatória o comportamento do material simulado. Os modelos constitutivos atuam como aproximações numéricas da real resposta mecânica do solo.

Romanel (2018) apresenta a comparação entre os principais mecanismos de tensão vs deformação simulados por modelos constitutivos de solos. A Figura 2-24a apresenta um resultado típico de ensaio triaxial em solo, enquanto a Figura 2-24b a Figura 2-24c a Figura 2-24d e a Figura 2-24e apresentam os diferentes tipos de comportamento simulados pelos modelos constitutivos.

(a)

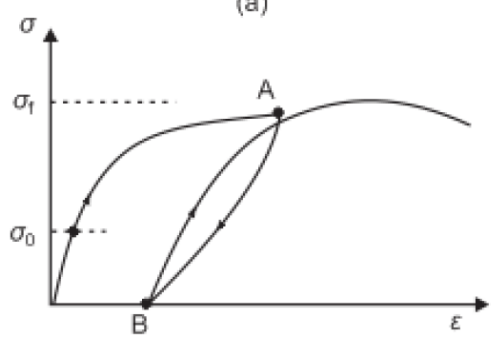

(b)

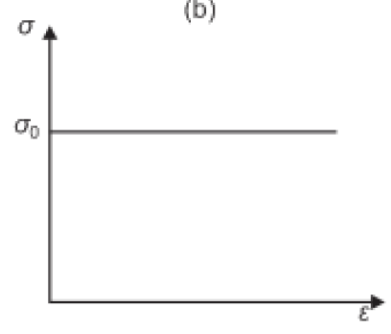

(d)

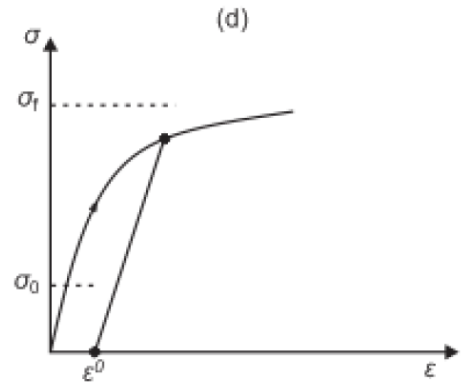

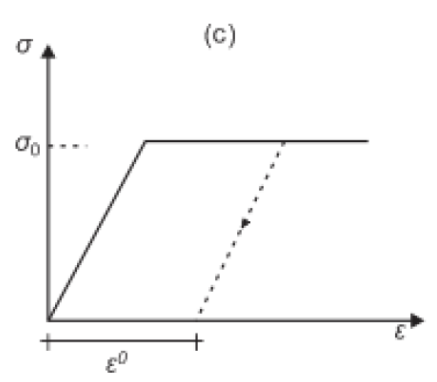

(e)

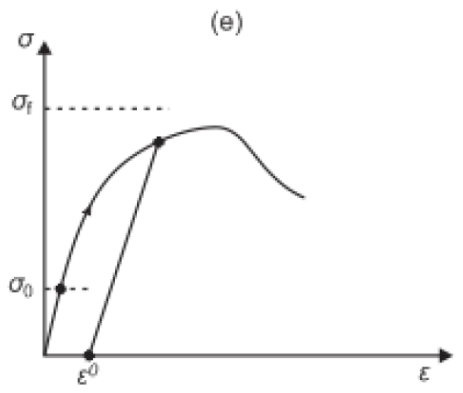

Figura 2-24 -Exemplos de curvas tensão vs deformação para o estado 1D de tensão: (a) típico resultado de ensaio de laboratório em solo; (b) material rígido perfeitamente plástico; (c) material elasto-perfeitamente plástico; (d) material plástico com endurecimento - hardening; (e) material plástico com amolecimento softening (Romanel, 2018) 
Modelos constitutivos relacionam acréscimos infinitesimais de tensão efetiva com acréscimos também infinitesimais de deformação, o que equivale matematicamente à seguinte equação:

$$
\dot{\underline{\sigma}}^{\prime}=\underline{\underline{M}}
$$

Onde $\mathrm{M}$ representa a matriz de rigidez do material simulado.

Além das relações constitutivas elásticas, um modelo constitutivo elastoplástico é composto por três pilares, a função de escoamento, a lei de fluxo e a lei de endurecimento ou amolecimento.

\section{Funcão de escoamento}

A teoria de plasticidade postula que as deformações plásticas ocorrem quando o estado de tensões satisfaz ao critério de escoamento do material.

A função de escoamento representa o limite entre a zona na qual o comportamento do material é puramente elástico, da zona do domínio plástico, e é expressa matematicamente com:

$$
F(\underline{\sigma})=0
$$

Onde F é a função escalar de escoamento, e $\underline{\sigma}$ representa o tensor das tensões do material. $\mathrm{O}$ solo se encontra no regime elástico quando $F(\underline{\sigma})<0$ atingindo o regime plástico quando $F(\underline{\sigma})=0$. O estado de tensões do material pode estar inserido dentro da superfície de escoamento ou sobre ela. Estados de tensão para os quais $F(\underline{\sigma})>0$ são impossíveis.

\section{Lei de fluxo e potencial plástico}

O desenvolvimento de deformações plásticas é regido pela lei de fluxo. A relação entre as deformações plásticas e as tensões é assumida como o produto da derivada da função $F$ em relação às tensões, com um multiplicador plástico representado pela letra $\lambda$ :

$$
\dot{\varepsilon}^{p}=\lambda \frac{\partial F}{\partial \sigma}
$$

O multiplicador $\lambda$ atua quando ocorre transição do regime elástico para o regime plástico, sendo nulo para deformações puramente elásticas e positivo quando há deformações plásticas. O multiplicador é um escalar que determina a 
magnitude da deformação plástica. O gradiente do potencial plástico, por sua vez, fornece a direção do fluxo.

A lei de fluxo é chamada associada, quando a direção dos vetores das deformações plásticas está associada à superfície de escoamento, isto é, ortogonal à superfície $F$. Quando não existe essa associação, a lei de fluxo é chamada de não associada.

No tradicional modelo de Mohr-Coulomb a lei de fluxo é não associada, desta forma adota-se uma função chamada potencial plástico (g), que forma uma superfície para a qual a deformação plástica incremental é ortogonal (Figura 2-25). Neste caso, a lei de fluxo é definida pela expressão abaixo, onde $\mathrm{g} \neq \mathrm{F}$.

$$
d \varepsilon^{p}=d \lambda \frac{\partial g}{\partial \sigma}
$$

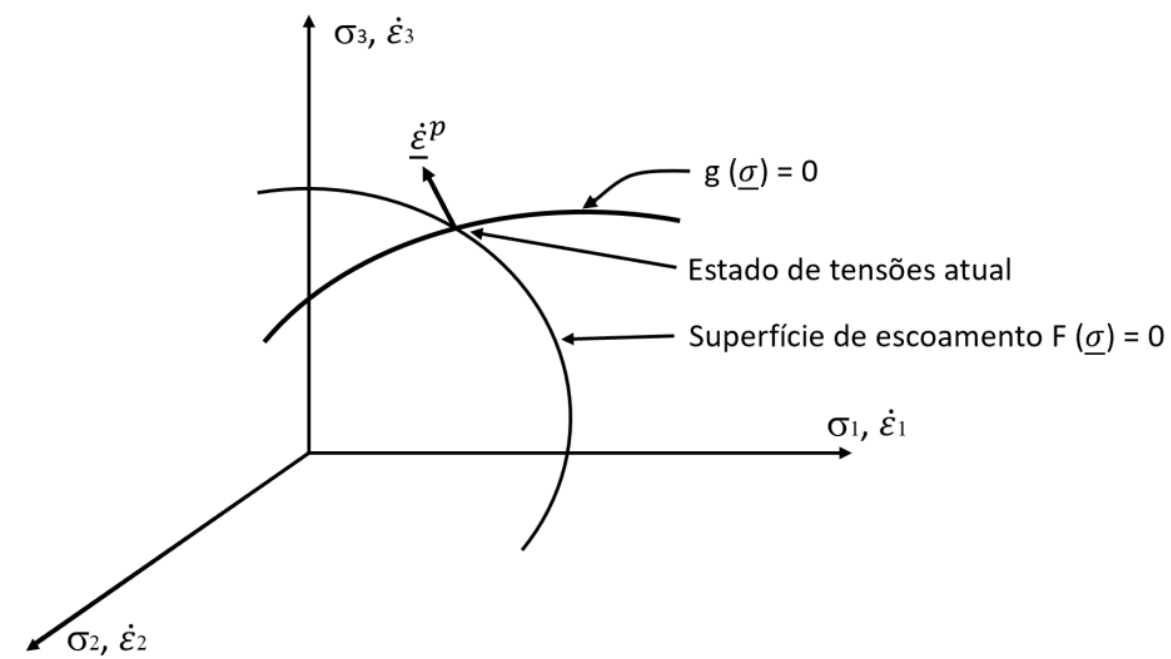

Figura 2-25 - Lei de fluxo não associada (adaptado de Naylor et al., 1981)

\section{Lei de endurecimento}

Para materiais com comportamento de endurecimento plástico, a função de escoamento não é fixa no espaço das tensões principais. Diferentemente dos materiais elásticos perfeitamente plásticos, estes materiais apresentam expansão da superfície de escoamento com as deformações plásticas.

O sentido físico do endurecimento reside na alteração da estrutura do material durante o fluxo plástico, que, consequentemente, provoca alteração de suas propriedades. Durante o endurecimento, o domínio elástico, inicialmente definido pela função de escoamento, se expande com as alterações estruturais induzidas pelo fluxo plástico. 
O endurecimento plástico pode ser dividido em dois tipos, onde o primeiro é função dos incrementos de deformação volumétrica "compression hardening", e o segundo é função dos incrementos de deformação plástica de desvio "shear hardening".

Em uma situação de solicitação multi-axial a função de escoamento deixa de depender apenas das tensões, sendo função também das deformações plásticas (Naylor et al., 1981). Portanto, a função de escoamento plástico pode ser expressa, genericamente, como:

$$
F\left(\underline{\sigma}, \varepsilon^{p}\right)=0 \text { ou } F(\underline{\sigma}, h)=0
$$

Onde $h$ representa uma função escalar das deformações plásticas, conhecida como parâmetro de endurecimento ou hardening parameter.

\subsubsection{Modelo Elástico Perfeitamente Plástico de Mohr- Coulomb}

O modelo elástico perfeitamente plástico de Mohr-Coulomb (Vermeer e Borst, 1984) envolve 5 parâmetros geotécnicos básicos:

- Módulo de Young, E;

- Coeficiente de Poisson, $v$;

- Coesão, $c^{\prime}$;

- Ângulo de atrito, $\phi$;

- Ângulo de dilatância, $\psi$.

A deformação sofrida por solos durante um carregamento triaxial pode ser dividida em uma componente elástica e uma componente plástica.

$$
\underline{\varepsilon}^{=} \underline{\varepsilon}^{e}+\underline{\varepsilon}^{p}
$$

Onde o expoente " $e$ " denota deformações elásticas e o expoente " $p$ " denota deformações plásticas.

Para a componente referente às deformações elásticas, a relação entre incrementos infinitesimais de deformação, ou taxas de deformação, e incrementos infinitesimais de tensões efetivas, é dada pela matriz de rigidez elástica da Lei de Hooke $\underline{\underline{D^{e}}}$. 


$$
\left[\begin{array}{c}
\dot{\sigma}_{x x}^{\prime} \\
\dot{\sigma}_{y y}^{\prime} \\
\dot{\sigma}_{z z}^{\prime} \\
\dot{\sigma}_{x y}^{\prime} \\
\dot{\sigma}_{y z}^{\prime} \\
\dot{\sigma}_{z x}^{\prime}
\end{array}\right]=\frac{E^{\prime}}{\left(1-2 v^{\prime}\right)\left(1+v^{\prime}\right)}\left[\begin{array}{cccccc}
1-v^{\prime} & v^{\prime} & v^{\prime} & 0 & 0 & 0 \\
v^{\prime} & 1-v^{\prime} & v^{\prime} & 0 & 0 & 0 \\
v^{\prime} & v^{\prime} & 1-v^{\prime} & 0 & 0 & 0 \\
0 & 0 & 0 & \frac{1}{2}-v^{\prime} & 0 & 0 \\
0 & 0 & 0 & 0 & \frac{1}{2}-v^{\prime} & 0 \\
0 & 0 & 0 & 0 & 0 & \frac{1}{2}-v^{\prime}
\end{array}\right]\left[\begin{array}{c}
\dot{\varepsilon}_{x x}^{\prime} \\
\dot{\varepsilon}_{y y}^{\prime} \\
\dot{\varepsilon}_{z z}^{\prime} \\
\dot{\gamma}_{x y}^{\prime} \\
\dot{\gamma}_{y z}^{\prime} \\
\dot{\gamma}_{z x}^{\prime}
\end{array}\right]
$$

Substituindo a eq. (47) na Lei de Hooke, obtém-se a seguinte expressão:

$$
\underline{\dot{\sigma}}^{\prime}=\underline{\dot{\varepsilon}}^{e} \underline{\underline{D}}=\underline{\underline{D}}\left(\underline{\dot{\varepsilon}}-\underline{\dot{\varepsilon}}^{p}\right)
$$

Esta expressão é incompleta, devendo ser complementada por uma equação que defina a taxa de deformação plástica do material.

A lei de fluxo do modelo de Morh-Coulomb é não associada, logo, é definida em torno da função de potencial plástico.

$$
\underline{\dot{\varepsilon}}^{p}=\lambda \frac{\partial g}{\partial \underline{\sigma}^{\prime}}
$$

Quando o multiplicador plástico $\lambda$ é nulo, isto é, quando o regime é elástico, a relação constitutiva é definida pela matriz de rigidez da Lei de Hook, já quando o multiplicador plástico assume valores positivos, o material sofre deformações plásticas. Esse comportamento é sumarizado pela eq. (51) (Vermeer e Borst, 1984).

$$
\underline{\dot{\sigma}}^{\prime}=\left(\underline{\underline{D^{e}}}-\frac{\alpha}{d} \underline{\underline{D^{e}}} \frac{\partial g}{\partial \underline{\sigma}^{\prime}} \frac{\partial f^{T}}{\partial \underline{\sigma}^{\prime}} \underline{\underline{D^{e}}}\right) \dot{\varepsilon} \text { onde: } d=\frac{\partial f^{T}}{\partial \underline{\sigma}^{\prime}} \underline{\underline{D^{e}}} \frac{\partial g}{\partial \underline{\sigma}^{\prime}}
$$

O parâmetro $\alpha$ é considerado nulo quando o comportamento do material é puramente elástico e 1 quando o comportamento é plástico, o que confere a ele uma propriedade de gatilho, alterando a relação constitutiva, quando há transição do regime elástico para o regime plástico.

A eq. (51) é restrita para superfícies de escoamento curvas e não se aplica para superfícies com diferentes contornos, como a do modelo de Mohr-Coulomb. Para sobrepor essa restrição, a teoria da plasticidade foi estendida por Koiter et al. (1960) para admitir vértices de fluxo envolvendo mais de uma função de potencial plástico (PLAXIS, 2020).

$$
\underline{\dot{\varepsilon}}^{p}=\lambda_{1} \frac{\partial g_{1}}{\partial \underline{\sigma}^{\prime}}+\lambda_{1} \frac{\partial g_{2}}{\partial \underline{\sigma}^{\prime}}+\cdots
$$


Um modelo elástico perfeitamente plástico possui uma superfície de escoamento fixa, definida pelos parâmetros do modelo numérico. Qualquer ponto cuja trajetória parta de um estado de tensão dentro da superfície de escoamento (F < 0) apresentará comportamento elástico com deformações reversíveis até que atinja a superfície de escoamento $(\mathrm{F}=0)$.

A superfície de escoamento do modelo de Mohr-Coulomb é delimitada por 6 (seis) funções de escoamento formuladas em termos de tensões principais efetivas. Estas funções separam o domínio elástico da plastificação, para estados de compressão e extensão triaxial.

$$
\begin{aligned}
& f_{1 a}=\frac{1}{2}\left(\sigma_{2}^{\prime}-\sigma_{3}^{\prime}\right)+\frac{1}{2}\left(\sigma_{2}^{\prime}+\sigma_{3}^{\prime}\right) \operatorname{sen} \varphi-c \cos \varphi \leq 0 \\
& f_{1 b}=\frac{1}{2}\left(\sigma_{3}^{\prime}-\sigma_{2}^{\prime}\right)+\frac{1}{2}\left(\sigma_{3}^{\prime}+\sigma_{2}^{\prime}\right) \operatorname{sen} \varphi-c \cos \varphi \leq 0 \\
& f_{2 a}=\frac{1}{2}\left(\sigma_{3}^{\prime}-\sigma_{1}^{\prime}\right)+\frac{1}{2}\left(\sigma_{3}^{\prime}+\sigma_{1}^{\prime}\right) \operatorname{sen} \varphi-c \cos \varphi \leq 0 \\
& f_{2 b}=\frac{1}{2}\left(\sigma_{1}^{\prime}-\sigma_{3}^{\prime}\right)+\frac{1}{2}\left(\sigma_{1}^{\prime}+\sigma_{3}^{\prime}\right) \operatorname{sen} \varphi-c \cos \varphi \leq 0 \\
& f_{3 a}=\frac{1}{2}\left(\sigma_{1}^{\prime}-\sigma_{2}^{\prime}\right)+\frac{1}{2}\left(\sigma_{1}^{\prime}+\sigma_{2}^{\prime}\right) \operatorname{sen} \varphi-c \cos \varphi \leq 0 \\
& f_{3 b}=\frac{1}{2}\left(\sigma_{2}^{\prime}-\sigma_{1}^{\prime}\right)+\frac{1}{2}\left(\sigma_{2}^{\prime}+\sigma_{1}^{\prime}\right) \operatorname{sen} \varphi-c \cos \varphi \leq 0
\end{aligned}
$$

A combinação das 6 (seis) funções de escoamento no espaço das tensões principais forma um cone aberto, com face em formato hexagonal, quando observado no plano octaédrico, ou plano pi (Figura 2-26).

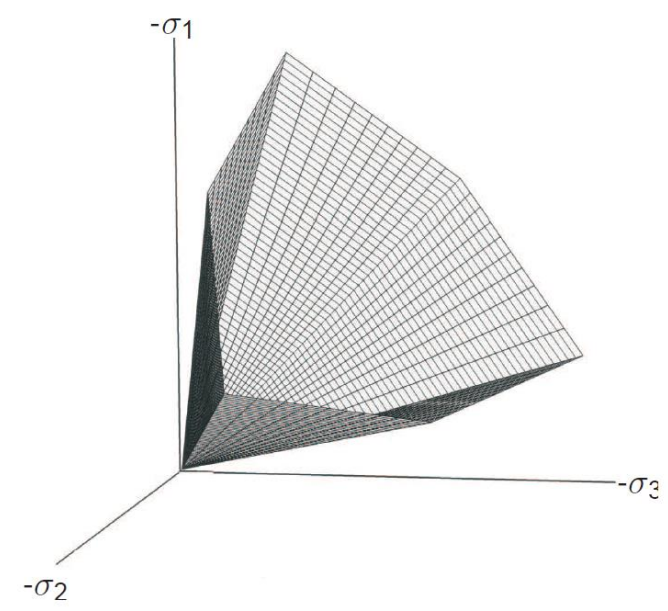

Figura 2-26 - Superfície de escoamento de Mohr-Coulomb no plano das tensões principais para c' $=0$ (PLAXIS, 2020) 
Para cada função de escoamento plástico, o modelo contém uma função de potencial plástico definida a partir do ângulo de dilatância $\psi$.

$$
\begin{aligned}
& g_{1 a}=\frac{1}{2}\left(\sigma_{2}^{\prime}-\sigma_{3}^{\prime}\right)+\frac{1}{2}\left(\sigma_{2}^{\prime}+\sigma_{3}^{\prime}\right) \operatorname{sen} \psi \\
& g_{1 b}=\frac{1}{2}\left(\sigma_{3}^{\prime}-\sigma_{2}^{\prime}\right)+\frac{1}{2}\left(\sigma_{3}^{\prime}+\sigma_{2}^{\prime}\right) \operatorname{sen} \psi \\
& g_{2 a}=\frac{1}{2}\left(\sigma_{3}^{\prime}-\sigma_{1}^{\prime}\right)+\frac{1}{2}\left(\sigma_{3}^{\prime}+\sigma_{1}^{\prime}\right) \operatorname{sen} \psi \\
& g_{2 b}=\frac{1}{2}\left(\sigma_{1}^{\prime}-\sigma_{3}^{\prime}\right)+\frac{1}{2}\left(\sigma_{1}^{\prime}+\sigma_{3}^{\prime}\right) \operatorname{sen} \psi \\
& g_{3 a}=\frac{1}{2}\left(\sigma_{1}^{\prime}-\sigma_{2}^{\prime}\right)+\frac{1}{2}\left(\sigma_{1}^{\prime}+\sigma_{2}^{\prime}\right) \operatorname{sen} \psi \\
& g_{3 b}=\frac{1}{2}\left(\sigma_{2}^{\prime}-\sigma_{1}^{\prime}\right)+\frac{1}{2}\left(\sigma_{2}^{\prime}+\sigma_{1}^{\prime}\right) \operatorname{sen} \psi
\end{aligned}
$$

A Tabela 2-5 lista os 5 (cinco) parâmetro de entrada do modelo constitutivo de Mohr-Coulomb.

Tabela 2-5 - Parâmetros do modelo elástico perfeitamente plástico de Mohr-Coulomb

\begin{tabular}{cl}
\hline Propriedade & \multicolumn{1}{c}{ Descrição } \\
\hline$v_{u r}$ & $\begin{array}{l}\text { Coeficiente de Poisson no descarregamento e } \\
\text { recarregamento }\end{array}$ \\
\hline$\phi$ & Ângulo de atrito interno efetivo \\
\hline$\psi$ & Ângulo de dilatância \\
\hline$c$ & Coesão efetiva \\
\hline$E$ & Módulo de Young \\
\hline$\sigma_{t}$ & Resistência à tração \\
\hline
\end{tabular}

\subsubsection{Modelo Hardening Soil}

O modelo HS difere do tradicional modelo elástico perfeitamente plástico com critério de ruptura de Mohr-Coulomb, pois distingue a trajetória de 
carregamento primário da trajetória de descarregamento. A superfície de escoamento para enrijecimento plástico não é fixa no espaço das tensões principais, de forma que se expande devido ao aumento das deformações plásticas. O modelo distingue também o enrijecimento por compressão, do enrijecimento por cisalhamento.

Originalmente formulado por Schanz (1998), o modelo HS parte da premissa de que solos submetidos a carregamentos desviadores primários apresentam rigidez decrescente à medida que as deformações plásticas irreversíveis ocorrem. Kondner (1963) aproximou a curva de tensão desviadora por deformação axial de ensaios triaxiais drenados por meio de uma função hiperbólica, obtendo bons resultados. Kondner e Zelasko (1963) formularam matematicamente a relação tensão vs deformação para carregamentos triaxiais drenados como:

$$
\begin{gathered}
\varepsilon_{1}=\varepsilon_{50} \frac{q}{q_{a}-q} \operatorname{com} q_{a}=\frac{2 \operatorname{sen} \varphi}{1-\operatorname{sen} \varphi}\left(\sigma_{3}+c \cot \varphi\right) \\
e \varepsilon_{50}=\frac{q_{50}}{E_{50}}=\frac{q_{a}}{2 E_{50}}
\end{gathered}
$$

A relação foi aprimorada por Duncan e Chang (1970), que introduziram a variável desviadora $q_{f}$ à formulação de Kondner e Zelasko (1963). A Figura 2-27 apresenta o efeito da variável $q_{f}$ na curva de tensão deformação originalmente formulada por Kondner e Zelasko.

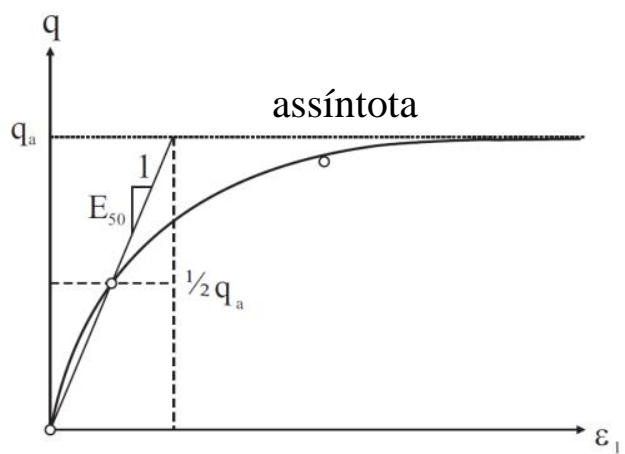

(a)

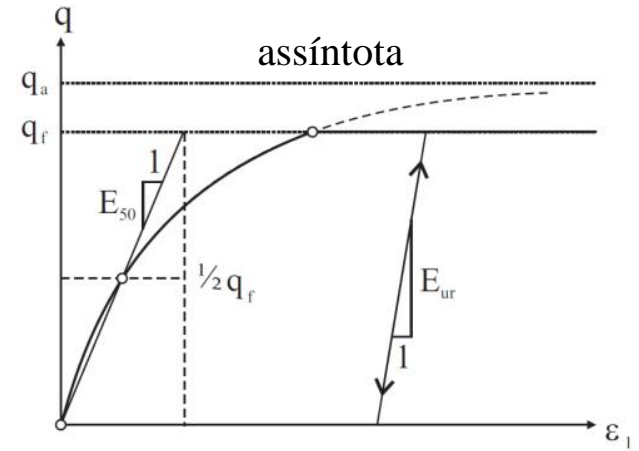

(b)

Figura 2-27 - Relação hiperbólica de tensão x deformação formulada por

Kondner e Zelasko (1963) (a), e sua modificação conforme Duncan e Chang (1970) (b) (Adaptado de Benz, 2007) 
Schanz; Vermeer e Bonnier (1999) reformularam o modelo hiperbólico hypoelástico de Duncan e Chang sob a luz da teoria da plasticidade, tornando-o um modelo elasto-plástico com a seguinte função de escoamento:

$$
f^{s}=\frac{q_{a}}{E_{50}} * \frac{q}{q_{a}-q}-\frac{2 q}{E_{u r}}-\gamma^{p}
$$

Onde o parâmetro $\gamma^{p}$ atua como um parâmetro de endurecimento, referenciando as deformações plásticas acumuladas devido aos carregamentos desviadores. Este parâmetro é definido como:

$$
\gamma^{p}=\varepsilon_{1}^{p}-\varepsilon_{2}^{p}-\varepsilon_{3}^{p}=2 \varepsilon_{1}^{p}-\varepsilon_{v}^{p} \approx 2 \varepsilon_{1}^{p}
$$

$\mathrm{Na}$ realidade, as deformações volumétricas plásticas $\varepsilon_{v}^{p}$ nunca serão precisamente iguais a zero, entretanto, para solos rígidos a variação tende a ser pequena quando comparada com a deformação axial, de forma que a aproximação da eq. (67) será razoavelmente precisa (Schanz; Vermeer e Bonnier 1999).

Conforme a plastificação aumenta o solo passa por diversas etapas de endurecimento plástico desviatório até a atingir a envoltória de resistência definida pelo critério de ruptura. Este endurecimento plástico desviatório pode ser observado no plano q-p', por zonas separadas por curvas de $\gamma^{p}$ constante, conforme apresentado na Figura 2-28.

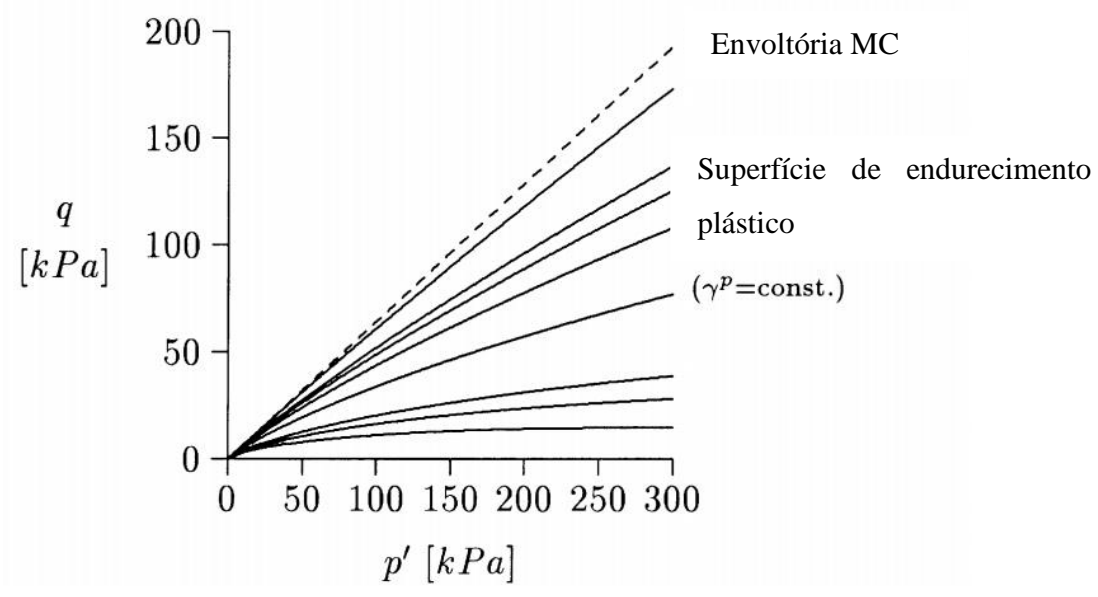

Figura 2-28 - Sucessivas envoltórias de escoamento para vários valores do parâmetro de plasticidade $\gamma^{\mathrm{p}}$ (Schanz; Vermeer e Bonnier 1999)

Quando aplicada no espaço das tensões principais, a função de escoamento definida por Schanz; Vermeer e Bonnier (1999) e apresentada na eq. (66) toma a forma apresentada pela eq. (68) e pela eq. (69). 


$$
\begin{aligned}
& f_{12}=\frac{q_{a}}{E_{50}} * \frac{\left(\sigma_{1}-\sigma_{2}\right)}{q_{a}-\left(\sigma_{1}-\sigma_{2}\right)}-\frac{2\left(\sigma_{1}-\sigma_{2}\right)}{E_{u r}}-\gamma^{p} \\
& f_{13}=\frac{q_{a}}{E_{50}} * \frac{\left(\sigma_{1}-\sigma_{3}\right)}{q_{a}-\left(\sigma_{1}-\sigma_{3}\right)}-\frac{2\left(\sigma_{1}-\sigma_{3}\right)}{E_{u r}}-\gamma^{p}
\end{aligned}
$$

A lei de fluxo do modelo HS relaciona as taxas de deformação plástica por meio da relação linear apresentada na eq. (70).

$$
\dot{\varepsilon}_{v}^{p}=\operatorname{sen} \psi_{m} \dot{\gamma}^{p}
$$

Onde $\psi_{m}$ é o ângulo de dilatância mobilizado pelas tensões de desvio durante o carregamento primário, calculado pela eq. (72), derivada da combinação das equações da teoria da dilatância de Rowe (1962), com a definição do ângulo de dilatância apresentada na eq. (71), de Schanz; Vermeer e Bonnier, (1999):

$$
\begin{gathered}
\operatorname{sen} \psi=\frac{\dot{\varepsilon}_{v} / \dot{\varepsilon}_{1}}{2-\dot{\varepsilon}_{v} / \dot{\varepsilon}_{1}} \\
\operatorname{sen} \psi_{m}=\frac{\operatorname{sen} \varphi_{m}-\operatorname{sen} \varphi_{c v}}{1-\operatorname{sen} \varphi_{m} * \operatorname{sen} \varphi_{c v}}
\end{gathered}
$$

Onde $\phi_{m}$ é o ângulo de atrito mobilizado e $\phi_{c v}$ o ângulo de atrito do solo no estado crítico.

No modelo HS o ângulo de atrito mobilizado é calculado pela relação:

$$
\operatorname{sen} \varphi_{m}=\frac{\sigma_{1}-\sigma_{3}}{\sigma_{1}+\sigma_{3}-2 c \cot \varphi_{p}} \dot{\varepsilon}_{v}^{p}=\operatorname{sen} \psi_{m} \dot{\gamma}^{p}
$$

De acordo com a teoria da dilatância de Rowe (1962), materiais sofrem contração quando $\phi_{m}<\phi_{c v}$ e sofrem dilatância quando $\phi_{m}>\phi_{c v}$. Na ruptura, quando o ângulo de atrito mobilizado se iguala ao ângulo de atrito de ruptura, obtém-se a seguinte relação.

$$
\operatorname{sen} \psi_{c v}=\frac{\operatorname{sen} \varphi_{p}-\operatorname{sen} \psi_{p}}{1-\operatorname{sen} \varphi_{p} * \operatorname{sen} \psi_{p}}
$$

Logo, o ângulo de atrito no estado crítico pode ser calculado por intermédio dos ângulos de atrito e dilatância na ruptura $\phi_{m}$ e $\psi_{m}$ (Schanz; Vermeer e Bonnier 1999). 
A definição da lei de fluxo em termos do ângulo de dilatância (eq. (70)) é equivalente à definição das funções de potencial plástico $g_{12}^{S}$ e $g_{13}^{S}$ :

$$
\begin{aligned}
& g_{12}^{s}=\frac{\left(\sigma_{1}-\sigma_{2}\right)}{2}-\frac{\sigma_{1}+\sigma_{2}}{2} \operatorname{sen} \psi_{m} \\
& g_{13}^{s}=\frac{\left(\sigma_{1}-\sigma_{3}\right)}{2}-\frac{\sigma_{1}+\sigma_{3}}{2} \operatorname{sen} \psi_{m}
\end{aligned}
$$

Uma vez que a lei de fluxo é não associada, usando a regra de Koiter (Koiter, 1960), que estende a teoria da plasticidade para escoamento dependente de duas ou mais superfícies de potencial plástico, obtém-se:

$$
\begin{aligned}
\underline{\dot{\varepsilon}}^{p}=\lambda_{12} \frac{\partial g_{s}, 12}{\partial \sigma} & +\lambda_{13} \frac{\partial g_{s}, 13}{\partial \sigma} \\
& =\lambda_{12}\left[\begin{array}{c}
1 / 2-1 / 2 \sin \psi \\
-1 / 2-1 / 2 \sin \psi \\
0
\end{array}\right]+\lambda_{13}\left[\begin{array}{c}
1 / 2-1 / 2 \sin \psi \\
0 \\
-1 / 2-1 / 2 \sin \psi
\end{array}\right]
\end{aligned}
$$

O cálculo das taxas de deformação plástica pela equação acima equivale à definição da eq. (70).

A função que define a superfície de escoamento do modelo HS forma um cone no espaço das tensões principais, cujo aspecto considera as deformações plásticas desviatórias. Para as deformações plásticas volumétricas, o modelo define uma segunda superfície de escoamento para fechar a região elastica na direção do eixo hidrostático. Esta superfície de fechamento é conhecida como Cap.

De forma análoga ao módulo secante $E_{50}$, que controla a superfície de escoamento desviatória, a superfície de fechamento depende do módulo oedométrico, $E_{\text {oed }}$, sendo definida pela eq. (78):

$$
f^{c}=\frac{\tilde{q}^{2}}{\alpha^{2}}-p^{2}-p_{p}^{2}
$$

Onde $\alpha$ é uma constante que controla a inclinação da superfície de fechamento no plano $p-q$, e $p_{p}$ é a pressão de pré-adensamento isotrópico.

O modelo faz uso de uma tensão de desvio modificada, $\tilde{q}$, definida pela eq. (78), para combinar as superfícies de escoamento por cisalhamento e por compressão $f_{s}$ e $f_{c}$, no espaço das tensões principais

$$
\tilde{q}=\sigma_{1}^{\prime}+(\delta-1) \sigma_{2}^{\prime}-\delta \sigma_{3}^{\prime}
$$

Para: 
Compressão triaxial: $\tilde{q}=\sigma_{1}^{\prime}-\sigma_{3}^{\prime}$

Extensão triaxial: $\tilde{q}=\delta\left(\sigma_{1}^{\prime}-\sigma_{3}^{\prime}\right) \operatorname{com} \delta=\frac{\left(3+\operatorname{sen} \varphi^{\prime}\right)}{\left(3-\operatorname{sen} \varphi^{\prime}\right)}$

A Figura 2-29 apresenta a superfície resultante da combinação da função de escoamento por deformação desviatória com a função de escoamento por compressão isotrópica.

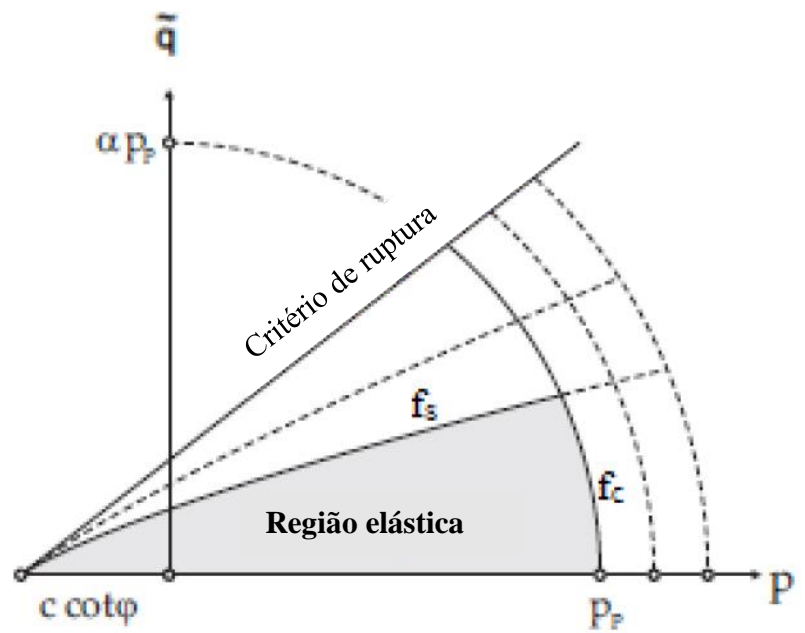

Figura 2-29 - Superfície de escoamento por compressão e cisalhamento (Benz, 2007)

A Figura 2-30 apresenta a superfície de escoamento do modelo HS no espaço das tensões principais. 


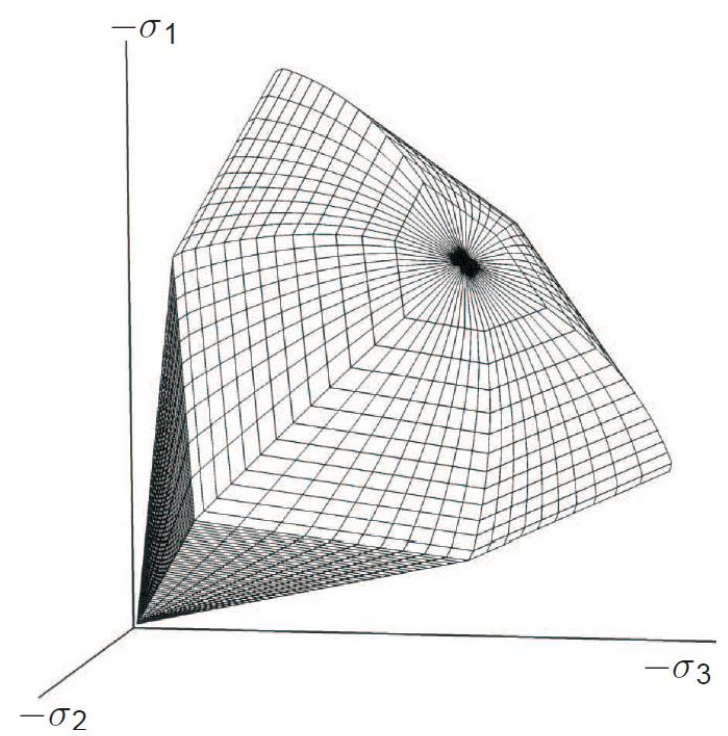

Figura 2-30 - Representação da superfície de escoamento completa do modelo HS no espaço das tensões principais, para um solo não coesivo (PLAXIS. 2020)

No modelo HS os módulos de deformabilidade $E_{50}, E_{o e d}$ e $E_{u r}$ variam em função da tensão confinante de referência, de forma que à médida que o confinamento aumenta, o solo torna-se mais rígido. A variação da rigidez é regida pelas seguintes funções:

$$
\begin{aligned}
& E_{50}=E_{50}^{r e f}\left(\frac{c \cos \varphi-\sigma_{3}^{\prime} \operatorname{sen} \varphi}{c \cos \varphi+p^{r e f} \operatorname{sen} \varphi}\right)^{m} \\
& E_{\text {ur }}=E_{\text {ur }}^{r e f}\left(\frac{c \cos \varphi-\sigma_{3}^{\prime} \operatorname{sen} \varphi}{c \cos \varphi+p^{r e f} \operatorname{sen} \varphi}\right)^{m} \\
& E_{\text {oed }}=E_{\text {oed }}^{r e f}\left(\frac{c \cos \varphi-\frac{\sigma_{3}^{\prime}}{K_{0}^{n c}} \operatorname{sen} \varphi}{c \cos \varphi+p^{r e f} \operatorname{sen} \varphi}\right)^{m}
\end{aligned}
$$

Onde o parâmetro $m$ é o expoente que define grau de dependência da rigidez com o confinamento, $p^{r e f}$ a tensão média de referência, e $K_{0}^{n c}$ o coeficiente de empuxo no repouso para a condição normalmente adensada. Janbu (1963) reporta valores do expoente $m$ próximos de 0,5 em seus estudos nas areias e siltes noruegueses, por outro lado, um valor de 1,0 simula o comportamento das curvas de compressão logarítmica típicas de argilas moles. A Figura 2-31 demonstra o 
efeito das variáveis das equações de variação da rigidez do modelo HS sobre o módulo de deformabilidade $E_{50}$.
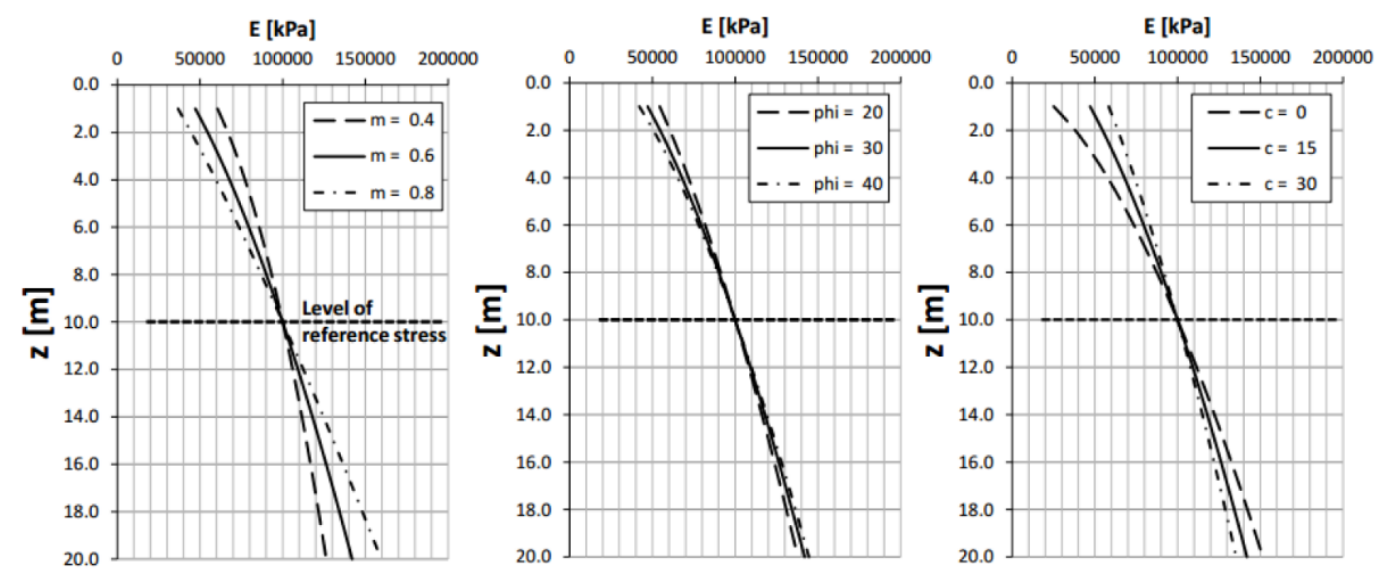

Figura 2-31 - Variação do módulo $E_{50}$ com os parâmetros $m, \phi{ }^{\prime}$ e $c^{\prime}$

(Obrzud, 2016)

A Figura 2-32 sintetiza as principais zonas de plastificação do modelo HS.

Em cenários de carregamento assimétrico, quando as deformações plásticas desviadoras se iniciam, o material sai da zona elástica e entre na zona de plastificação desviadora. À medida que as deformações plásticas desviadoras aumentam, o material se aproxima da envoltória de resistência, sofrendo ruptura ao atingi-la (1). No cenário de adensamento hidrostático, a envoltória de fechamento se expande, provocando o endurecimento plástico do material (2). O modelo HS ainda admite a ocorrência de carregamentos que provocam plastificação desviadora e volumétrica simultaneamente (3). 


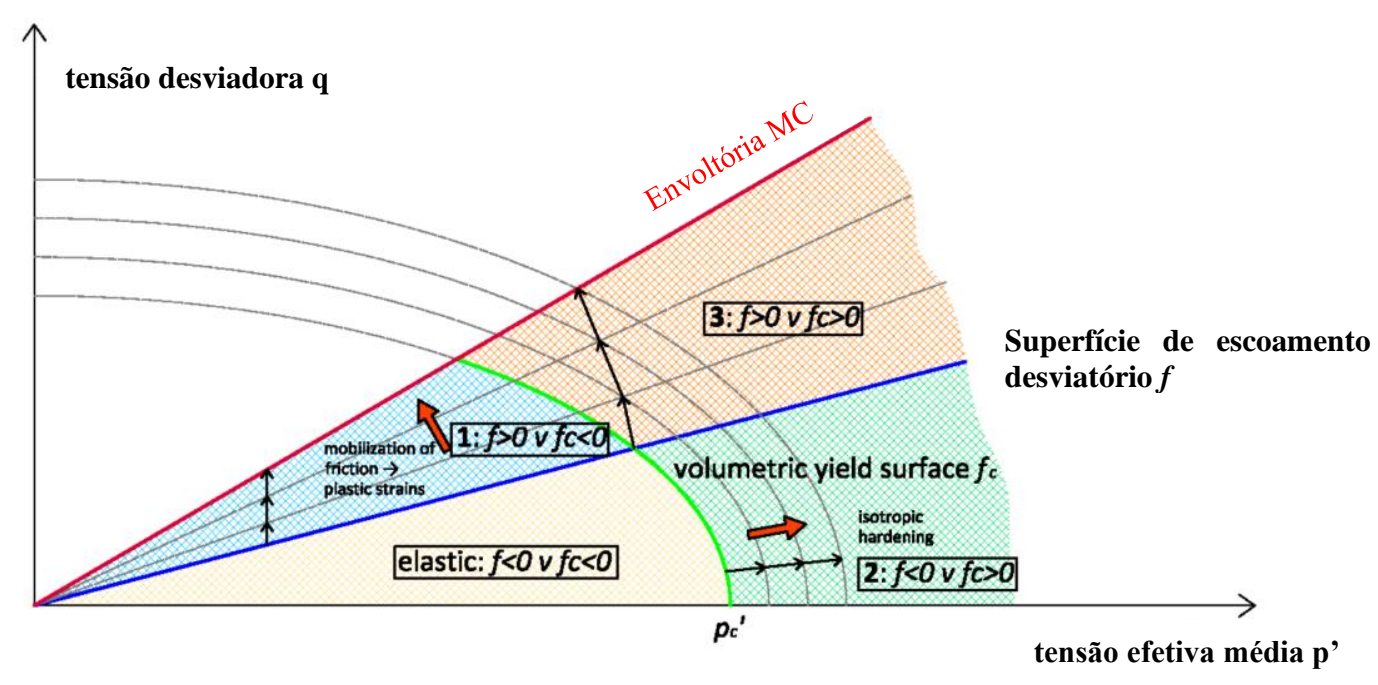

Figura 2-32 - Representação pelo modelo HS do comportamento de solos ativação das superfícies de escoamento por carregamentos desviadores $\boldsymbol{f} \boldsymbol{s}$ e volumétricos $\boldsymbol{f} \boldsymbol{c}$ (Zelger, 2012)

O módulo $E_{u r}$ representa um parâmetro puramente elástico que rege as deformações do material em cenários de descarregamento e recarregamento. A eq. (83) apresenta a relação do parâmetro $E_{u r}$ com as deformações elásticas principais $\varepsilon_{1}, \varepsilon_{2}$ e $\varepsilon_{3}$.

$$
-\varepsilon_{1}^{e}=\frac{q}{E_{u r}} \quad-\varepsilon_{2}^{e}=-\varepsilon_{3}^{e}=v_{u r} \frac{q}{E_{u r}}
$$

Em termos de resistência o modelo segue o conhecido critério de MohrCoulomb (Figura 2-33), no qual a ruptura pode ocorrer por compressão, extensão ou cisalhamento puro.

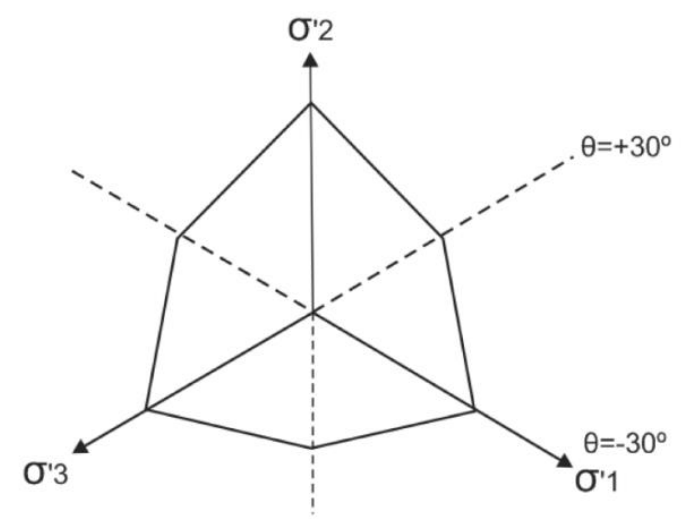

Figura 2-33 -Seção transversal da superfície de escoamento do critério de Mohr Coulomb no plano octaédrico 
O ângulo de Lode indica o tipo de carregamento (compressão, extensão ou cisalhamento) e é calculado pela expressão:

$$
\begin{gathered}
\tan \theta=\frac{2 \sigma_{2}-\sigma_{1}-\sigma_{3}}{\sqrt{3}\left(\sigma_{1}-\sigma_{3}\right)}=\frac{1}{\sqrt{3}}\left\lfloor 2 * \frac{\sigma_{2}-\sigma_{3}}{\sigma_{1}-\sigma_{3}}-1\right\rfloor \\
\text { para }-30^{\circ} \leq \theta \leq+30^{\circ}
\end{gathered}
$$

Onde:

- Compressão triaxial: $\theta=-30^{\circ}$;

- Extensão triaxial: $\theta=30^{\circ}$;

Como parâmetros de resistêcia para carregamentos drenados e não drenados, o modelo adota, o ângulo de atrito efetivo $\phi^{\prime}$ e a coesão efetiva $c$ ', conforme indicado na Figura 2-34.

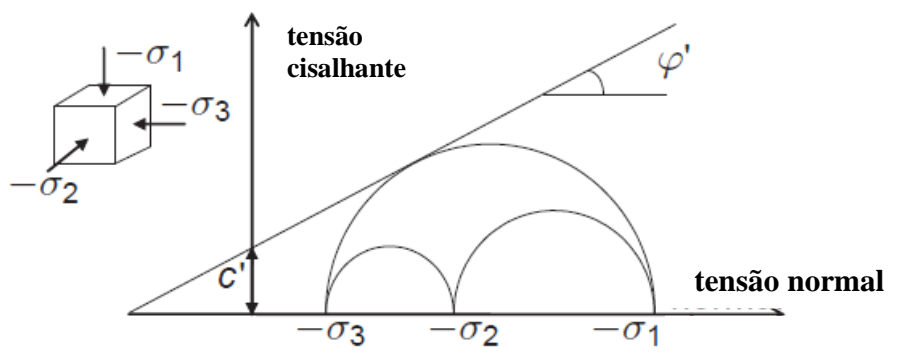

Figura 2-34 - Lúnula de tensões para carregamentos do tipo drenado e não drenado (A)

Em suma, as principais características do modelo HS são:

1. Deformação plástica devido à compressão primária;

2. Relação hiperbólica entre tensão e deformação;

3. Rigidez dependente do estado de tensões;

4. Endurecimento isotrópico para as superfícies de escoamento $f_{c}$ e $f_{s}$;

5. Descarregamento / recarregamento elástico.

A Tabela 2-6 apresenta os parâmetros de entrada do modelo HS. 
Tabela 2-6 - Parâmetros de entrada do modelo constitutivo Hardening Soil

\begin{tabular}{cl}
\hline Propriedade & \\
\hline$v_{u r}$ & $\begin{array}{l}\text { Coeficiente de Poisson no descarregamento e } \\
\text { recarregamento }\end{array}$ \\
\hline$\phi^{\prime}$ & Ângulo de atrito interno efetivo \\
\hline$\psi$ & Ângulo de dilatância \\
\hline$c^{\prime}$ & Coesão efetiva \\
\hline$E_{50}^{r e f}$ & Rigidez secante a 50 \% da tensão de ruptura \\
\hline$E_{\text {oed }}^{r e f}$ & Rigidez tangente na compressão primária oedométrica \\
\hline$E_{u r}^{r e f}$ & Rigidez no descarregamento e recarregamento \\
\hline$R_{f}^{\text {nc }}$ & Coeficiente de empuxo no repouso para a condição \\
\hline$p^{\text {ref }}$ & normalmente adensada \\
\hline expoente de dependência da rigidez em relação à tensão
\end{tabular}

\section{4.}

\section{Geração e Caracterização do Rejeito de Ferro}

O processo de explotação mineral consiste na extração de minerais de valor econômico de dentro de maciços rochosos caracterizados pela presença destes minerais em grande concentração. Esse processo requer a lavra de rochas sem concentração mineral e, portanto, sem valor econômico, durante o decapeamento da mina para atingir o corpo mineralizado. $\mathrm{O}$ material decapeado é denominado estéril, sendo usualmente disposto na natureza na forma de pilhas. 
De acordo com o Sumário Mineral Brasileiro (ANM, 2018), os principais estados produtores de minério de ferro no Brasil são: Minas Gerais (62,0\%), Pará (37,3\%) e Mato Grosso do Sul (0,6\%). Sendo estes responsáveis por uma produção superior a 450 milhões de toneladas, com teor médio de ferro de $63,7 \%$, o que representa a quase totalidade da produção mineral brasileira.

Luz et al. (2010) classifica o processo de beneficiamento de minério nas seguintes etapas:

- Britagem e moagem;

- Peneiramento (separação por dimensão);

- Concentração (gravítica, magnética, flotação, etc);

- Desaguamento (espessamento e filtragem);

- Secagem (spray dryer, secador rotativo, etc);

- Disposição de rejeito.

A Figura 2-35 apresenta o fluxograma típico do processo de beneficiamento de minério e geração de rejeitos. 


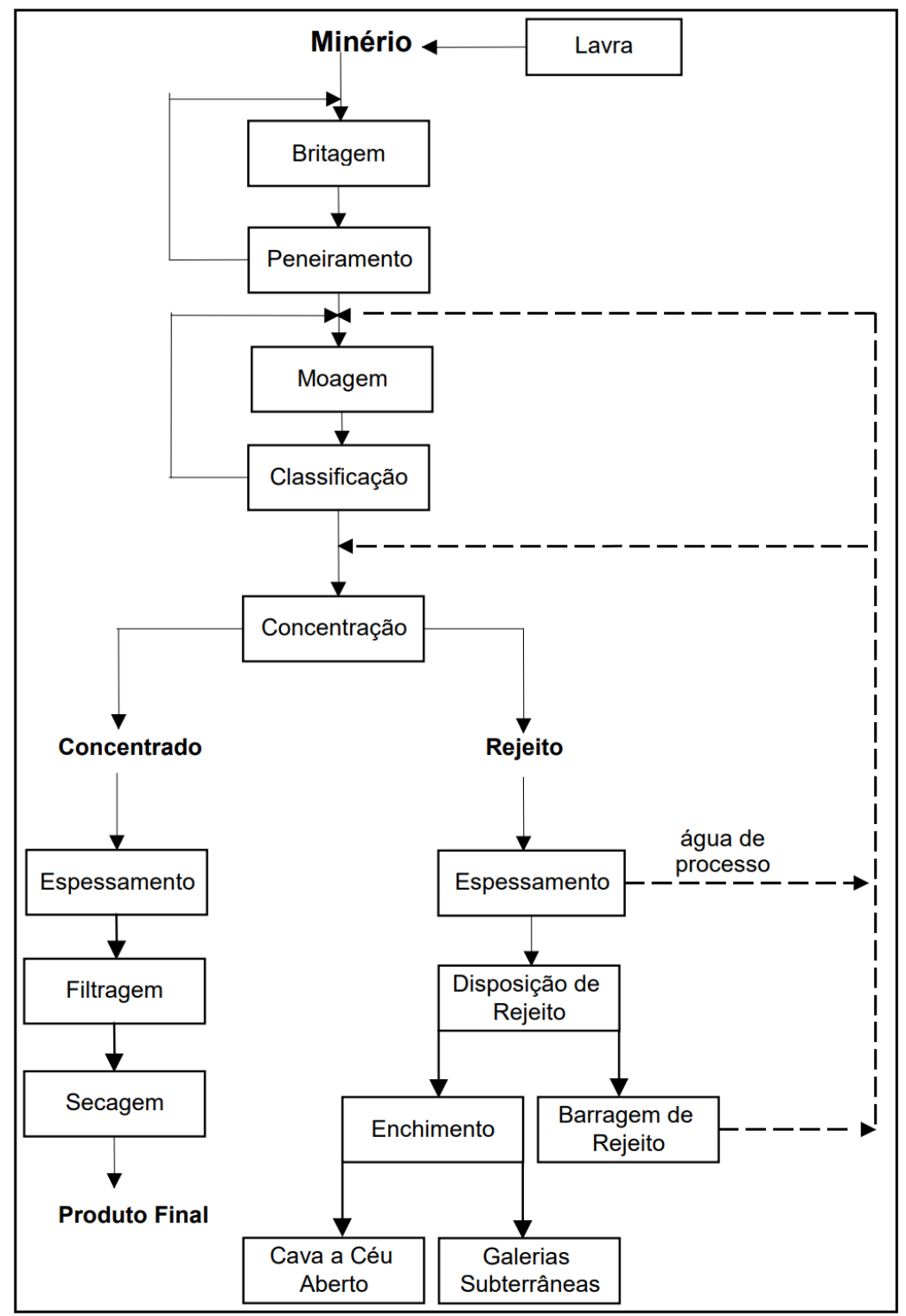

Figura 2-35 - Fluxograma típico de tratamento de minério (Luz et al., 2010)

Os rejeitos resultantes de beneficiamento podem possuir textura granular, similar a materiais arenosos, apresentando alta permeabilidade e baixa compressibilidade. Rejeitos com essas características são tipicamente classificados como rejeito arenoso ou rejeito granular. Rejeitos de minério também podem apresentar matriz de granulometria fina, com baixa permeabilidade, alta plasticidade e compressibilidade, estes são usualmente classificados como lama.

A experiência mostra que os rejeitos são materiais distintos, com características específicas impressas pelo processo de beneficiamento utilizado. Desta forma, o comportamento geotécnico destes materiais, em geral, não pode ser 
caracterizado de forma plena com uso das metodologias adotadas para os solos naturais (Bittar, 2006).

\subsection{1.}

\section{Barragens de Rejeito}

As Barragens de Rejeito são estruturas de terra construídas para contenção ou acumulação de resíduos sólidos e água oriundos do processo de beneficiamento do minério, podendo ser construídas com materiais compactados originados de áreas de empréstimo, ou mesmo com o próprio rejeito, fazendo uso da parcela grossa resultante do processo de beneficiamento.

A classificação das barragens de rejeito é feita de acordo com o método de construção da estrutura. Desta forma, destacam-se 3 (Três) métodos para construção e alteamento de barragens de rejeito, são eles:

- Método de Montante;

- Método de Jusante;

- Método de Linha de Centro.

\section{Método de Montante}

O método de montante é o mais usual dentre os métodos apresentados, tendo como principais vantagens o baixo custo e a simplicidade de execução. O método consiste na construção de um dique de partida, em geral constituído por material argiloso ou enrocamento, em seguida, os rejeitos são dispostos hidraulicamente a partir da crista do dique de partida, formando uma praia. $\mathrm{O}$ adensamento deste material ao longo do tempo provoca um ganho de resistência, permitindo que este material seja utilizado como fundação para futuros diques de alteamento, que são compostos pelo mesmo material do rejeito. Esse processo é repetido sucessivas vezes, até que a cota de alteamento da estrutura seja alcançada, conforme indicado na Figura 2-36. 


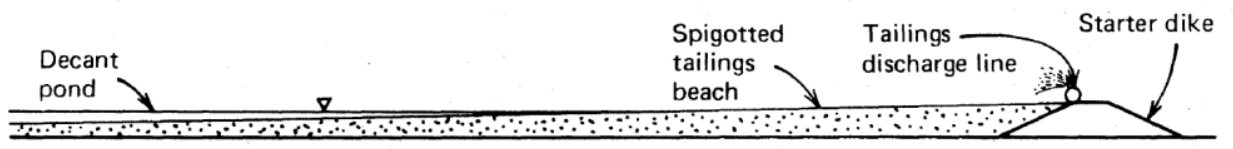

(a)

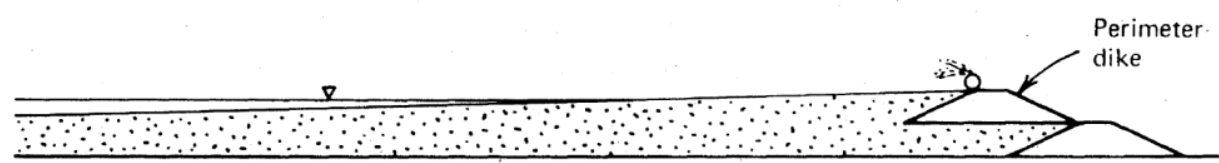

$(b)$

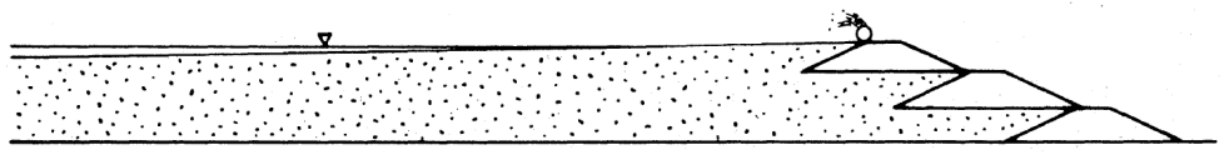

(c)

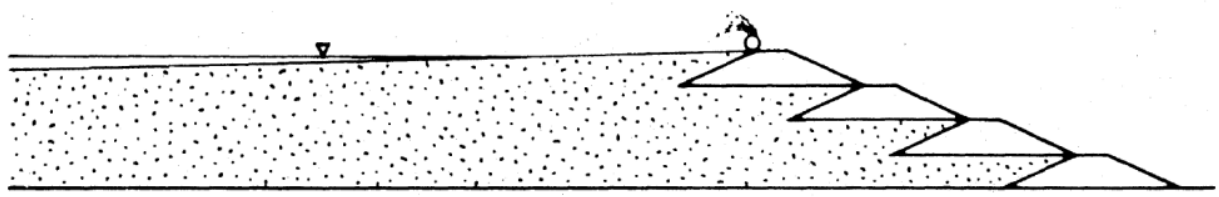

(d)

Figura 2-36 -Seção típica de uma barragem alteada para montante (Vick, 1990)

A cada novo alteamento utilizando o método de montante, o volume necessário para elevar a cota do reservatório diminui, o que significa que a taxa de alteamento se torna cada vez mais rápida à medida que a estrutura é alteada (DixonHardy \& Engels, 2008). Taxas de alteamento excessivas levam ao aumento das poropressões, e consequentemente, à redução da resistência do rejeito, uma vez que o processo de adensamento pode levar décadas (Jakubick et al., 2003).

\section{Método de Jusante}

A primeira etapa do método de alteamento para jusante é similar ao método de montante, de tal forma que se constrói um dique de partida, a partir do qual, os rejeitos são lançados para montante. $\mathrm{O}$ alteamento da estrutura ocorre pela ampliação do dique de partida, deslocando subsequentemente o eixo da barragem para jusante. No Método de Jusante, a barragem pode ser construída com o próprio rejeito não saturado, ou com material compactado oriundo de áreas de empréstimo. A associação do método à estruturas de controle do nível freático como tapetes 
drenantes, filtros verticais e núcleos argilosos, pode aumentar significativamente a segurança da barragem.

A Figura 2-37 ilustra a sequência de construção de uma barragem de rejeitos alteada pelo Método de Jusante.

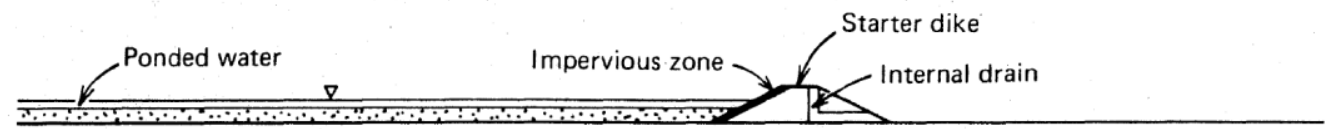

(a)

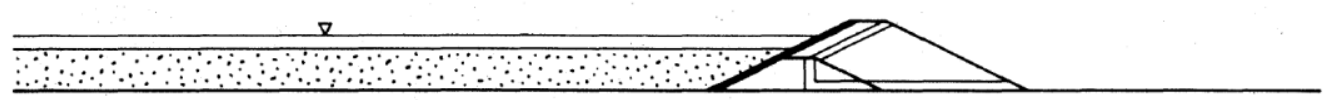

(b)

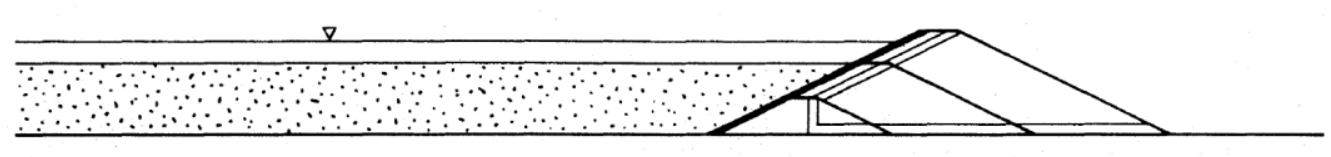

(c)

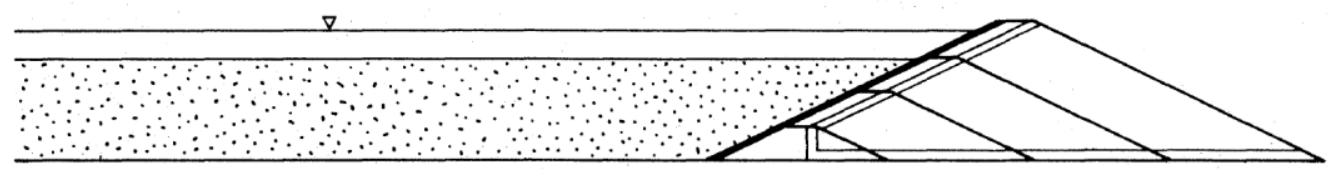

(d)

Figura 2-37 - Alteamento sequencial de barragem construída pelo Método de Jusante (Vick, 1990)

O método de construção com alteamentos a jusante apresenta inúmeras vantagens, no que tange a segurança da barragem. Klhon (1981) cita como principais vantagens do método de alteamento para jusante:

- O processo de construção da barragem pode ser controlado por métodos convencionais de controle de compactação;

- O sistema de drenagem é construído juntamente com a barragem, podendo ser prolongado com cada nova etapa de alteamento;

- A barragem pode ser projetada para suportar às solicitações previstas em projeto, incluindo forças sísmicas;

- As atividades de construção não interferem no lançamento de rejeitos;

- A barragem não fica assente sobre rejeito. 
Em contrapartida às diversas vantagens do ponto de vista da segurança, dentre os 3 (três) métodos construtivos mais usuais, o Método de Montante é o mais oneroso. O grande volume de aterro necessário para diversas etapas de alteamento, também pode impor uma restrição construtiva para o método. A cada novo alteamento o volume de aterro necessário aumenta exponencialmente. Consequentemente, é necessário um planejamento que garanta uma produção de material de aterro suficiente para construção de cada etapa de alteamento durante a vida útil da estrutura (Vick, 1990).

Um ponto muito relevante para a elaboração de projetos de barragens alteadas para jusante, é a compressibilidade do material de fundação. O sucessivo alargamento da base, inerente ao método, provoca significativas solicitações de compressão, em porções cada vez mais extensas do terreno a jusante, podendo levar a recalques expressivos, caso haja ocorrência de materiais compressíveis em algum ponto da fundação. Este fenômeno reforça a importância de um programa de investigação cuidadoso, que leve em conta todas as etapas de alteamento prevista na vida útil da barragem.

\section{Método de Linha de Centro}

O Método de Linha de Centro representa uma solução intermediária entre os métodos de montante e jusante. Esta afirmação é verdadeira tanto do ponto de vista geométrico, quanto do custo de implementação. A solução consiste no alteamento da barragem segundo um eixo vertical, coincidente com o eixo dique de partida, de modo que o lançamento e compactação do aterro da barragem é feito com avanço sobre o limite de montante da crista do dique de partida.

A técnica se destaca pela facilidade construtiva associada à menor demanda volumétrica de material. Há de se destacar também a possibilidade de execução de um sistema de drenagem interna, permitindo o controle da linha freática, tal qual no Método de Jusante (Albuquerque Filho, 2004). 


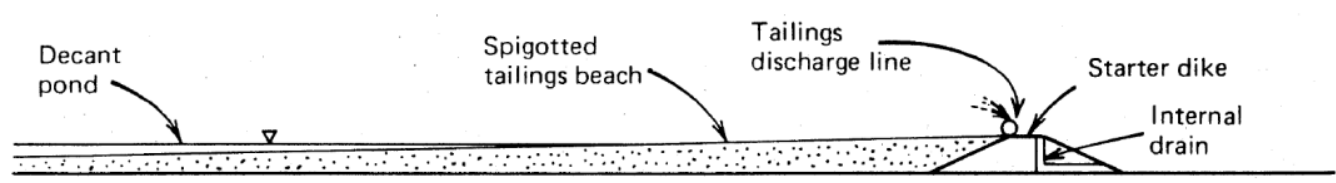

(a)

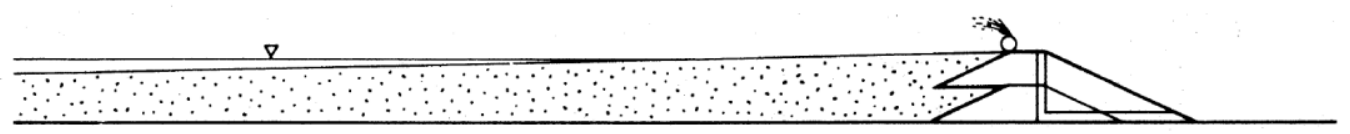

(b)

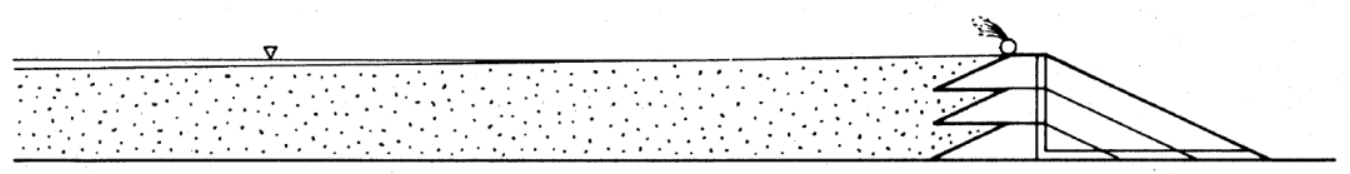

(c)

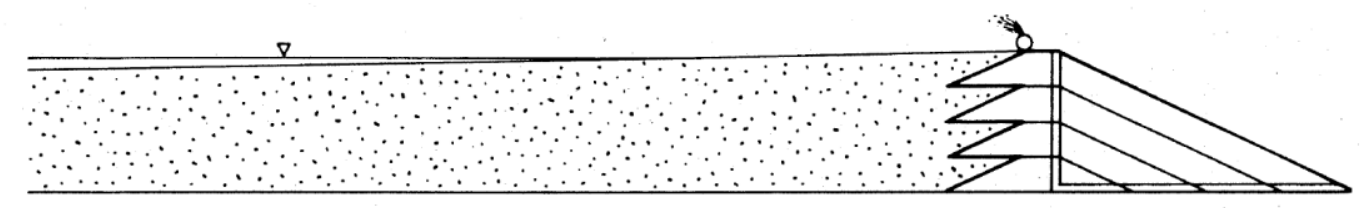

(d)

Figura 2-38 - Alteamento sequencial de barragem construída pelo Método de Linha de Centro (Vick, 1990)

Vick (1990) destaca que na eventualidade de liquefação da praia de rejeitos podem ocorrer ruptura localizadas na porção de montante do aterro, construída sobre o rejeito. Entretanto, desde que a porção central e a porção de jusante do aterro permaneçam íntegras, e que a água não esteja em contato direto com o aterro, a estabilidade do aterro não será afetada.

Um fenômeno comumente observado em barragens construídas por este método, é o surgimento de trincas longitudinais na crista da barragem. A ocorrência das trincas se dá pelo fato de haver diferenças de compressibilidade entre o material compactado a jusante e o material lançado a montante, o que propicia o desenvolvimento de esforços de tração na crista da barragem. 


\section{3 Estudo de Caso - Barragem de Rejeito de Mineração de Ferro}

\section{1. Histórico da Barragem}

A Barragem escolhida como objeto deste estudo, foi construída na década de 1980. Ao final da construção da primeira etapa do maciço, a barragem possuía aproximadamente 53 metros de altura, sendo composta por espaldares de composição silte argilosa, com um núcleo central constituído de argila siltosa de baixa permeabilidade.

Em sua configuração inicial, a barragem possuía uma estrutura de drenagem interna composta por um filtro chaminé de areia, deslocado 25 metros do eixo central na direção de jusante, conectado à um filtro horizontal que se inicia no contato entre o espaldar de jusante e o núcleo argiloso, se estendendo até o pé da barragem. O filtro horizontal é composto por brita, com camada de transição granulométrica de areia média a grossa. A Figura 3-1 ilustra a configuração da barragem em sua etapa inicial.

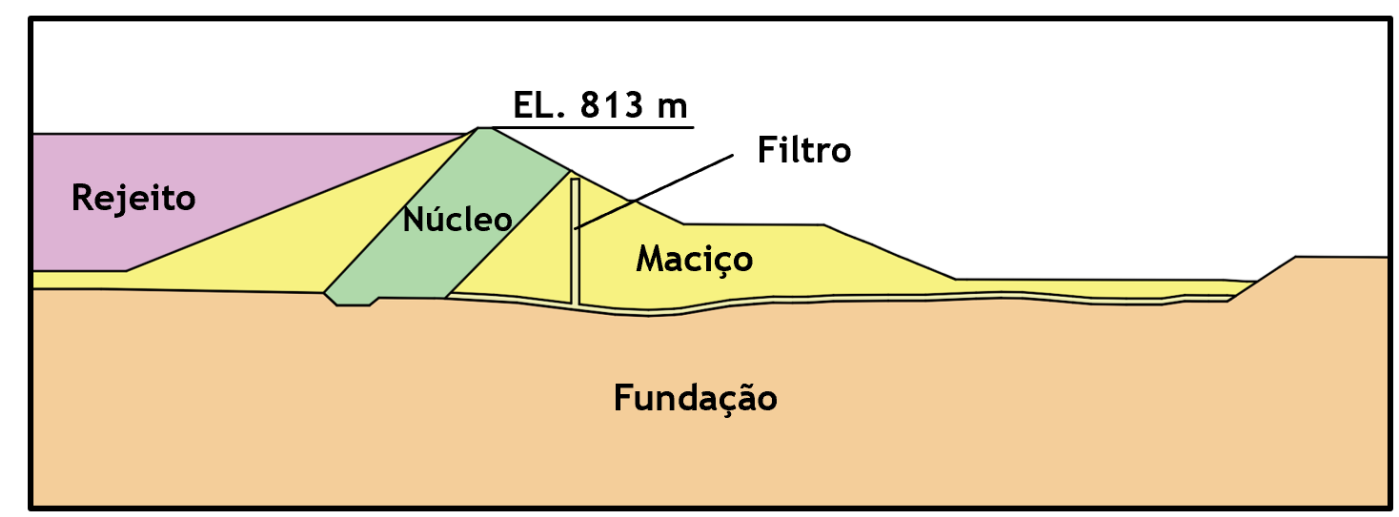

Figura 3-1 - Desenho esquemático da configuração da barragem na época de sua construção

Com o avanço dos lançamentos de rejeito no reservatório, 24 anos após a construção do maciço de partida, houve a necessidade de realização de uma obra emergencial antes da finalização do projeto executivo do $1^{\circ}$ alteamento previsto 
para a estrutura. Essa obra emergencial consistiu na construção de 4 (quatro) novas bancadas apoiadas sobre a berma de equilíbrio do maciço de partida. Essa intervenção resultou em um alteamento de 5,5 m na crista da barragem, provocando um deslocamento do seu eixo 20 metros para jusante, o que exigiu a construção de um novo sistema de drenagem interna composto por um tapete drenante no contato entre o maciço de partida e o novo alteamento, e um filtro vertical inclinado com saída na face do novo aterro, em espera para o alteamento.

O primeiro alteamento, finalizado 6 (seis) anos após a intervenção emergencial, elevou a crista da barragem em 15,5 metros, deslocando seu eixo central 35 metros para jusante. Com o alteamento, o filtro inclinado foi prolongado até aproximadamente $3 \mathrm{~m}$ da nova crista da barragem. Nesta configuração, a barragem atingiu 73 metros de altura. A Figura 3-2 ilustra a configuração da barragem após seu primeiro alteamento.

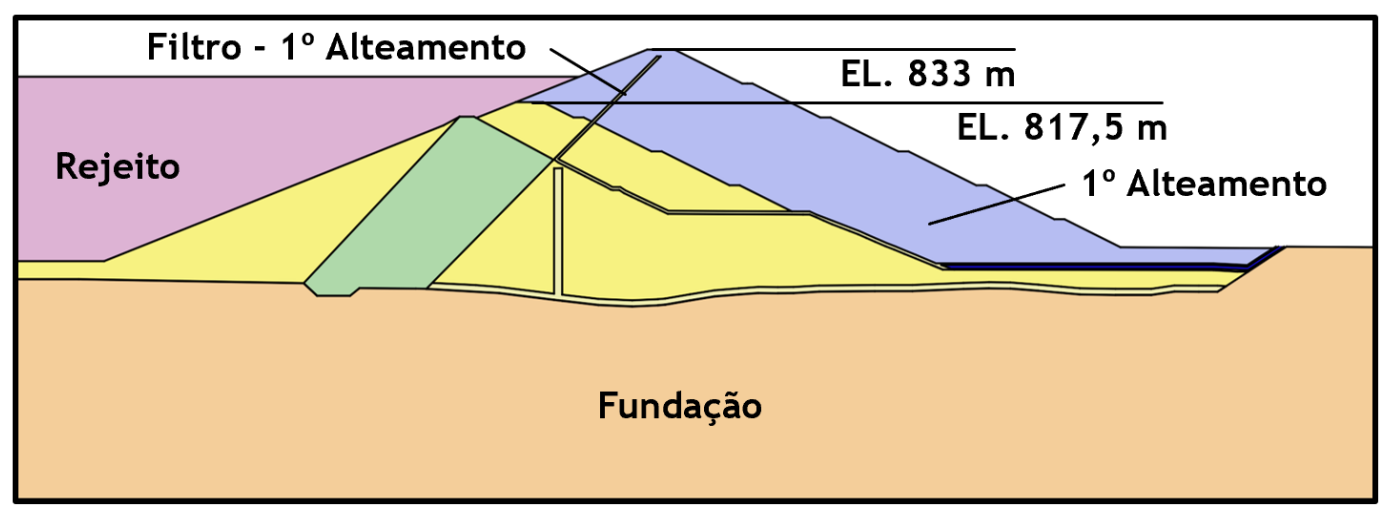

Figura 3-2 - Desenho esquemático da barragem após o primeiro alteamento

Cinco anos após o primeiro alteamento, devido à um extenso período de seca, o nível do reservatório sofreu rebaixamento, provocando o avanço de um grande volume de rejeitos em direção ao lago principal. Esse fenômeno implicou na necessidade de execução de um alteamento de 3 metros de altura na crista da barragem, a fim de assegurar a segurança hidráulica da estrutura. A Figura 3-3 apresenta a configuração da barragem nesta etapa construtiva. 


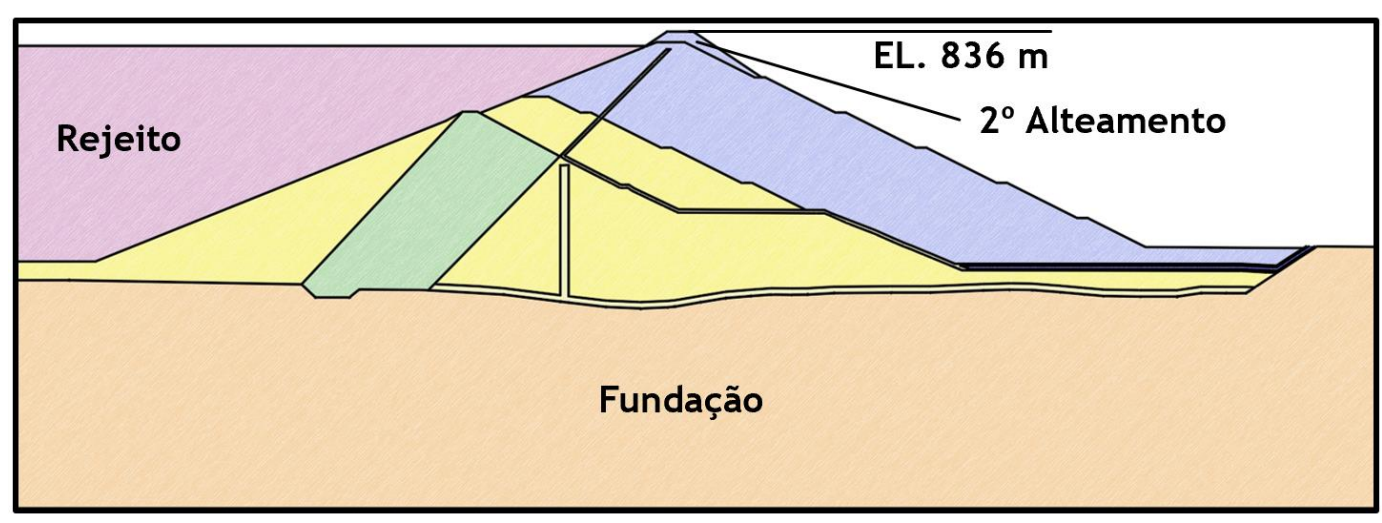

Figura 3-3 - Desenho esquemático da configuração da barragem após o $2^{\circ}$ alteamento

Nos 3 (três) anos subsequentes ao coroamento, foi elaborado o projeto do terceiro e último alteamento previsto na vida útil estrutura, o qual elevaria a crista da barragem em mais 14 metros, totalizando 90 metros de altura. A taxa de construção das bancadas de alteamento foi acelerada, de forma que cada bancada de 10 metros de altura foi construída em um período de aproximadamente 10 dias. Após a construção da quarta bancada, observou-se o surgimento de trincas longitudinais de extensão métrica, no contato entre o aterro de alteamento e o aterro existente. Identificou-se também a formação de trincas transversais no maciço, concentradas próximo do contato com a ombreira esquerda da barragem. Após estes eventos, a mineradora Vale decidiu paralisar as obras de alteamento, até que fossem identificadas as causas do surgimento destas patologias. A Figura 3-4 ilustra a configuração da barragem na época da paralisação das obras do terceiro alteamento.

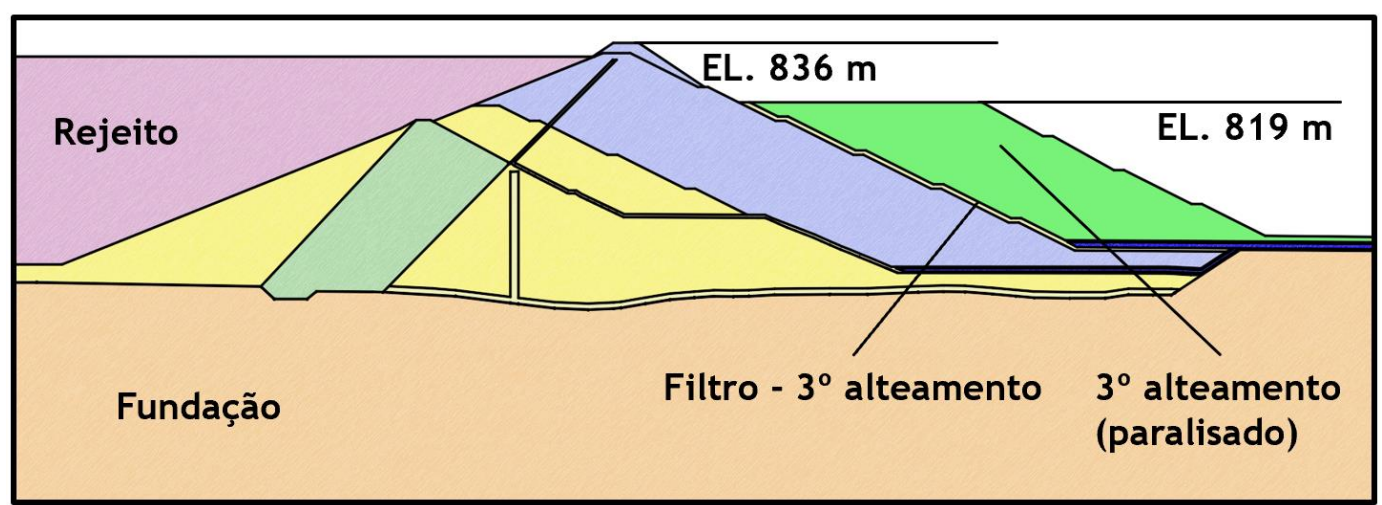

Figura 3-4 - Desenho esquemático da configuração da barragem após a paralisação do $3^{\circ}$ alteamento

A Figura 3-5 e a Tabela 3-1 sintetizam o histórico construtivo da barragem de rejeito objeto deste estudo. Não houve autorização por parte da mineradora Vale 
para identificação nominal da estrutura, por essa razão, o nome da barragem foi omitido do estudo.

Tabela 3-1 - Histórico construtivo da barragem de rejeitos analisada

\begin{tabular}{ccccc}
\hline Fase & $\begin{array}{c}\text { Linha do } \\
\text { tempo }\end{array}$ & Altura (m) & Maciço/Alteamento & Drenagem \\
\hline $\begin{array}{c}\text { Dique de } \\
\text { partida }\end{array}$ & 0 & 53,00 & $\begin{array}{c}\text { Núcleo argiloso com } \\
\text { espadares compostos por } \\
\text { material silto-arenoso }\end{array}$ & $\begin{array}{c}\text { Filtro arenoso a } \\
\text { jusante da linha } \\
\text { de centro }\end{array}$ \\
\hline 10 alteamento & 28 anos & 73,00 & $\begin{array}{c}\text { Aterro argiloso } \\
\text { compactado. Alteamento } \\
\text { pelo método de jusante }\end{array}$ & $\begin{array}{c}\text { Filtro arenoso } \\
\text { inclinado a } \\
\text { montante da nova } \\
\text { linha de centro }\end{array}$ \\
\hline $2^{\circ}$ alteamento & 32 anos & 76,00 & $\begin{array}{c}\text { Aterro argiloso } \\
\text { compactado. Alteamento } \\
\text { pelo método de jusante }\end{array}$ & $\begin{array}{c}\text { Filtro arenoso } \\
\text { inclinado a } \\
\text { montante da nova } \\
\text { linha de centro }\end{array}$ \\
\hline $3^{\circ}$ alteamento & 38 anos & $\begin{array}{c}\text { Em processo } \\
\text { de alteamento } \\
\text { para } 90,00 \mathrm{~m}\end{array}$ & $\begin{array}{c}\text { Aterro argiloso } \\
\text { compactado. Alteamento } \\
\text { pelo método de jusante. }\end{array}$ & $\begin{array}{c}\text { Filtro arenoso } \\
\text { inclinado a } \\
\text { montante da nova } \\
\text { linha de centro }\end{array}$ \\
\hline
\end{tabular}



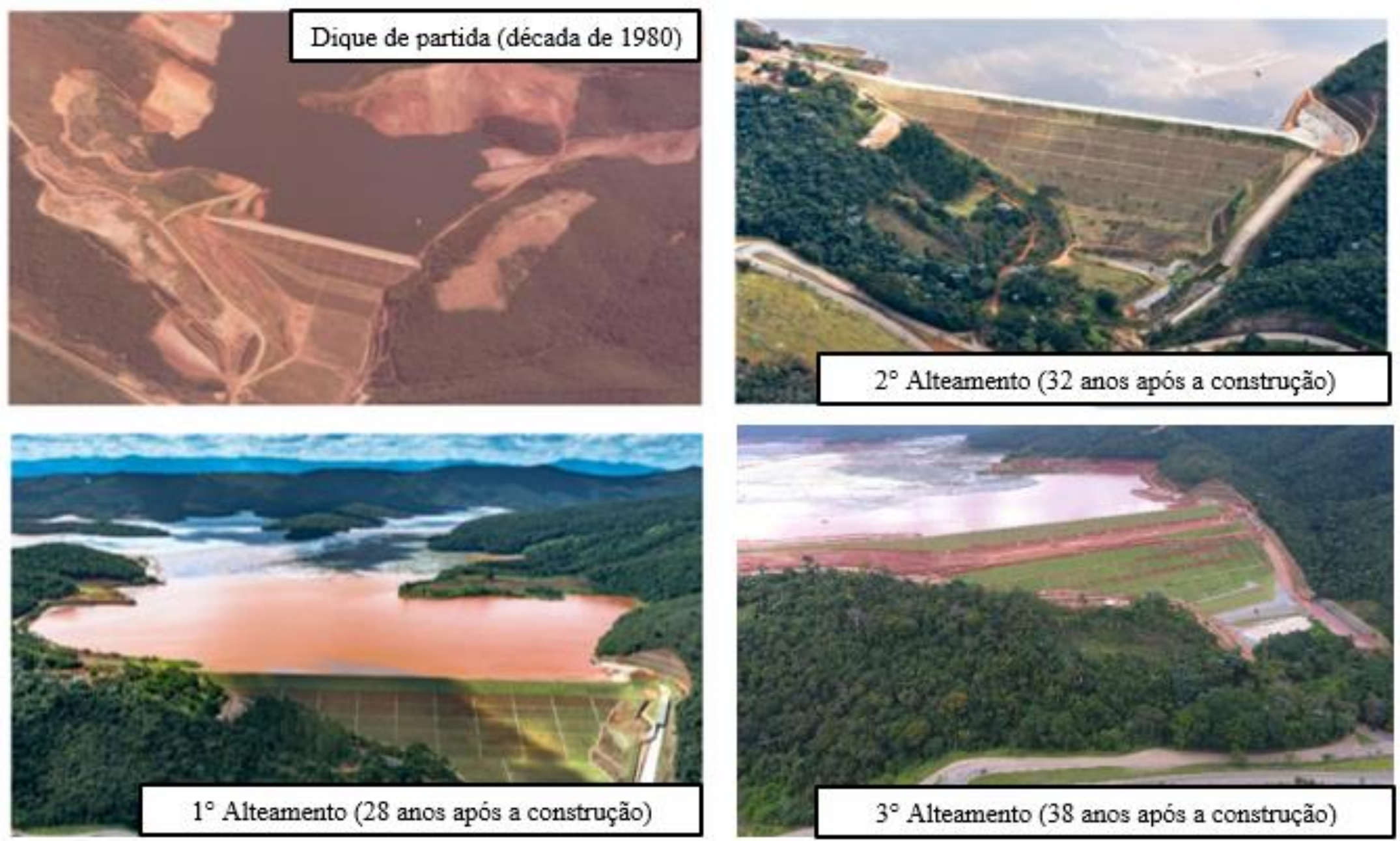

Figura 3-5 - Histórico de alteamentos da barragem de rejeitos estudada 


\section{2.}

\section{Aspectos Geológico-Geotécnicos}

De acordo com os documentos de projeto, a fundação da barragem é constituída predominantemente por solo residual de gnaisse milonítico, com lentes esparsas de xisto. Além disso, próximo da ombreira direita, foi evidenciada a ocorrência de bolsões de colúvio poroso, com SPT entre 3 a 4 golpes. Porém, esses bolsões se encontram confinados. O horizonte de colúvio apresenta índice de resistência próximo a 9 golpes, com permeabilidade entre $1,0 \times 10^{-6}$ a 2 x $100^{7} \mathrm{~m} / \mathrm{s}$.

A fundação imediata da barragem está em solo residual jovem (solo saprolítico) de gnaisse, relativamente homogêneo, de constituição silte-arenosa a argilosa. O solo saprolítico apresenta índice de resistência SPT variando entre 10 e 20 golpes, com coeficiente de permeabilidade em torno de $5,0 \times 10^{-7} \mathrm{~m} / \mathrm{s}$.

O modelo geológico-geotécnico da barragem mostra uma interface com padrão de altos e baixos sucessivos entre o solo saprolítico e o saprolito, em que os aprofundamentos do saprolito devem corresponder a zonas preferenciais de penetração do intemperismo. Desde as primeiras campanhas de investigação, já se observava esse padrão dominado por bolsões de solos mais fracos com valores de $\mathrm{N}$ inferiores a 10 golpes, frequentemente atingindo valores próximos a 5 golpes. BVP (2020) agrupou estes bolsões de solos de alta compressibilidade em uma unidade geotécnica denominada SAC (Solos de Alta Compressibilidade). A unidade SAC é composta pelo agrupamento dos colúvios com a porção mais compressível dos solos residuais existentes na fundação.

Nos trechos da fundação constituídos pelo gnaisse, as espessuras do perfil de alteração são bastante variáveis, de forma que ocorrem trechos com ausência de algumas camadas de intemperismo, configurando um topo rochoso irregular, de forma que o perfil de alteração forma regiões de solos de maior espessura, concentrados principalmente na porção central da barragem, sob o maciço da $1^{\text {a }}$ Etapa de alteamento, na qual há trechos em que o solo residual passa bruscamente para o saprolito (BVP, 2020).

O conhecimento atual da condição geotécnica da barragem é baseado nas informações obtidas por meio de quatro campanhas de investigação executadas durante as fases de projeto e obra de cada alteamento sofrido ao longo das décadas. 
O modelo geológico-geotécnico da barragem, apresentado em BVP (2020), foi desenvolvido a partir da compilação de todas as informações das campanhas de investigação disponíveis.

Desde a construção da barragem foram realizadas 4 campanhas de investigação geotécnica, executadas por diferentes empresas ao longo das décadas. A barragem apresenta um elevado quantitativo de investigações, o que permitiu a definição de um modelo geotécnico com qualidade superior à usual para projetos similares.

Ao todo foram realizadas aproximadamente 70 sondagens a percussão, sendo 60 destas executadas antes da construção do dique de partida da barragem, 40 sondagens rotativas e 50 sondagens mistas, algumas destas executadas em furos utilizados para instalação de instrumentos. As investigações foram distribuídas entre a fundação imediata da barragem e as regiões de montante e jusante da estrutura.

No âmbito deste estudo, considerou-se uma seção transversal na região na qual ocorre o perfil mais espesso da camada SAC, região essa que também registrou os maiores deslocamentos verticais durante a construção da barragem. A Figura 3-6 mostra a localização da seção de análise adotada neste estudo.

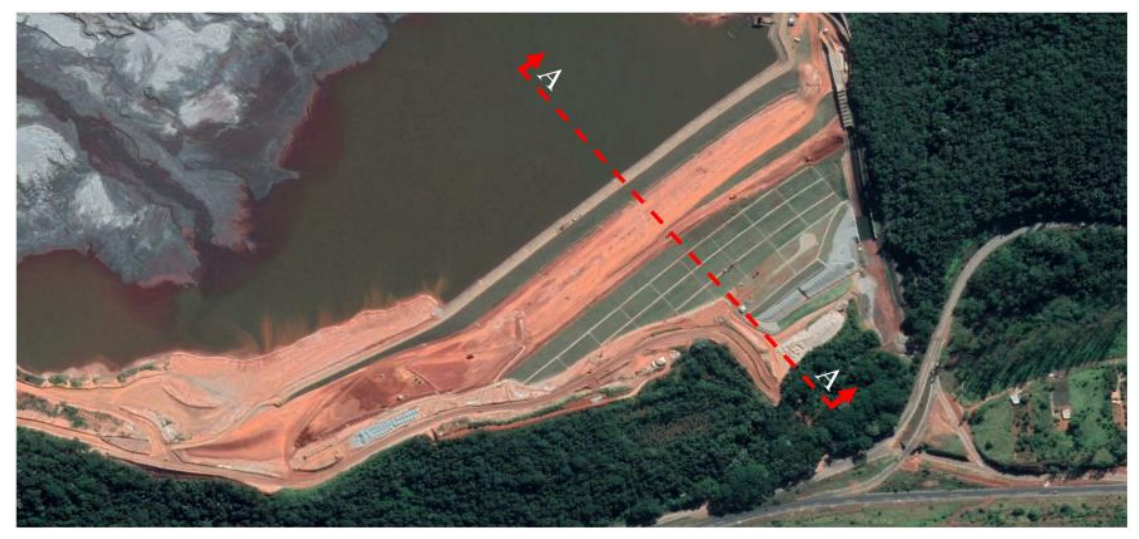

Figura 3-6 - Localização da seção de análise A-A (fonte: Google Earth, 2021)

A Figura 3-7 e a Figura 3-8 apresentam respectivamente os modelos geotécnicos do maciço e da fundação da barragem na seção A-A, conforme apresentado em BVP (2020). 


\begin{tabular}{|c|c|c|c|c|c|}
\hline Identificação & Estrutura & Classificação & Identificação & Estrutura & Classificação \\
\hline 1 & Dique de partida - Núcleo & Aterro argiloso & 6 & $1^{\circ}$ alteamento - Filtro & $\begin{array}{c}\text { Filtro de brita com } \\
\text { transição de areia }\end{array}$ \\
\hline 2 & Dique de partida - Espaldares & Aterro silto-arenoso & 7 & $3^{\circ}$ alteamento - Filtro & $\begin{array}{c}\text { Filtro de brita com } \\
\text { transição de areia }\end{array}$ \\
\hline 3 & Reservatório de rejeito & $\begin{array}{l}\text { Rejeito siltoso de minério } \\
\text { de ferro }\end{array}$ & 8 & Dique de partida - Filtro & Areia \\
\hline 4 & $1^{\circ}$ alteamento & Aterro silto-arenoso & 9 & $2^{\circ}$ alteamento - Corpo & Aterro silto-argiloso \\
\hline 5 & $3^{\circ}$ alteamento (paralisado) & Aterro argilo-siltoso & 10 & Alteamento emergencial & Aterro silto-arenoso \\
\hline
\end{tabular}

Figura 3-7 - Modelo geotécnico do maciço da Seção A-A 


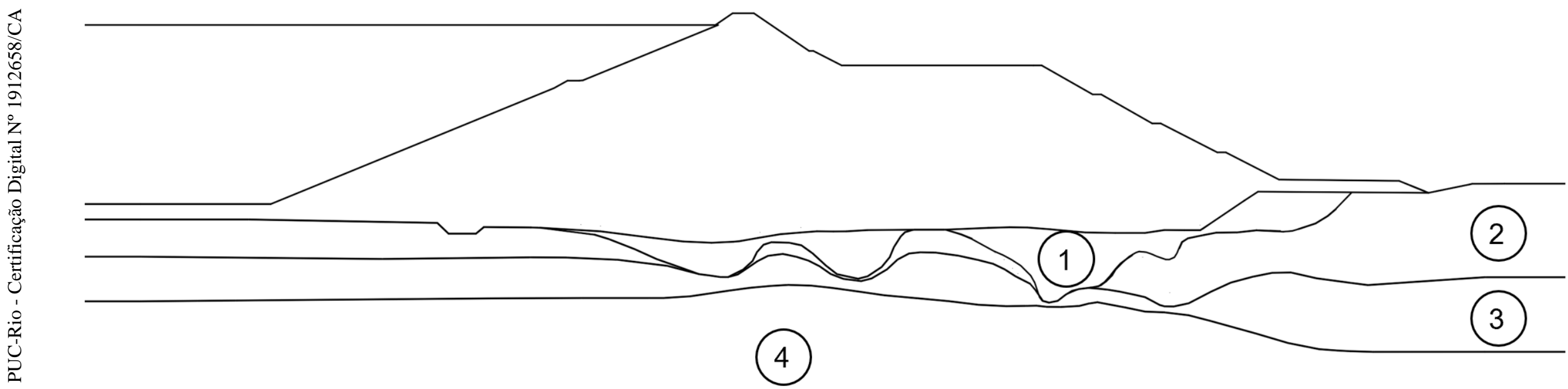

\begin{tabular}{ccc}
\hline Identificação & Unidade Geotécnica & Classificação \\
\hline 1 & Solos compressíveis (SAC) & $\begin{array}{c}\text { Agrupamento de solos } \\
\text { residuais e solos saprolíticos } \\
\text { compressiveis }\end{array}$ \\
\hline 2 & Solo saprolítico de gnaisse (SSG) & $\begin{array}{c}\text { Solos saprolíticos de média } \\
\text { compressibilidade }\end{array}$ \\
\hline
\end{tabular}

\begin{tabular}{ccc}
\hline Identificação & Unidade Geotécnica & Classificação \\
\hline 3 & Saprolito de gnaisse & $\begin{array}{c}\text { Solo de origem gnaisse com } \\
\text { textura silte arenosa, pouco } \\
\text { compressível }\end{array}$ \\
\hline 4 & Gnaisse alterado & $\begin{array}{c}\text { Embasamento cristalino } \\
\text { alterado }\end{array}$ \\
\hline
\end{tabular}

Figura 3-8 - Modelo geotécnico da fundação da seção A-A 


\section{3. \\ Comportamento Tensão x Deformação}

\subsection{1.}

\section{Construção do Modelo Numérico}

O estudo aqui apresentado tem como foco a avaliação da segurança da barragem em dois momentos específicos após a paralisação do $3^{\circ}$ alteamento:

1. Imediatamente após a paralisação da construção, quando os excessos de poropressão na fundação atingem seus valores máximos;

2. Após a dissipação total dos excessos de poropressão provocados pela construção do $3^{\circ}$ alteamento.

Todos os materiais foram simulados pelo modelo constitutivo Hardening Soil, utilizando dados de monitoramento da barragem na calibração dos módulos de deformabilidade dos materiais da fundação, enquanto os parâmetros de deformabilidade dos materiais que compõem os maciços compactados foram obtidos mediante reprodução numérica das curvas de tensão-deformação dos ensaios triaxiais realizados.

A geometria da seção submetida à análise foi reproduzida em uma malha de elementos finitos composta por aproximadamente 17.000 elementos triangulares de 15 nós.

A Figura 3-9 mostra a distribuição dos elementos finitos na malha adotada no estudo.

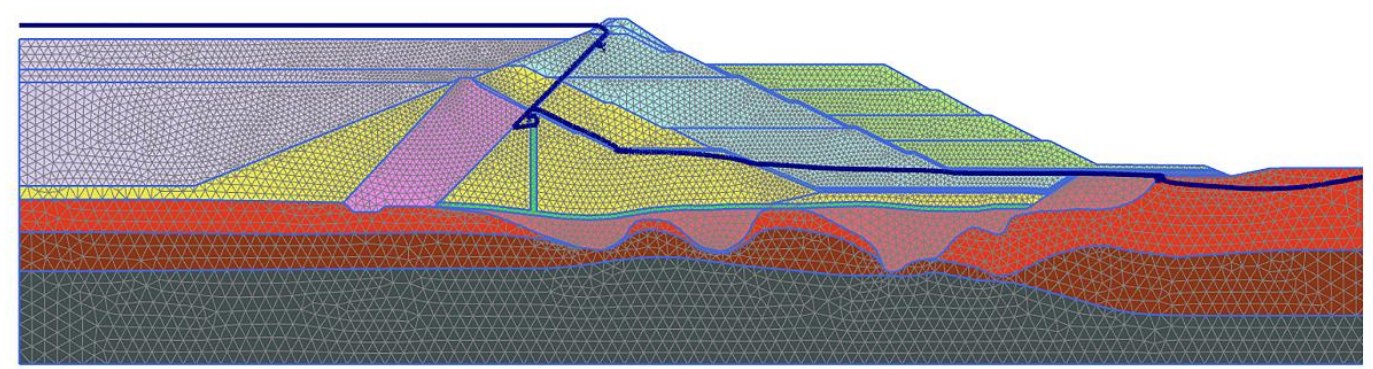

Figura 3-9 - Malha de elementos finitos da Seção A-A

O modelo numérico simulou todas as etapas construtivas da barragem, desde sua construção, até a dissipação total dos excessos de poropressão da fundação após a paralisação da obra. Esse tipo de simulação exige que as condições de contorno 
da análise de percolação sejam alteradas à medida que a barragem sofre novos alteamentos e deposições de rejeito à montante. Dessa forma, o modelo numérico foi construído em etapas intercaladas de construção, estabelecimento de fluxo no regime permanente e consolidação.

Por se tratar de uma construção muito antiga, não foram encontrados registros detalhados a respeito do tempo de construção do maciço inicial da barragem, posta esta limitação, considerando que o tempo entre a finalização do maciço inicial e a construção do primeiro alteamento foi superior a 25 anos, assumiu-se que houve dissipação total dos excessos de poropressão impostos pelo carregamento do maciço de partida, antes da construção do alteamento emergencial. Para as demais etapas de alteamento, adotou-se os tempos reais de construção.

No modelo numérico, o nível d'água do reservatório é alterado conforme novas camadas de rejeito são depositadas à montante, o que provoca alteração dos caminhos de percolação entre as etapas, à medida que o regime de fluxo permanente é estabelecido.

O objetivo final da simulação numérica das etapas construtivas da barragem é estabelecer o estado de tensões inicial do sistema maciço-fundação, que representa o ponto de partida para as avaliações de segurança realizadas neste estudo.

Após o estabelecimento do estado de tensões da barragem no instante do início do $3^{\circ}$ alteamento, as condições de contorno do modelo numérico foram calibradas com as leituras dos piezômetros e medidores de nível d'água existentes no maciço e na fundação, de forma a reproduzir a rede de fluxo da barragem naquele instante de tempo.

Conforme descrito no Capítulo 3.1, a construção das quatro primeiras bancadas de alteamento ocorreu à uma taxa acelerada. Para simulação dessa construção acelerada no modelo numérico, adotou-se etapas construtivas do tipo "consolidation", as quais simulam simultaneamente o acréscimo de carga devido ao peso próprio da camada, a geração e a dissipação dos excessos de poropressão em função do tempo. Neste tipo de análise, a carga aplicada varia linearmente com o tempo de construção estabelecido, e a poropressão total é a soma da poropressão hidroestática com o excesso de poropressão gerado pelo carregamento, cuja magnitude é diretamente influenciada pela permeabilidade dos materiais e varia em função do tempo. 
Dessa forma, para cada etapa de construção de uma bancada de 10 metros, simulou-se uma etapa do tipo "consolidation", com período de 10 dias, totalizando 4 (quatro) etapas. Ao final da construção da quarta bancada, quando as poropressões construtivas atingem seu ápice, o campo de distribuição de poropressões foi importado para o software Slide 2.0 para realização de análises de estabilidade por equilíbrio limite, utilizando a mesma base de poropressões do modelo numérico. Paralelamente, considerou-se uma etapa de verificação do fator de segurança pelo método Phi-c Reduction, no PLAXIS 2D.

Após a construção das quatro bancadas de alteamento, simulou-se a paralisação da obra até a dissipação total dos excessos de poropressão gerados pela construção das bancadas de alteamento. De forma análoga à etapa anterior, o campo de distribuição de poropressões gerado nesta fase foi importado para o Slide 2.0 e, paralelamente, foi adicionada ao modelo uma fase de verificação do fator de segurança pelo método Phi-c Reduction. A Figura 3-10 apresenta as distribuições de poropressão no maciço e na fundação da barragem ao final da construção da quarta bancada de alteamento e após a dissipação total dos excessos de poropressão do modelo. $\mathrm{O}$ valor da poropressão é crescente partindo das cores frias para as cores quentes.

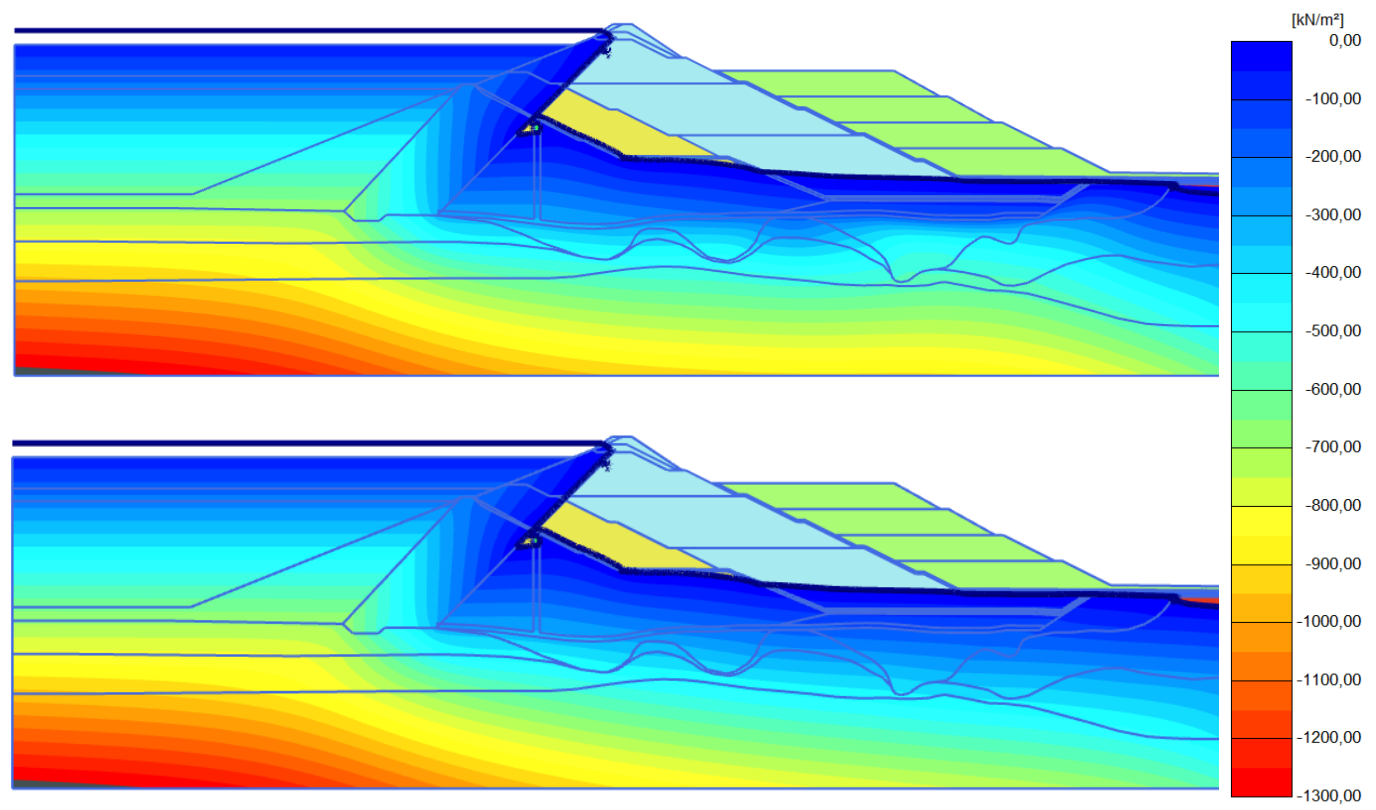

Figura 3-10 - Distribuição de poropressões no maciço e na fundação da barragem, ao final da construção das bancadas de alteamento e após a dissipação total dos excessos de poropressão construtivos 


\subsubsection{Parâmetros geomecânicos}

Conforme descrito anteriormente, o modelo constitutivo adotado para a simulação do comportamento geomecânico dos materiais que compõem a fundação e o maciço da barragem foi o Hardening Soil. Esse modelo foi adotado por representar de forma satisfatória as variações de rigidez dos materiais em função dos níveis de tensão confinante. Além disso, por se tratar de um modelo hiperbólico, o HS apresenta melhor aderência às curvas de carregamento desviatório primário e às trajetórias de tensão dos ensaios de compressão triaxial, quando comparado ao modelo elástico perfeitamente plástico de Mohr-Coulomb.

Obteve-se os parâmetros de resistência dos materiais mediante análise da dispersão dos pontos de máxima obliquidade e máxima tensão desviadora dos ensaios triaxiais realizados nas 4 (quatro) campanhas de investigação disponíveis.

Este estudo utilizou um total 31 ensaios triaxiais, sendo 13 realizados em amostras da camada SAC e 18 em amostras da camada SSG. A Figura 3-11 apresenta os pontos de ruptura no plano p'-q dos ensaios utilizados, assim como os parâmetros de resistência $c$ ' e $\phi$ ' obtidos por meio da transformação das envoltórias de resistência efetiva para o plano $\tau-\sigma$.

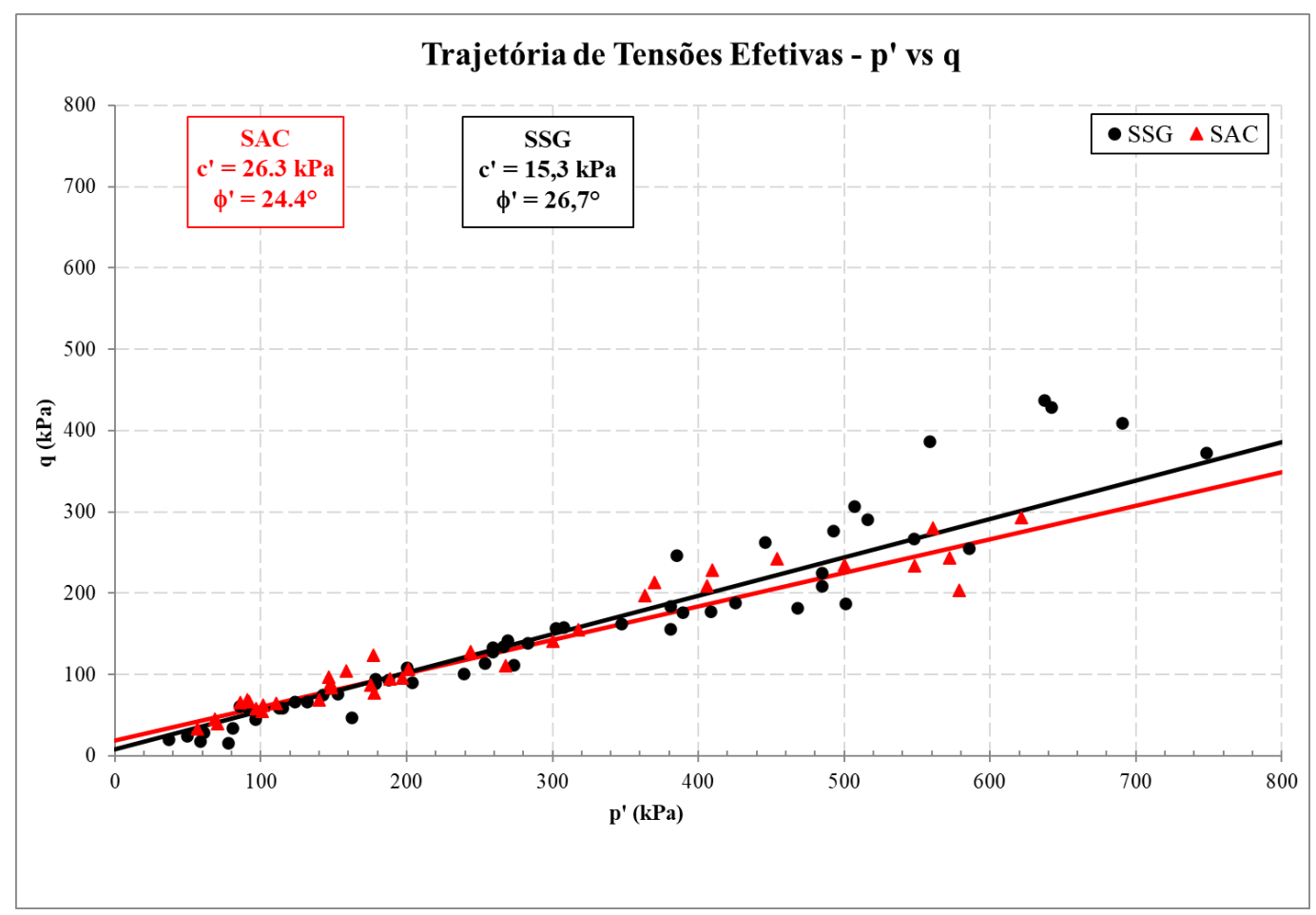

Figura 3-11 - Envoltórias de resistência efetiva das camadas SAC e SSG no plano p'-q 
Vale salientar que, dentre os dados utilizados, há ensaios antigos cujos resultados disponíveis se resumem aos parâmetros de resistência obtidos, impossibilitando a reconstrução das trajetórias de tensão. Por esta razão, não foi possível utilizar as envoltórias obtidas pela nuvem de pontos no plano p'-q para fins de estimativa das propriedades estatísticas dos materiais, dessa forma, os valores médios dos parâmetros $c^{\prime}, \phi^{\prime}$ e $\gamma_{n}$ foram admitidos como a média aritmética dos resultados dos ensaios triaxiais.

A Tabela 3-2 apresenta o peso específico, os regimes de drenagem e os parâmetros de resistência adotados no modelo numérico, obtidos em BVP (2020).

Tabela 3-2 - Parâmetros geotécnicos adotados nas análises (BVP, 2020)

\begin{tabular}{ccccc}
\hline Material & $\begin{array}{c}\text { Peso específico } \\
\text { não saturado }\end{array}$ & $\begin{array}{c}\text { Regime de } \\
\text { drenagem }\end{array}$ & $\begin{array}{c}\text { Coesão } \\
\text { efetiva }\end{array}$ & $\begin{array}{c}\text { Ângulo de } \\
\text { atrito } \\
\text { efetivo }\end{array}$ \\
\cline { 2 - 5 }$\gamma_{\text {unsat }}\left(\mathbf{k N} / \mathbf{m}^{3}\right)$ & - & $\boldsymbol{c}^{\prime}(\mathbf{k P a})$ & $\left.\boldsymbol{\phi}^{\prime} \mathbf{(}^{\circ}\right)$ \\
\hline $\begin{array}{c}\text { Aterro Maciço de } \\
\text { Partida (espaldares) }\end{array}$ & 18 & Drenado & 25 & 30 \\
\hline $\begin{array}{c}\text { Aterro Maciço de } \\
\text { Partida (núcleo) }\end{array}$ & 18 & $\begin{array}{c}\text { Não } \\
\text { drenado }\end{array}$ & 30 & 31 \\
\hline Aterro 10 Alteamento & 18 & Drenado & 13 & 31 \\
\hline Aterro 2o Alteamento & 18 & Drenado & 36 & 30 \\
\hline $\begin{array}{c}\text { Areia (transição } \\
\text { granulométrica) }\end{array}$ & 18 & Drenado & 1 & 33 \\
\hline Brita (filtros) & 22 & Drenado & 1 & 40 \\
\hline SAC & 16,92 & $\begin{array}{c}\text { Não } \\
\text { drenado }\end{array}$ & 20,1 & 24,4 \\
\hline Solo Saprolítico de & 17,53 & $\begin{array}{c}\text { Não } \\
\text { Grenado }\end{array}$ & 9,22 & 28,16 \\
\hline Saprolisse & 22 & $\begin{array}{c}\text { Não } \\
\text { drenado }\end{array}$ & 50 & 30 \\
\hline Gnaisse & 26,5 & \begin{tabular}{l} 
Drenado \\
\hline
\end{tabular} & 500 & 50 \\
\hline
\end{tabular}

Admitiu-se, para fins de modelagem, que os aterros compactados das diferentes etapas de alteamento apresentam os mesmos parâmetros de deformabilidade. Tal consideração é admissível, uma vez que não se observou diferença significativa nas curvas de tensão desviadora versus deformação axial, nem nas trajetórias de tensão desenvolvidas nos ensaios triaxiais realizados sobre 
estes materiais. Ademais, estes materiais também apresentam mesma origem, além de apresentar curvas granulométricas e Limites de Atterberg similares.

Os módulos de deformabilidade dos materiais de fundação foram calibrados de forma a reproduzir os recalques medidos pela instrumentação da barragem após a paralisação da obra.

A deformabilidade da fundação foi calibrada a partir de leituras de marcos superficiais e prismas instalados nas bermas da barragem.

$\mathrm{O}$ expoente $m$, que define o grau de dependência da rigidez em relação à tensão média, foi estimado de acordo com as frações granulométricas predominantes nos materiais. Adotou-se 1,0 para materiais argilosos e 0,5 para materiais arenosos. Para materiais de composição granulométrica mista, isto é, sem predominância clara de areia ou argila, admitiu-se valores intermediários para o expoente $m$.

A Tabela 3-3 sintetiza os parâmetros de deformabilidade utilizados na simulação numérica pelo modelo HS, conforme BVP (2020).

Tabela 3-3 - Parâmetros de deformabilidade dos materiais simulados no modelo numérico (BVP, 2020)

\begin{tabular}{|c|c|c|c|c|}
\hline Material & $\begin{array}{l}\text { Módulo de } \\
\text { deformabilidade } \\
\text { secante }\end{array}$ & $\begin{array}{c}\text { Módulo } \\
\text { oedométrico }\end{array}$ & $\begin{array}{c}\text { Módulo de } \\
\text { descarregamento } \\
\text { e } \\
\text { recarregamento }\end{array}$ & Expoente \\
\hline & $E_{50}(k P a)$ & $E_{\text {oed }}(\mathrm{kPa})$ & $E_{u r}(k P a)$ & $m$ \\
\hline $\begin{array}{l}\text { Aterro Maciço } \\
\text { de Partida } \\
\text { (espaldares) }\end{array}$ & 8817 & 7053 & 63480 & 0,8 \\
\hline $\begin{array}{l}\text { Aterro Maciço } \\
\text { de Partida } \\
\text { (núcleo) }\end{array}$ & 3306 & 2645 & 11900 & 1 \\
\hline $\begin{array}{c}\text { Aterro } 1^{\circ} \\
\text { Alteamento }\end{array}$ & 8817 & 7053 & 63480 & 0,8 \\
\hline $\begin{array}{c}\text { Aterro } 2^{0} \\
\text { Alteamento }\end{array}$ & 8817 & 7053 & 63480 & 0,8 \\
\hline $\begin{array}{c}\text { Areia } \\
\text { (transição } \\
\text { granulométrica) }\end{array}$ & 30000 & 30000 & 90000 & 0,5 \\
\hline Brita (filtros) & 60000 & 60000 & 180000 & 0,5 \\
\hline SAC & 1568 & 1255 & 11029 & 0,8 \\
\hline
\end{tabular}




\begin{tabular}{ccccc}
\hline Material & $\begin{array}{c}\text { Módulo de } \\
\text { deformabilidade } \\
\text { secante }\end{array}$ & $\begin{array}{c}\text { Módulo } \\
\text { oedométrico }\end{array}$ & $\begin{array}{c}\text { Módulo de } \\
\text { descarregamento } \\
\mathbf{e} \\
\text { recarregamento }\end{array}$ & Expoente \\
\cline { 2 - 5 } & $E_{50}(\mathbf{k P a})$ & $E_{\text {oed }}(\mathbf{k P a})$ & $E_{u r}(\mathbf{k P a})$ & $\boldsymbol{m}$ \\
\hline $\begin{array}{c}\text { Solo } \\
\text { Saprolítico de } \\
\text { Gnaisse }\end{array}$ & 2060 & 1648 & 14840 & 0,65 \\
\hline $\begin{array}{c}\text { Saprolito de } \\
\text { Gnaisse }\end{array}$ & 50000 & 50000 & 150000 & 0,6 \\
\hline
\end{tabular}

\section{4 .}

\section{Avaliação de Segurança}

A avaliação de estabilidade da estrutura foi realizada mediante aplicação dos métodos de equilíbrio limite de Morgenstern \& Price e Bishop Simplificado. As verificações de FS realizadas no modelo numérico fazem uso do método Phi-c Reduction, do PLAXIS.

\subsection{1. Metodologia}

Como descrito no Capítulo 1.2, o objetivo geral deste estudo foi apresentar uma análise comparativa dos métodos de avaliação de estabilidade e desempenho de uma barragem de rejeitos, adotando a abordagem probabilística com auxílio de análises de tensão x deformação por MEF. Com este objetivo, são apresentados os resultados de análises de estabilidade de uma barragem de rejeito de mineração de ferro, pela abordagem probabilística, utilizando os métodos FOSM e Monte Carlo.

Definiu-se como variáveis aleatórias do estudo os parâmetros c', $\phi^{\prime}$ e $\gamma_{\mathrm{n}}$ das duas unidades geotécnicas predominantes na fundação da barragem: o agrupamento dos colúvios e solos residuais de gnaisse de alta compressibilidade (SAC) e o solo saprolítico de gnaisse (SSG), o que totaliza 6 parâmetros variáveis.

A metodologia empregada para determinação das propriedades estatísticas necessárias para elaboração das funções de densidade de probabilidade consistiu na construção de histogramas de cada uma das 6 variáveis aleatórias, permitindo o cálculo dos valores médios, desvios padrão e definição das funções de densidade de probabilidade mais aderentes aos resultados. A Tabela 3-4 sumariza as distribuições estatísticas dos parâmetros admitidos como variáveis aleatórias do estudo. 
Tabela 3-4 - Distribuições probabilísticas das variáveis aleatórias (BVP, 2021)

\begin{tabular}{|c|c|c|c|c|c|c|}
\hline \multirow{3}{*}{ Dado } & \multicolumn{3}{|c|}{ SSG } & \multicolumn{3}{|c|}{ SAC } \\
\hline & $c^{\prime}$ & $\phi^{\prime}$ & $\gamma$ & $c^{\prime}$ & $\phi^{\prime}$ & $\gamma$ \\
\hline & $k P a$ & Graus & $k N / m^{3}$ & $k P a$ & Graus & $\mathrm{kN} / \mathrm{m}^{3}$ \\
\hline Distribuição & $\begin{array}{c}\text { Log- } \\
\text { normal }\end{array}$ & Normal & Normal & $\begin{array}{c}\text { Log- } \\
\text { normal }\end{array}$ & $\begin{array}{c}\text { Log- } \\
\text { normal }\end{array}$ & Normal \\
\hline Média & 9,22 & 28,16 & 17,53 & 20,1 & 24,42 & 16,92 \\
\hline Desvio Padrão & 10,49 & 4,71 & 1,84 & 12,41 & 3,16 & 1,85 \\
\hline Mínimo relativo & 9,22 & 14,13 & 5,52 & 20,1 & 9,48 & 5,55 \\
\hline Máximo relativo & 100 & 14,13 & 5,52 & 100 & 9,48 & 5,55 \\
\hline $\begin{array}{c}\text { Quantidade de } \\
\text { ensaios }\end{array}$ & 18 & 18 & 18 & 13 & 13 & 13 \\
\hline
\end{tabular}

Os valores de CV obtidos para os ângulos de atrito do SAC e do SSG foi compatível com o intervalo típico sugerido em Sayão et al. (2012) e Duncan (2014). O valor obtido para a coesão do material SAC também encontra respaldo no intervalo típico publicado em Sayão et al. (2012). Os coeficientes de variação dos pesos específicos naturais dos materiais SAC e SSG, se mostraram ligeiramente superiores aos intervalos relatados pelos autores supracitados. A coesão do SSG apresentou CV superior aos intervalos da literatura, o que equivale a afirmar que se trata de um parâmetro com alto grau de incerteza. Os valores de CV de todas as variáveis aleatórias são apresentados na Figura 3-12.

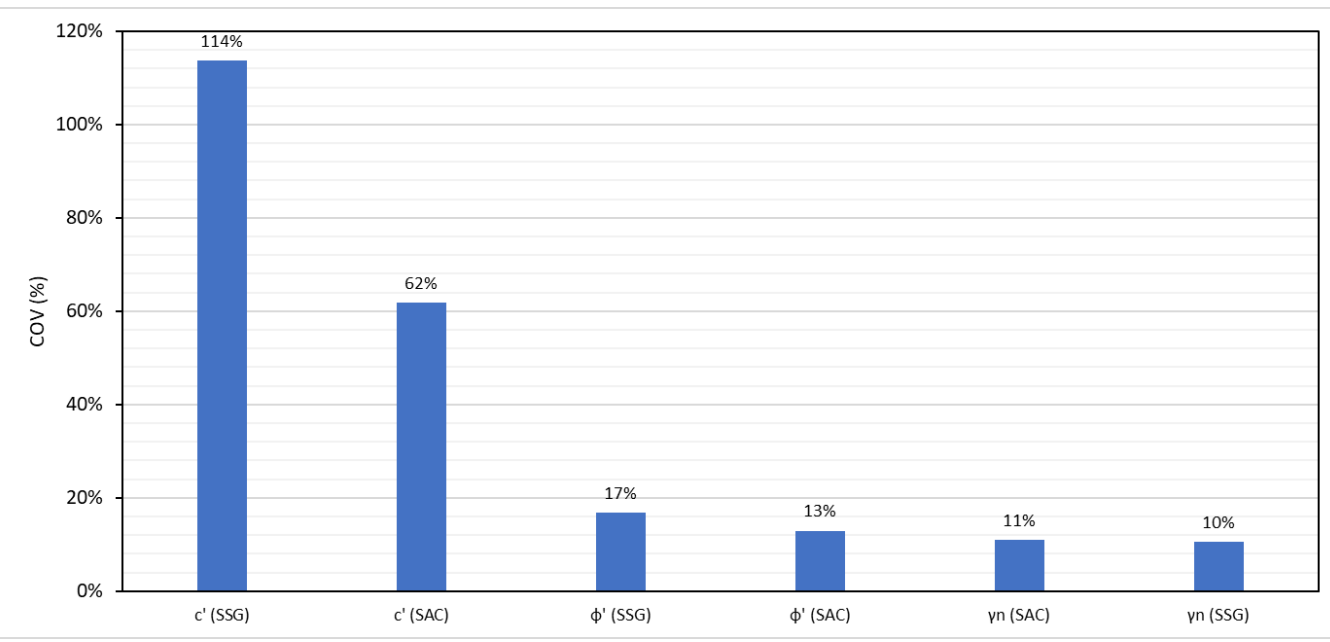

Figura 3-12 - Coeficientes de variação das variáveis aleatórias

Determinados os valores médios, desvios padrão e funções de densidade de cada variável, é possível realizar as análises probabilísticas. A metodologia de 
estudo consiste na elaboração de análises probabilísticas pelo método FOSM, utilizando os métodos de equilíbrio limite de Bishop Simplificado (1955) e Morgenstern e Price (1965), além do método numérico Phi-c Reduction. São apresentadas, também, análises probabilísticas pelo método de Monte Carlo, adotando amostragem do tipo Hipercubo Latino.

As análises de estabilidade foram realizadas considerando dois momentos distintos da obra, ao final da construção da quarta berma de alteamento, e após a dissipação total dos excessos de poropressão induzidos pelo carregamento imposto pelas quatro bermas de alteamento.

Como forma de assegurar que houvesse compatibilidade entre os resultados obtidos pelos métodos de equilíbrio limite e tensão x deformação, as poropressões calculadas nas análises de tensão x deformação foram exportadas para o modelo de equilíbrio limite, evitando assim distorções que podem ser provocadas por diferenças no algoritmo de fluxo dos softwares. A exportação do campo de poropressões do modelo de tensão x deformação para os modelos de equilíbrio limite apresenta como vantagem, também, a realização de análises de estabilidade sobre campos de distribuições de poropressões mais complexos, capazes de considerar não apenas as poropressões em fluxo permanente mais também os excessos de poropressão induzidos por carregamentos não drenados, parcialmente dissipados durante o tempo de construção.

Uma vez que o problema apresenta 6 variáveis aleatórias, para utilização do método FOSM, é necessário realizar um número mínimo de 7 análises $(n+1)$ para cada método, para cada momento da obra, além de uma análise de Monte Carlo para cada momento da obra.

Para o método FOSM, a derivada parcial de FS em relação a cada parâmetro $(\delta F S / \delta x i)$ foi definida por meio do coeficiente angular da reta formada pelos valores de FS obtidos a partir de acréscimos e decréscimos de $10 \%$ nos valores médios de cada parâmetro. A Figura 3-13 exemplifica o método de cálculo das derivadas parciais de FS em relação aos parâmetros admitidos como variáveis aleatórias. 


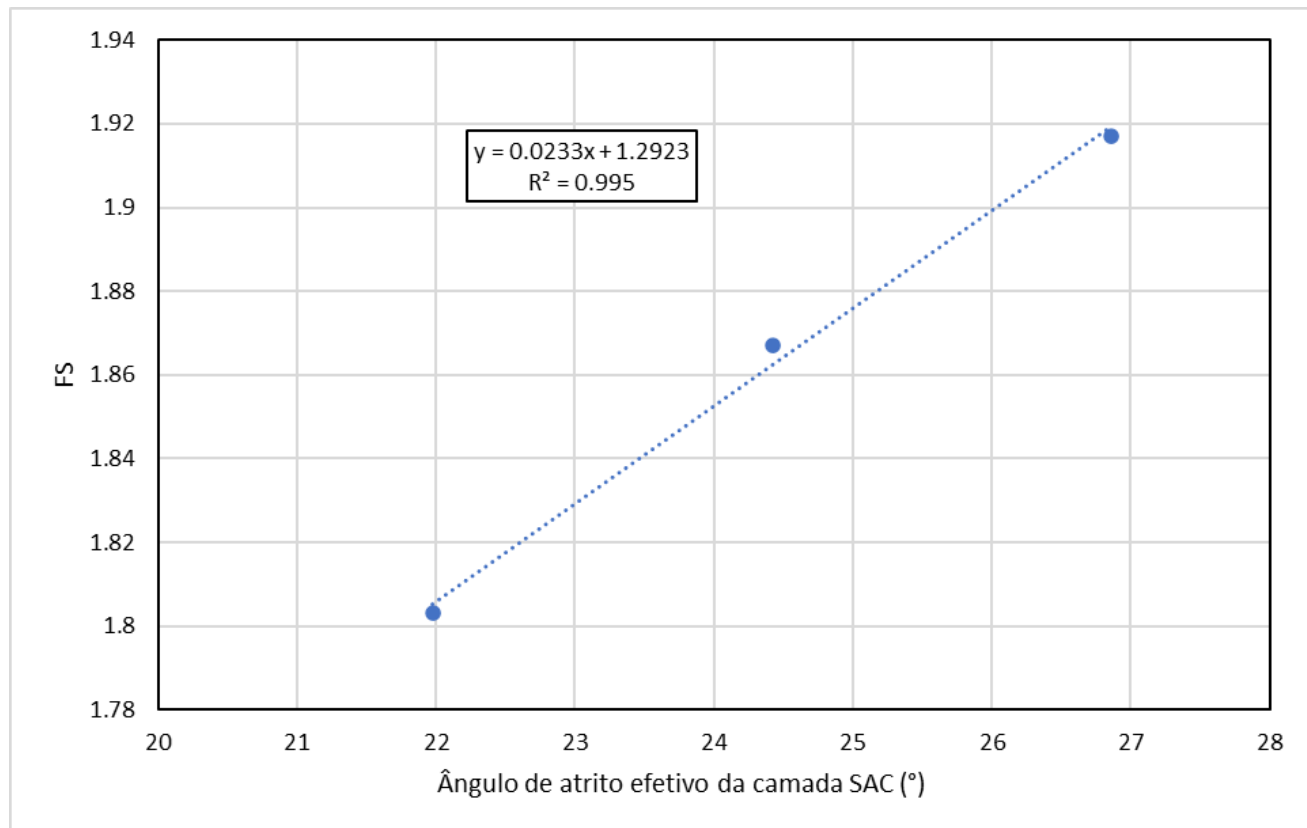

Figura 3-13 - Cálculo da derivada parcial de FS em relação ao ângulo de atrito do SAC

O procedimento descrito foi repetido para cada método de cálculo e para cada campo escalar de poropressões, resultando em um total de 52 análise de equilíbrio limite e 26 análises de tensão x deformação para o método FOSM. Adicionalmente foram realizadas quatro análises de equilíbrio limite probabilísticas pelo método de Monte Carlo, totalizando 82 análises. 


\section{4}

\section{Análise dos Resultados}

Este capítulo tem por finalidade apresentar os resultados obtidos para cada cenário de análise, pela aplicação dos métodos FOSM e Monte Carlo.

\section{1. Aplicação do Método FOSM}

\section{Análises de tensão $x$ deformacão}

A Figura 4-1 apresenta a superfície de ruptura crítica obtida pelo método Phi-c Reduction, apresentada pela distorção incremental do modelo, no cenário pós construtivo, quando as poropressões na fundação atingem seu pico. Esta análise considera os valores médios de todos os parâmetros variáveis.

Observa-se que a superfície de ruptura crítica parte da extremidade de montante do platô do aterro paralisado, saindo próximo do dreno de pé da barragem. A superfície é relativamente profunda, tangenciando a interface entre o SSG e o Saprolito de Gnaisse. Analisando a contribuição da fundação para a estabilidade da seção, observa-se que a maior parte da superfície de ruptura crítica atravessa o SSG, enquanto o SAC corresponde pela menor parcela. Ao se analisar o diagrama de excessos de poropressão na fundação, nota-se que a base da superfície de ruptura atravessa a região onde ocorrem os maiores excessos de poropressão, o que se justifica pela redução das tensões efetivas nessa região. A Figura 4-2 apresenta a influência relativa de cada parâmetro na variância do FS das análises Phi-c Reduction. 


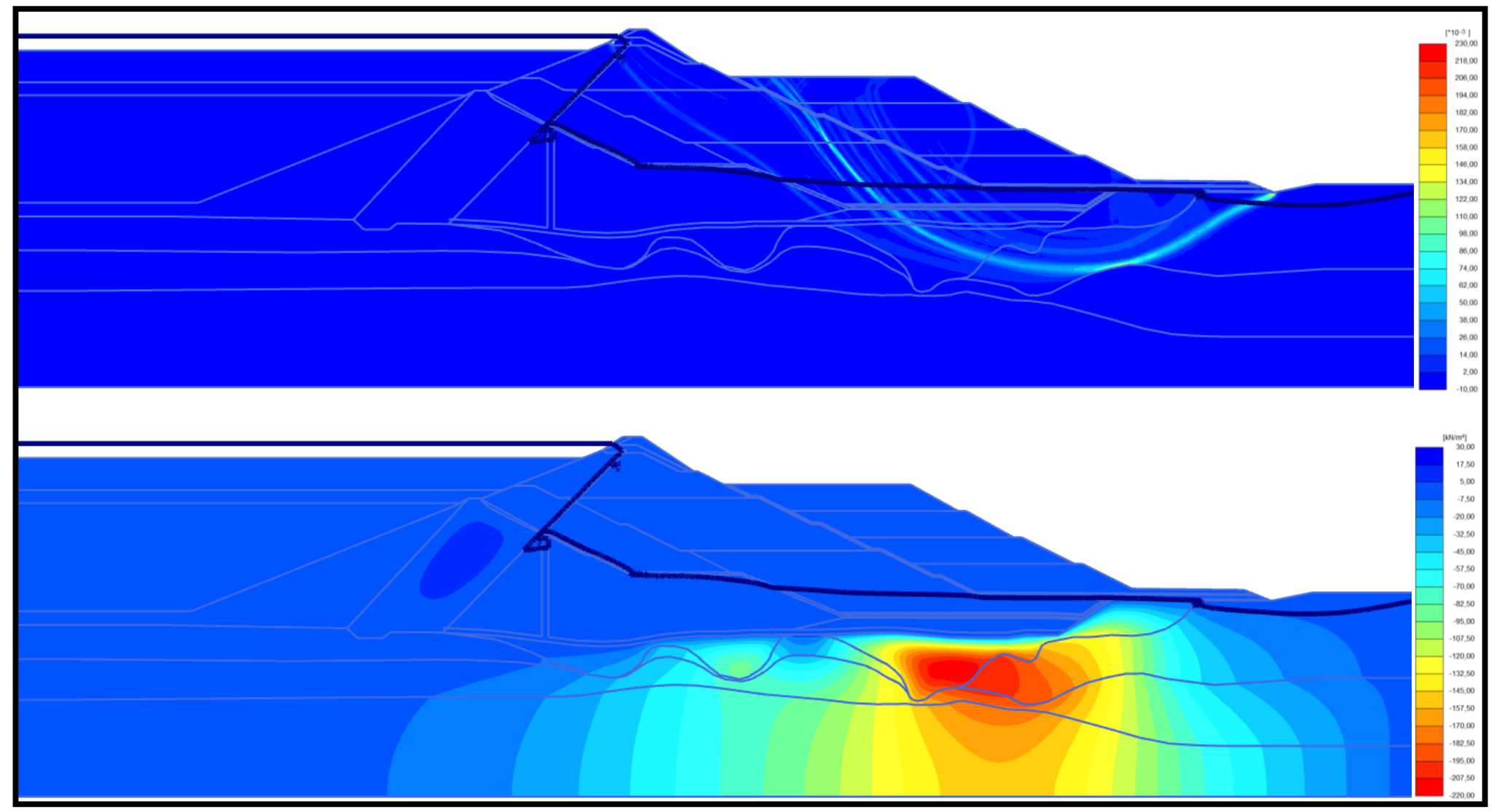

Figura 4-1 - a) superfície de ruptura crítica no cenário pós construtivo b) escalar dos excessos de poropressão na fundação no cenário pós construtivo 


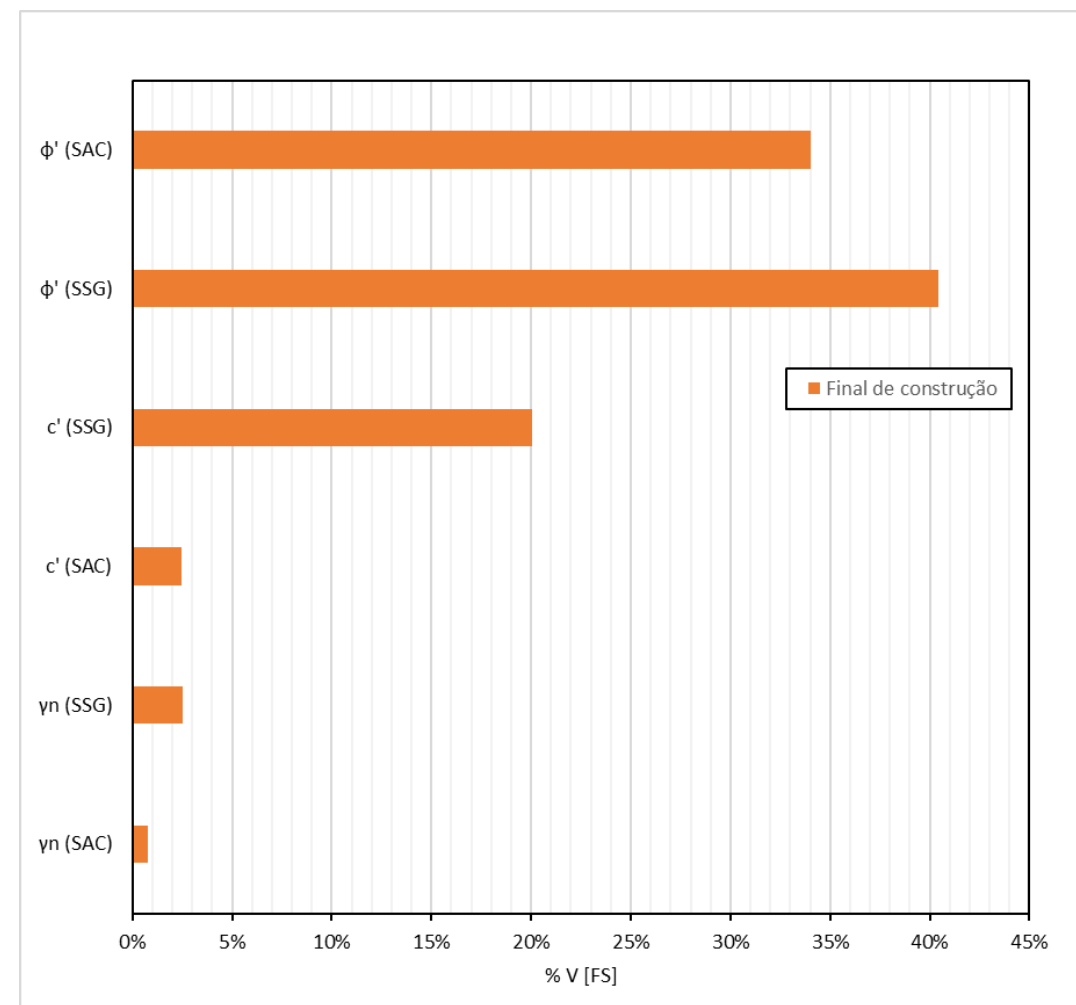

Figura 4-2 - Influência relativa dos parâmetros variáveis na variância do FS

- Método Phi-c Reduction - Final de Construção

Por se tratar de uma superfície de ruptura profunda, a influência relativa do ângulo de atrito dos materiais tende a ser preponderante, pois no critério de MohrCoulomb a magnitude da parcela friccional aumenta com a tensão de confinamento, enquanto a parcela coesiva é fixa, tendo, em geral, maior influência em superfícies de ruptura mais rasas.

Outro ponto de destaque nos resultados é a discrepância entre a influência da coesão do SSG e a coesão do SAC. Essa diferença se justifica pelo fato de o maior trecho da superfície de ruptura estar situado na camada SSG, o que naturalmente aumenta a influência relativa dos parâmetros deste material para o FS. Por dedução lógica, a mesma discrepância deveria ocorrer com a influência relativa dos ângulos de atrito. Entretanto, há de se observar que a camada SAC está submetida a elevadas tensões de confinamento, o que torna sua resistência ao cisalhamento altamente condicionada pelo ângulo de atrito, fazendo com que a influência deste parâmetro no FS seja grande, mesmo que haja em uma porção limitada da superfície de ruptura.

No segundo cenário de análise, após a dissipação total dos excessos de poropressão, o ponto de entrada da superfície de ruptura crítica migra do platô 
formado pelo maciço do último alteamento, para o limite de montante da crista da barragem, aumentando significativamente o raio da superfície de instabilidade. $\mathrm{O}$ fenômeno responsável por esta alteração na posição da superfície tem origem no processo de adensamento da fundação da barragem.

Durante a construção das quatro bancadas de alteamento, houve um aumento progressivo dos excessos de poropressão na fundação da barragem. Com a dissipação desse excesso, os materiais da fundação sofreram deformação volumétrica, gerando recalques no maciço. No entanto, o significativo contraste de compressibilidade dos materiais de fundação somado ao alto mergulho dos contatos do perfil de intemperismo, propiciou a formação de uma zona de grandes distorções no contato entre os materiais SAC, SSG e Saprolito de Gnaisse. A Figura 4-3 ilustra, por meio da tensão cisalhante relativa, o aumento da mobilização de resistência no maciço e na fundação da barragem entre o cenário pós construtivo e o cenário pós dissipação de poropressão.

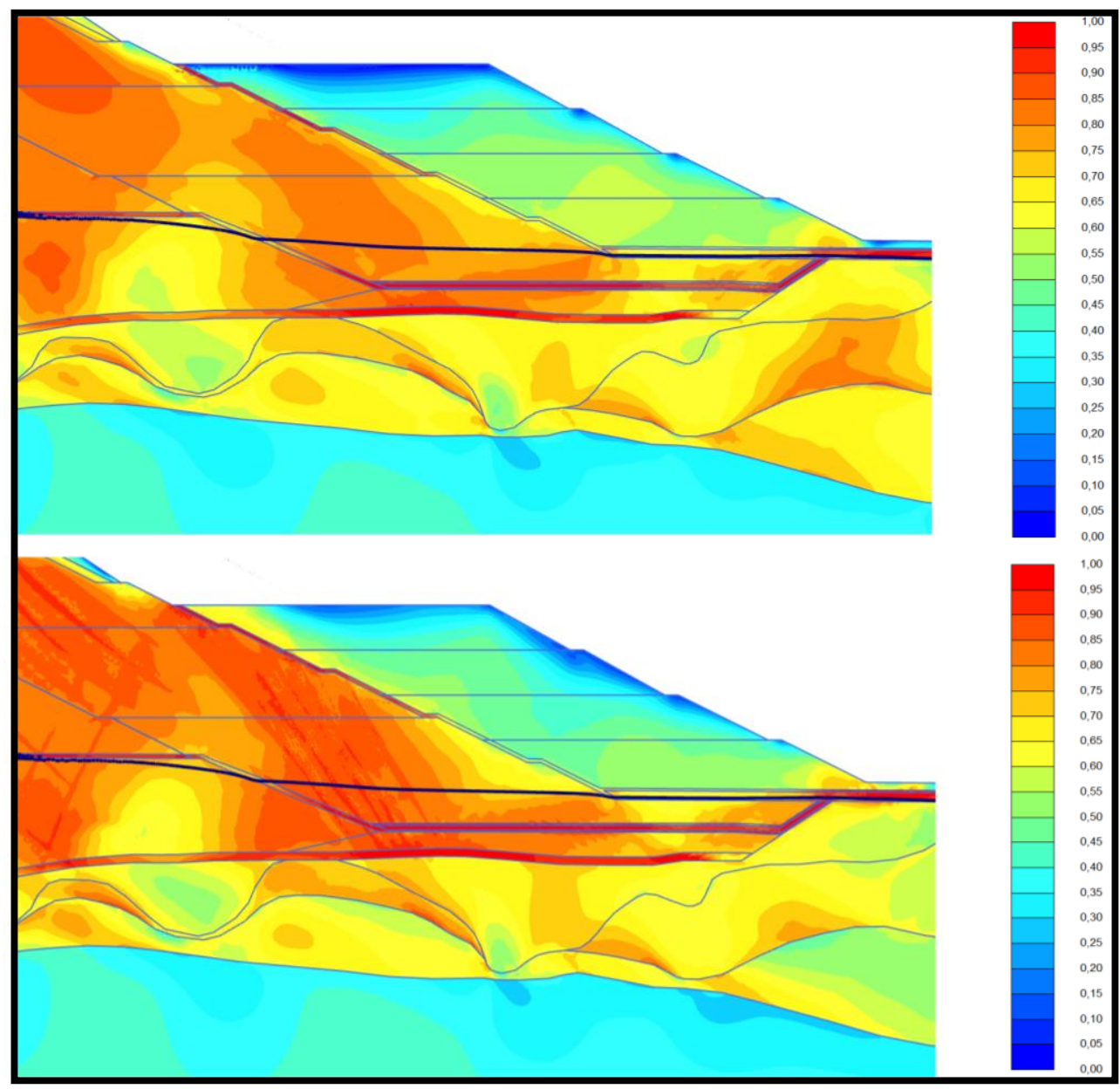

Figura 4-3 - Tensão cisalhante relativa a) cenário pós construtivo b) cenário pós dissipação dos excessos de poropressão 
Com a formação da banda de grandes deformações cisalhantes no contato entre os materiais de fundação ocorre um aumento da mobilização de resistência ao cisalhamento nesta região, formando uma zona de iminência de plastificação. Uma vez que o método Phi-c Reduction realiza um procedimento sucessivo de redução dos parâmetros de resistência dos materiais, a zona de contato, fragilizada pelas distorções, sofre plastificação, redistribuindo assim as tensões excedentes para os pontos adjacentes, que por sua vez também sofrem plastificação, induzindo a ocorrência do fenômeno de ruptura progressiva. Cabe ressaltar que evento descrito ocorre em decorrência do adensamento simulado no modelo numérico, o que não poderia ser previsto em um modelo de equilíbrio limite, o qual considera mobilização plena de resistência ao longo de toda a superfície de ruptura.

A Figura 4-4 apresenta a superfície de ruptura crítica obtida pelo método Phi-c Reduction no cenário pós dissipação de poropressão. 


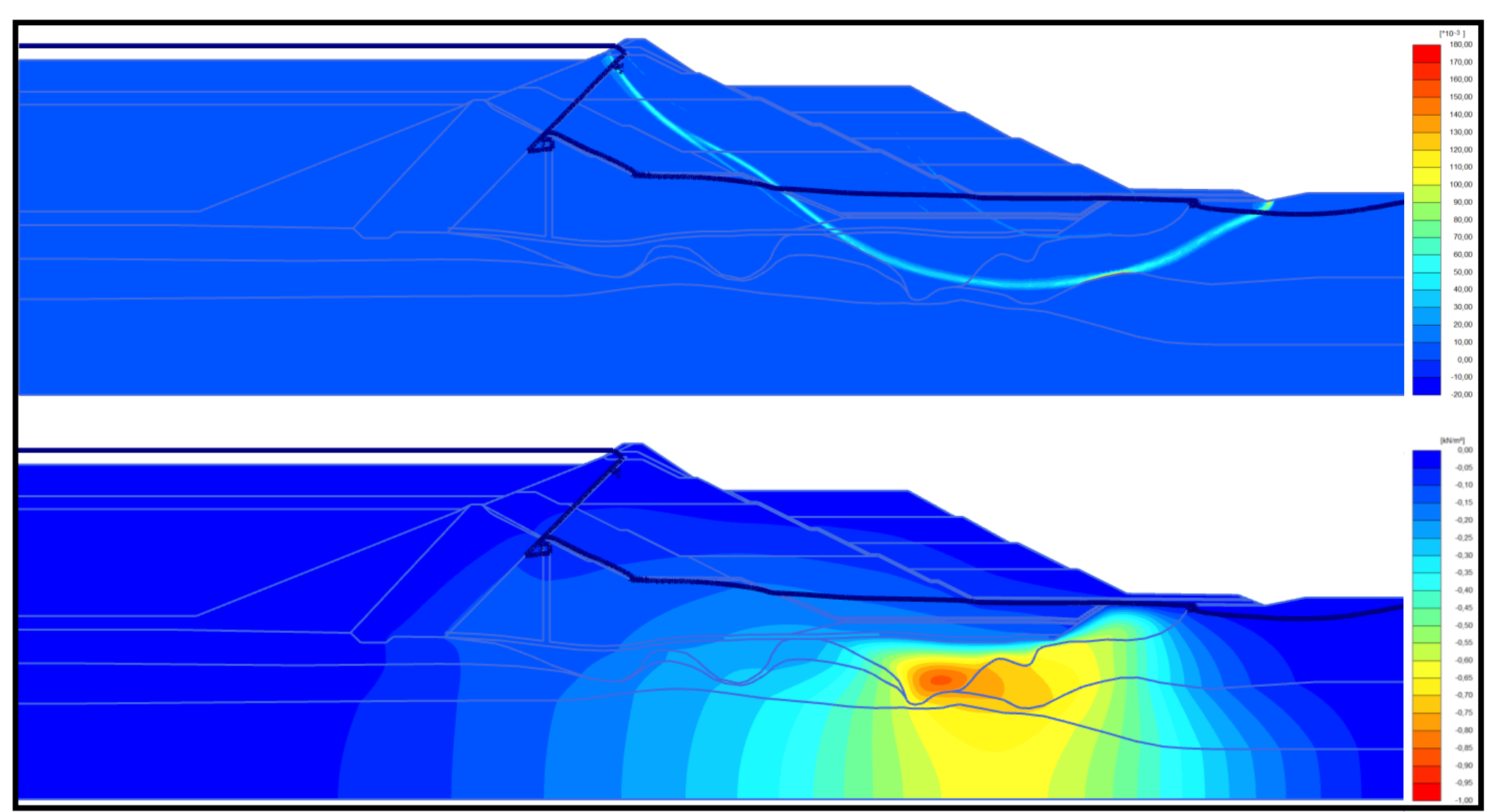

Figura 4-4 - a) superfície de ruptura crítica no cenário pós dissipação de poropressão b) escalar dos excessos de poropressão na fundação no cenário pós dissipação de poropressão 
$\mathrm{O}$ aumento do raio da superfície de ruptura naturalmente provoca uma alteração da influência relativa dos parâmetros na variância de FS.

A Figura 4-5 ilustra a variação da influência relativa dos parâmetros variáveis para a variância de FS pelo método FOSM.

Com o aprofundamento da superfície de ruptura, somado ao aumento das tensões efetivas na fundação por efeito do adensamento. O ângulo de atrito da camada SAC aumenta sua participação relativa na variância de FS, pelo aumento da magnitude da parcela friccional do critério de Mohr-Coulomb. Por outro lado, o ângulo de atrito e a coesão da camada SSG tornam-se menos influentes, pois, com o aumento do raio da superfície, a resistência mobilizada por essa camada se torna menor, em proporção à condição apresentada no cenário anterior. Não foram registradas variações significativas na influência relativa dos demais parâmetros para a variância de FS entre os dois cenários de análise.

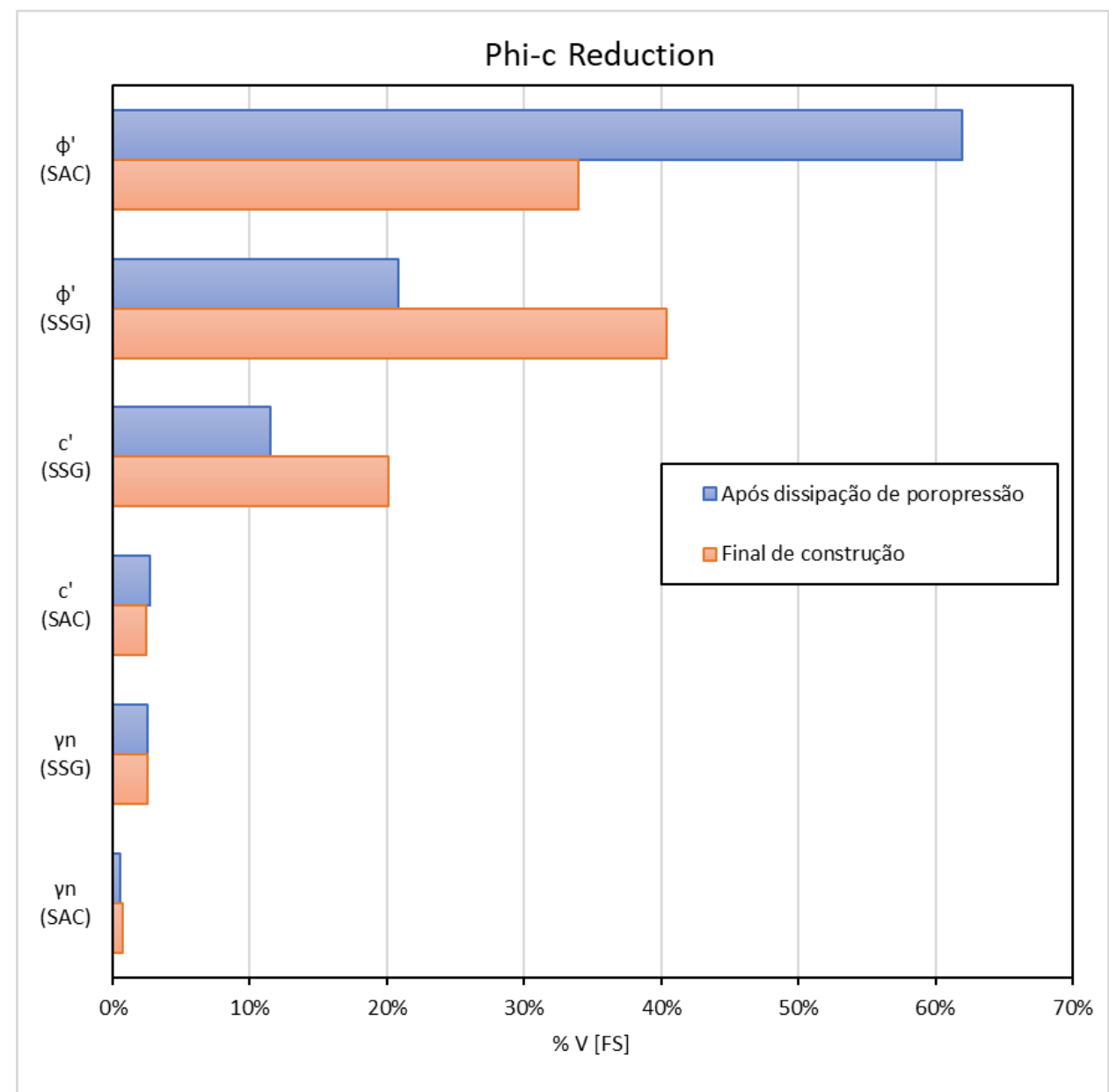

Figura 4-5 - Variação da influência dos parâmetros na variância de FS entre cenários de análise pelo método Phi-c Reduction 


\section{$\underline{\text { Análises de equilíbrio limite }}$}

A seguir são apresentados os resultados das análises de estabilidade pelos métodos de equilíbrio limite de Morgenstern-Price e Bishop Simplificado.

No cenário pós construtivo a influência relativa dos parâmetros apresentou boa concordância entre os métodos analisados. As análises de estabilidade determinísticas, isto é, considerando os valores médios dos parâmetros, apresentam superfície de ruptura que atravessam principalmente a camada SAC, apenas tangenciando a camada SSG, como pode ser observado na Figura 4-6.

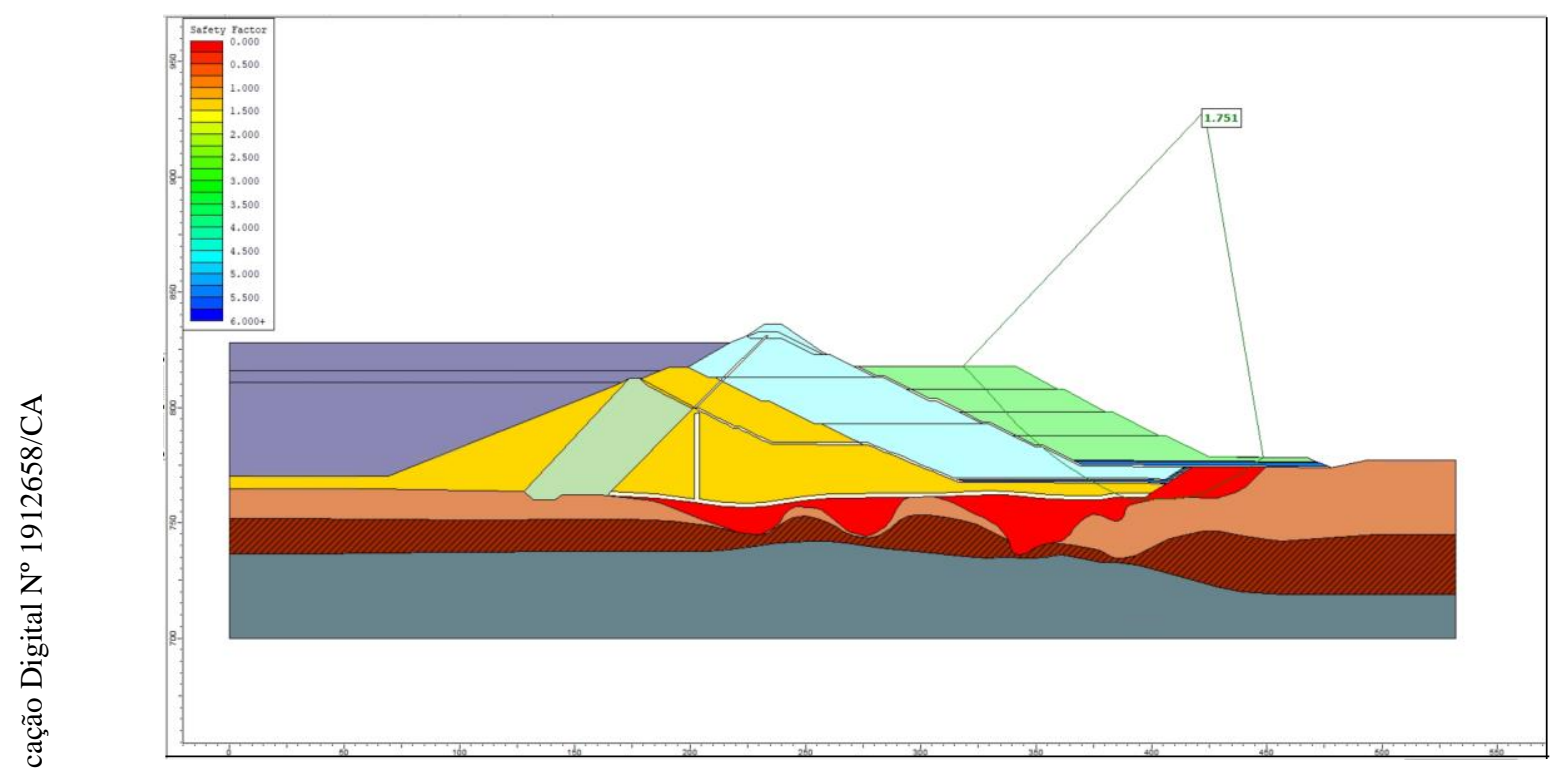

Figura 4-6 - Análise de estabilidade considerando parâmetros médios no cenário pós construtivo

A existência de excessos de poropressão na fundação neste cenário, observada de forma mais acentuada na camada SAC por ela apresentar o menor coeficiente de permeabilidade, propicia a ocorrência de superfícies críticas nesta camada, mesmo quando ocorre aumento dos parâmetros de resistência do material. A consistência com que as superfícies de ruptura ocorrem na camada SAC justifica a elevada influência de seu ângulo de atrito na variância do FS. O mesmo não ocorre para a coesão, pois a maioria das superfícies críticas ocorre em regiões profundas, onde a parcela friccional apresenta maior relevância para a resistência ao cisalhamento do material. 
A Figura 4-7 apresenta a influência relativa de cada parâmetro na variância de FS pelos métodos de equilíbrio limite de Morgenstern \& Price e Bishop Simplificado, no cenário pós construtivo.

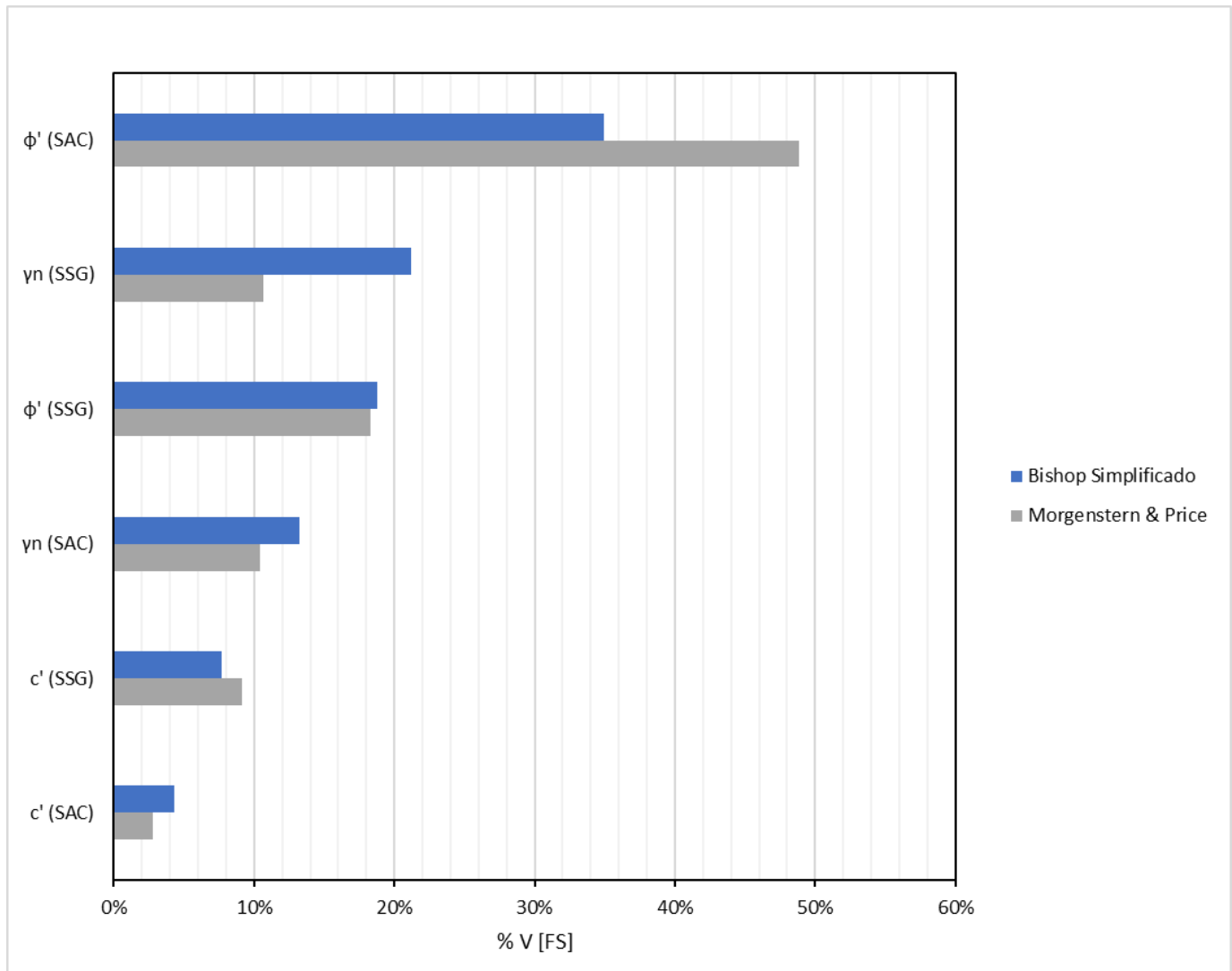

Figura 4-7 - Influência relativa dos parâmetros na variância de FS nos métodos de equilíbrio limite no cenário pós construtivo

No cenário pós dissipação dos excessos de poropressão, também se observa boa concordância entre os métodos na influência relativa dos parâmetros. Um ponto de destaque é a elevada influência da coesão do SSG em ambos os métodos, que chega a ultrapassar a marca de $50 \%$ no método de Morgenstern \& Price. Esse fato se explica por dois fatores. Como pode ser verificado na Figura 4-8, no cenário pós construtivo a superfície de ruptura encontra-se majoritariamente inserida na camada SSG. Quando os parâmetros de resistência desta camada sofrem aumento, a superfície de ruptura crítica migra da camada SSG para a camada SAC, aferindo assim um pequeno aumento no FS. Em contrapartida, quando os parâmetros da camada SSG sofrem redução, a superfície de ruptura permanece na mesma posição da condição média, apresentada na Figura 4-8, aumentando assim a influência relativa dos parâmetros do SSG, uma vez que este estudo considera tanto os acréscimos e decréscimos para aproximação da derivada parcial $\delta F S / \delta x i$. Desse 
modo, pode-se concluir que, neste caso, a variação decremental dos parâmetros produziu maior efeito no FS do que a variação incremental. Entretanto, o fenômeno é produto da consideração de uma superfície de ruptura livre. O segundo fator que contribui para a grande influência da coesão do SSG para o FS, é a elevada incerteza atribuída ao parâmetro, que pode ser observada por seu elevado coeficiente de variação.

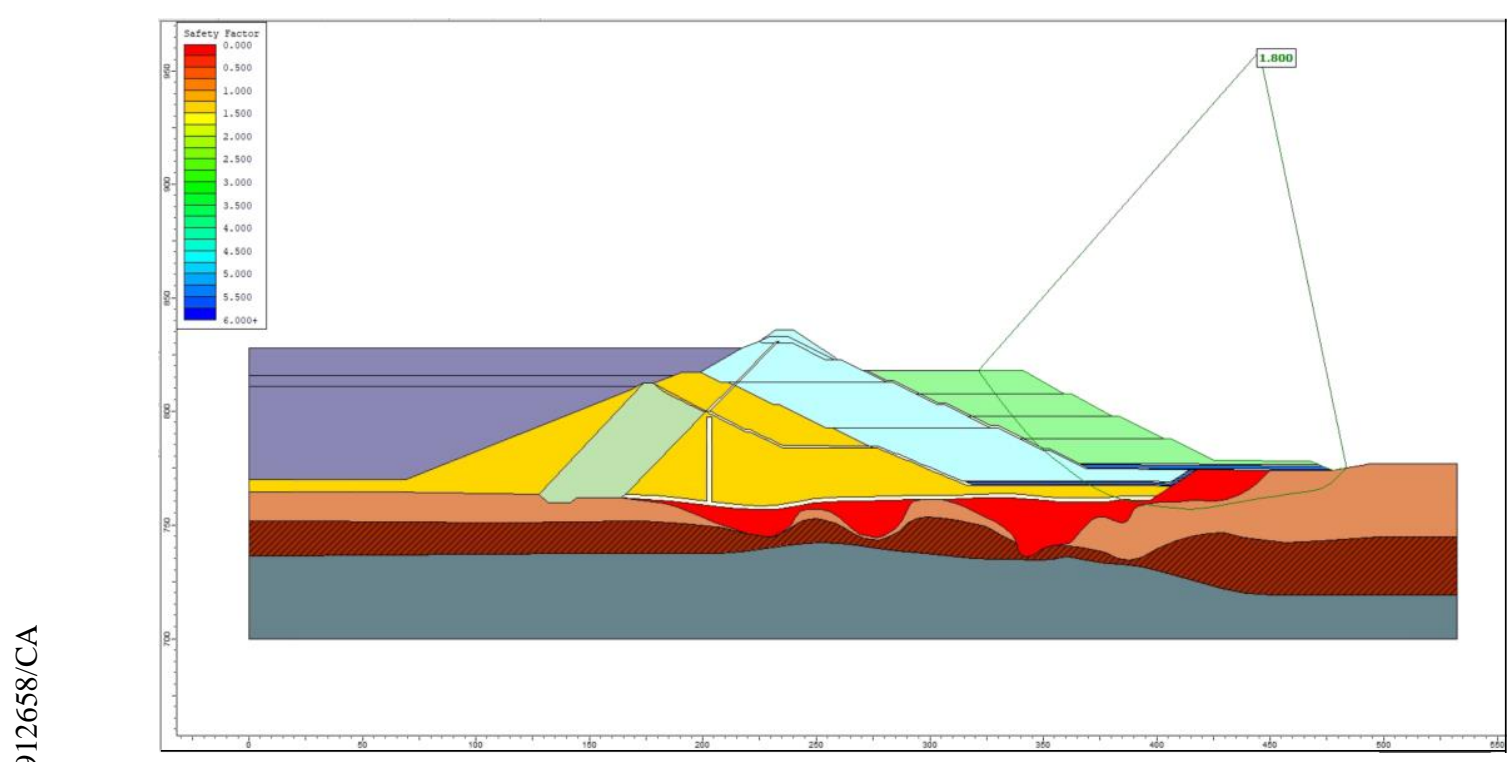

Figura 4-8 - Análise de estabilidade considerando parâmetros médios no cenário pós dissipação de poropressão

A Figura 4-9 apresenta a influência relativa de cada parâmetro na variância de FS pelos métodos de equilíbrio limite de Morgenstern \& Price e Bishop Simplificado no cenário pós dissipação de poropressão. 


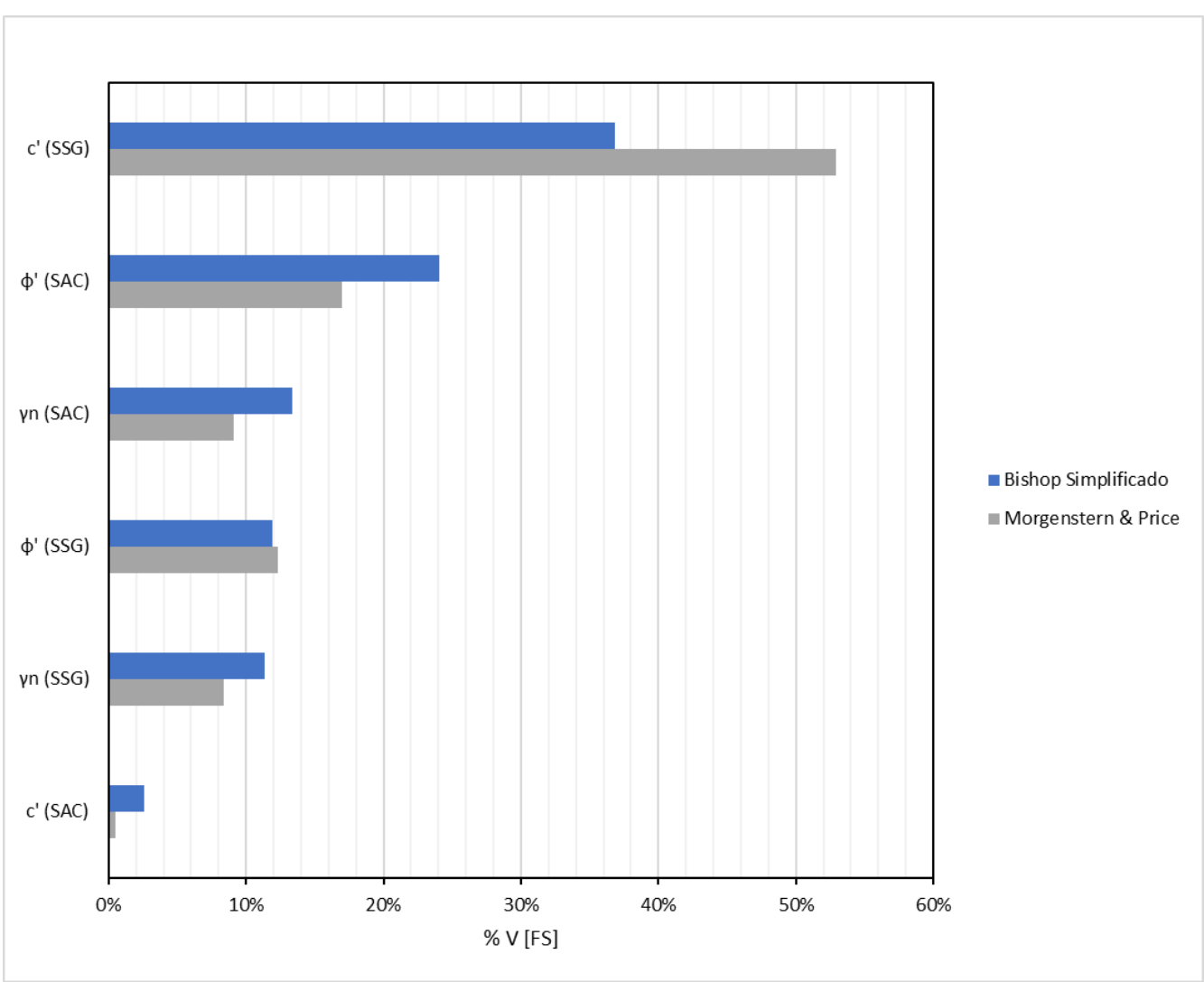

Figura 4-9 - Influência relativa dos parâmetros na variância de FS nos métodos de equilíbrio limite no cenário pós dissipação de poropressão

As Figura 4-10 Figura 4-11 apresentam a comparação das influências dos parâmetros para os três métodos considerados no estudo. Nota-se uma coerência entre os resultados dos métodos de Bishop Simplificado e Morgenstern \& Price, tendo o segundo se destacado pela maior influência da coesão do material SSG para o FS. Observa-se também uma redução na influência do ângulo de atrito da camada SAC após a dissipação dos excessos de poropressão. Em contrapartida, a coesão da camada SSG torna-se o parâmetro mais relevante para a variância de FS nesse cenário.

Os resultados do método numérico Phi-c Reduction destoam dos demais por apresentar distribuição de influências relativas incompatível com o observado nos métodos de equilíbrio limite. A divergência observada pode estar relacionada com a forma com que os métodos calculam o FS. Enquanto no método de equilíbrio limite o FS é calculado considerando a mobilização total de resistência dos materiais ao longo da superfície de ruptura, o método de elementos finitos considera a redistribuição de tensões provocada pela plastificação dos elementos, o que, por si só, pode induzir a formação zonas de fragilidade no maciço. 


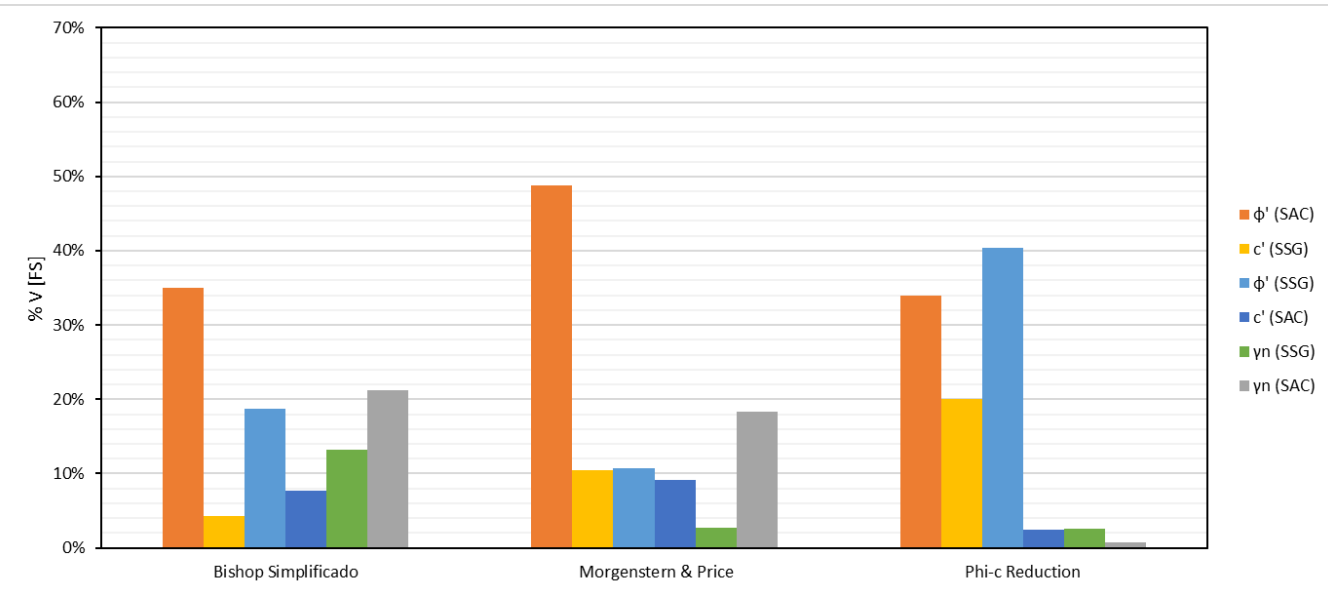

Figura 4-10 - Comparação da influência dos parâmetros na variância do FS para os três métodos no cenário pós construtivo

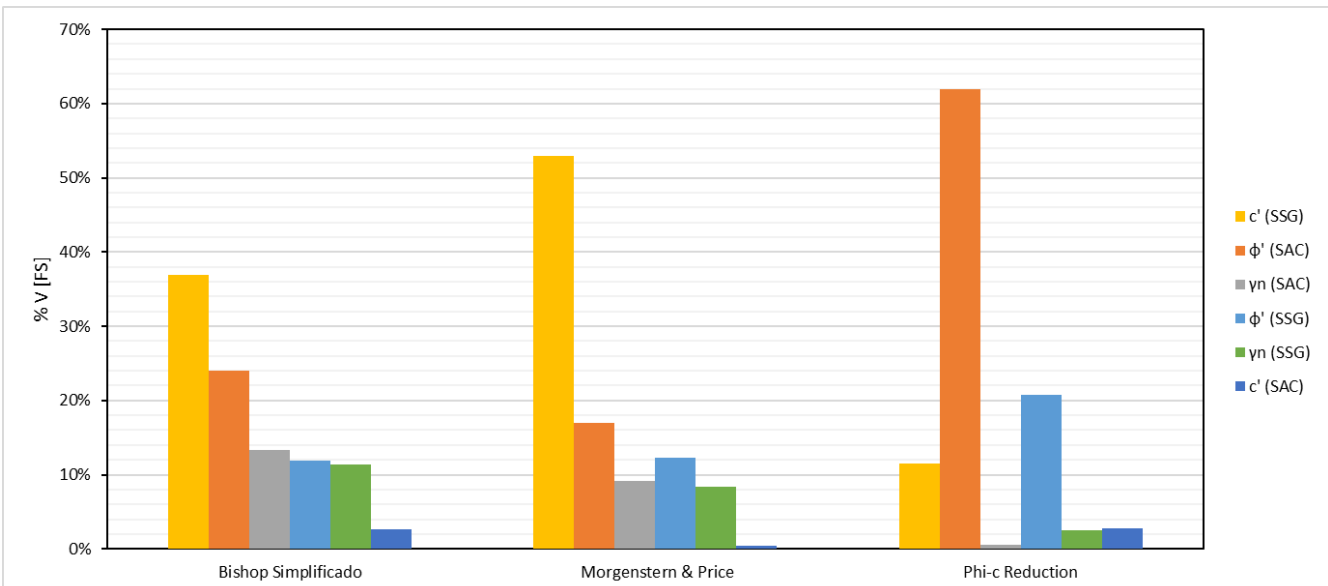

Figura 4-11 - Comparação da influência dos parâmetros na variância do FS para os três métodos no cenário pós dissipação de poropressão

A Tabela 4-1 resume os resultados das análises probabilísticas FOSM realizadas pelos três métodos de cálculo de FS adotados no estudo.

Tabela 4-1 - Resultados das análises probabilísticas pelo Método FOSM

\begin{tabular}{|c|c|c|c|c|c|c|}
\hline $\begin{array}{l}\text { Método de } \\
\text { estabilidade }\end{array}$ & Cenário & $E[F S]$ & $\mathrm{V}[\mathrm{FS}]$ & $\sigma[\mathrm{FS}]$ & $\beta$ & PR \\
\hline \multirow{2}{*}{$\begin{array}{c}\text { Bishop } \\
\text { Simplificado }\end{array}$} & $\begin{array}{c}\text { Final de } \\
\text { construção }\end{array}$ & 1,51 & 0,01750 & 0,1322 & 3,90 & $1: 2,15 \mathrm{E}+04$ \\
\hline & $\begin{array}{l}\text { Após dissipação } \\
\text { de poropressão }\end{array}$ & 1,64 & 0,02047 & 0,1431 & 4,47 & $1: 2,59 \mathrm{E}+05$ \\
\hline \multirow{2}{*}{$\begin{array}{l}\text { Morgernstern } \\
\text { \&Price }\end{array}$} & $\begin{array}{l}\text { Final de } \\
\text { construção }\end{array}$ & 1,75 & 0,02138 & 0,1462 & 5,13 & $1: 7,09 E+06$ \\
\hline & $\begin{array}{l}\text { Após dissipação } \\
\text { de poropressão }\end{array}$ & 1,80 & 0,02462 & 0,1569 & 5,59 & $1: 8,85 E+07$ \\
\hline
\end{tabular}




\begin{tabular}{ccccccc}
\cline { 2 - 3 } $\begin{array}{c}\text { Phi-c } \\
\text { Reduction }\end{array}$ & $\begin{array}{c}\text { Final de } \\
\text { construção }\end{array}$ & 1,66 & 0,01843 & 0,1357 & 4,87 & $1: 1,84 \mathrm{E}+06$ \\
\cline { 2 - 6 } & $\begin{array}{c}\text { Após dissipação } \\
\text { de poropressão }\end{array}$ & 1,86 & 0,01943 & 0,1394 & 6,21 & $1: 4,02 \mathrm{E}+09$ \\
\hline
\end{tabular}

A Figura 4-12 mostra a variação dos valores de PR obtidos pelo Método FOSM entre os dois cenários analisados neste estudo.

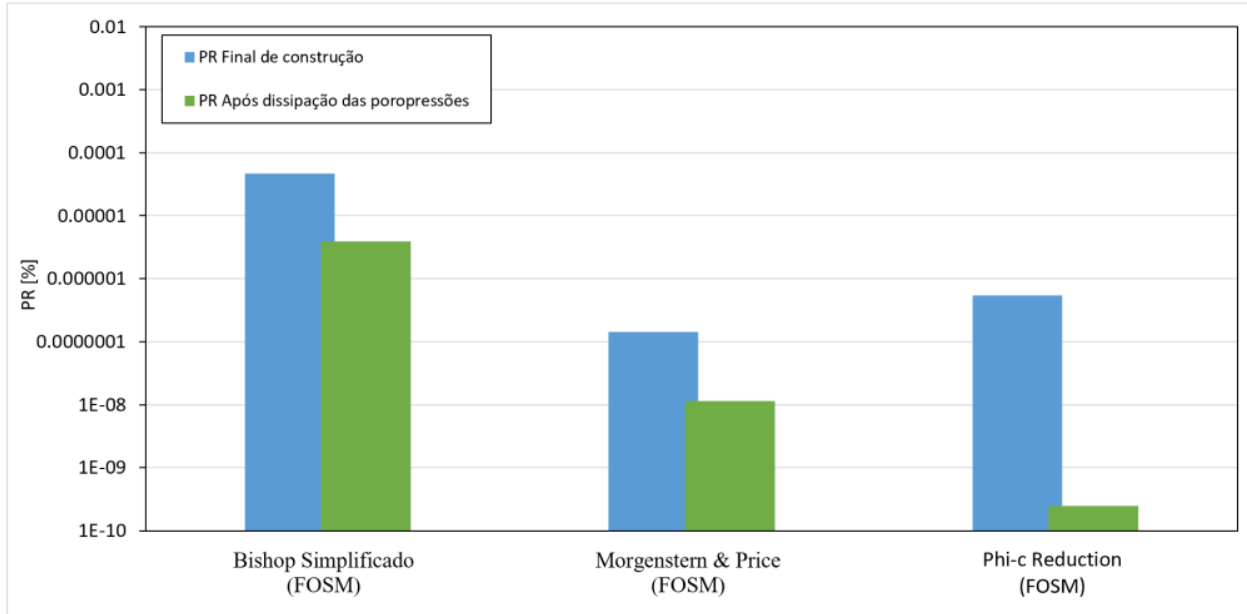

Figura 4-12 - Probabilidade de ruptura nos dois cenários de análise pelo método de FOSM

O Apêndice A e o Apêndice B deste trabalho apresentam os resultados de todas as análises realizadas pelo método FOSM.

\section{2.}

\section{Aplicação do Método de Monte Carlo}

Para a aplicação do método de Monte Carlo foram adotados como dados de entrada os parâmetros apresentados na Tabela 3-4. O software utilizado para os cálculos foi o Slide 2.0, da Rocscience, com método de amostragem por Hipercubo Latino e algoritmo de busca de superfícies livre.

A Tabela 4-2 apresenta os resultados das análises probabilísticas pelo método de Monte Carlo nos dois cenários de análise. Assim como no método FOSM, nota-se um aumento no FS médio e no índice de confiabilidade após a dissipação dos excessos de poropressão, que reflete em uma redução da probabilidade de ruptura da estrutura. 
Tabela 4-2 -Resultados das análises probabilísticas pelo Método de Monte Carlo

\begin{tabular}{|c|c|c|c|c|c|c|}
\hline $\begin{array}{l}\text { Método de } \\
\text { estabilidade }\end{array}$ & Cenário & FS $_{\text {MÉDIO }}$ & V [FS] & $\sigma[\mathrm{FS}]$ & $\beta$ & PR \\
\hline \multirow[b]{2}{*}{$\begin{array}{c}\text { Bishop } \\
\text { Simplificado }\end{array}$} & $\begin{array}{c}\text { Final de } \\
\text { construção }\end{array}$ & 1,47 & 0,01522 & 0,1234 & 3,84 & $1: 1,69 \mathrm{E}+04$ \\
\hline & $\begin{array}{c}\text { Após } \\
\text { dissipação de } \\
\text { poropressão }\end{array}$ & 1,56 & 0,01615 & 0,1271 & 4,42 & $1: 2,04 \mathrm{E}+05$ \\
\hline \multirow[b]{2}{*}{$\begin{array}{l}\text { Morgernstern } \\
\text { \& Price }\end{array}$} & $\begin{array}{c}\text { Final de } \\
\text { construção }\end{array}$ & 1,66 & 0,01874 & 0,1369 & 4,86 & $1: 1,75 \mathrm{E}+06$ \\
\hline & $\begin{array}{c}\text { Após } \\
\text { dissipação de } \\
\text { poropressão }\end{array}$ & 1,71 & 0,01753 & 0,1324 & 5,37 & $1: 2,54 \mathrm{E}+07$ \\
\hline
\end{tabular}

A Figura 4-13 ilustra a variação da probabilidade de ruptura pelo método de Monte Carlo entre os dois cenários analisados neste estudo.

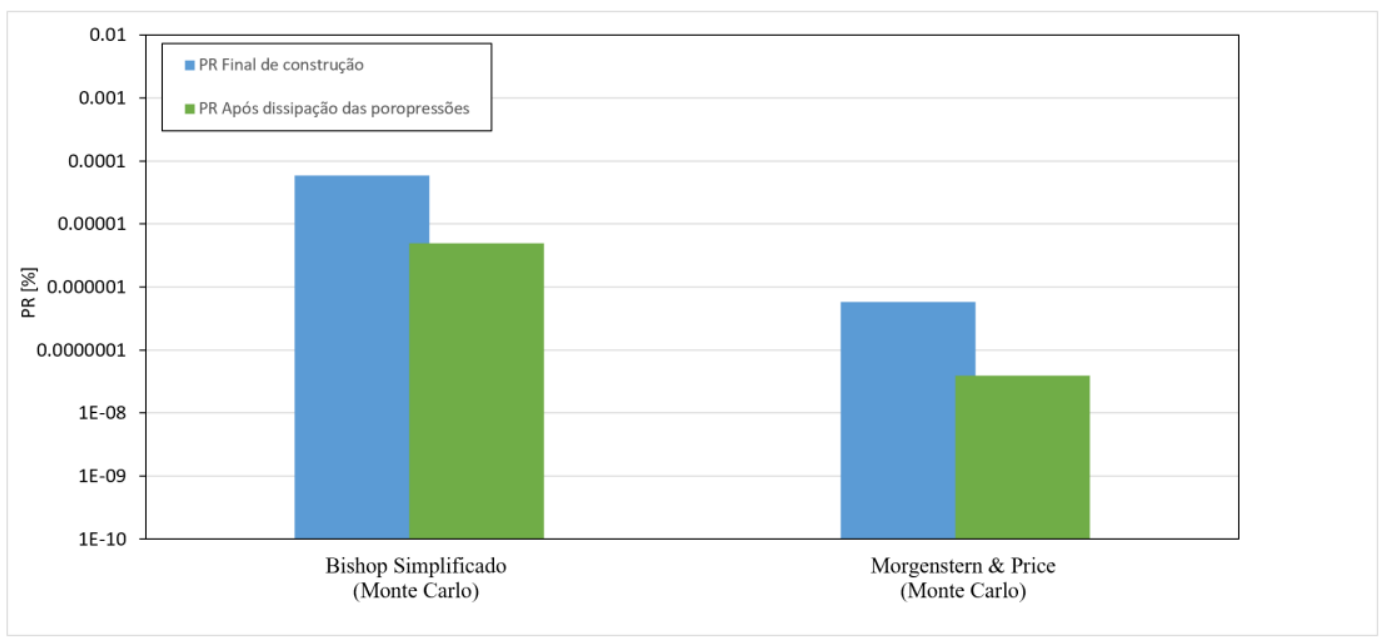

Figura 4-13 - Probabilidade de ruptura nos dois cenários de análise pelo Método de Monte Carlo

\section{3.}

\section{Comparação dos Resultados}

Os resultados obtidos a partir das análises realizadas pelo método FOSM, utilizando elementos finitos e equilíbrio limite, e pelo método de Monte Carlo por equilíbrio limite, foram comparados e resumidos na Tabela 4-3. 
Tabela 4-3 - Resumo dos resultados das análises probabilísticas

\begin{tabular}{|c|c|c|c|c|c|c|}
\hline \multicolumn{7}{|c|}{ Método FOSM } \\
\hline $\begin{array}{c}\text { Método de } \\
\text { estabilidade }\end{array}$ & Cenário & $\begin{array}{c}\mathbf{E} \\
{[\mathbf{F S}]}\end{array}$ & $\mathbf{V}[\mathbf{F S}]$ & $\sigma[\mathrm{FS}]$ & $\beta$ & $\mathbf{P R}$ \\
\hline \multirow{2}{*}{$\begin{array}{c}\text { Bishop } \\
\text { Simplificado }\end{array}$} & $\begin{array}{c}\text { Final de } \\
\text { construção }\end{array}$ & 1,51 & 0,01750 & 0,1322 & 3,90 & $1: 2,15 \mathrm{E}+04$ \\
\hline & $\begin{array}{l}\text { Após dissipação } \\
\text { de poropressão }\end{array}$ & 1,64 & 0,02047 & 0,1431 & 4,47 & $1: 2,59 \mathrm{E}+05$ \\
\hline \multirow{2}{*}{$\begin{array}{l}\text { Morgernstern \& } \\
\text { Price }\end{array}$} & $\begin{array}{l}\text { Final de } \\
\text { construção }\end{array}$ & 1,75 & 0,02138 & 0,1462 & 5,13 & $1: 7,09 \mathrm{E}+06$ \\
\hline & $\begin{array}{l}\text { Após dissipação } \\
\text { de poropressão }\end{array}$ & 1,80 & 0,02462 & 0,1569 & 5,59 & $1: 8,85 \mathrm{E}+07$ \\
\hline \multirow{2}{*}{ Phi-c Reduction } & $\begin{array}{c}\text { Final de } \\
\text { construção }\end{array}$ & 1,66 & 0,01843 & 0,1357 & 4,87 & $1: 1,84 \mathrm{E}+06$ \\
\hline & $\begin{array}{l}\text { Após dissipação } \\
\text { de poropressão }\end{array}$ & 1,86 & 0,01943 & 0,1394 & 6,21 & $1: 4,02 E+09$ \\
\hline \multicolumn{7}{|c|}{ Método de Monte Carlo } \\
\hline \multirow{2}{*}{$\begin{array}{c}\text { Bishop } \\
\text { Simplificado }\end{array}$} & $\begin{array}{c}\text { Final de } \\
\text { construção }\end{array}$ & 1,47 & 0,01522 & 0,1234 & 3,84 & $1: 1,69 \mathrm{E}+04$ \\
\hline & $\begin{array}{l}\text { Após dissipação } \\
\text { de poropressão }\end{array}$ & 1,56 & 0,01615 & 0,1271 & 4,42 & $1: 2,04 \mathrm{E}+05$ \\
\hline \multirow{2}{*}{$\begin{array}{l}\text { Morgernstern \& } \\
\text { Price }\end{array}$} & $\begin{array}{c}\text { Final de } \\
\text { construção }\end{array}$ & 1,66 & 0,01874 & 0,1369 & 4,86 & $1: 1,75 \mathrm{E}+06$ \\
\hline & $\begin{array}{l}\text { Após dissipação } \\
\text { de poropressão }\end{array}$ & 1,71 & 0,01753 & 0,1324 & 5,37 & $1: 2,54 \mathrm{E}+07$ \\
\hline
\end{tabular}

Em todas as análises realizadas observa-se uma clara tendência de redução da PR entre o cenário pós construtivo e o cenário pós dissipação de poropressão. A redução ocorre devido ao ganho de resistência provocado pelo aumento das tensões efetivas na fundação, entre os dois cenários. Esse fenômeno é particularmente acentuado na análise pelo método Phi-c Reduction, na qual o índice de confiabilidade apresentou aumento de 28 \% após a dissipação dos excessos de poropressão, contra uma variação percentual média de $12 \%$ nas demais análises.

Os índices de confiabilidade obtidos pelos métodos Bishop Simplificado e Morgenstern \& Price apresentaram variações de ordem similar com a alteração do campo de poropressões entre os cenários de análises. Os valores de $\beta$ obtidos nas análises pelo método de Bishop Simplificado apresentaram, respectivamente pelos métodos FOSM e Monte Carlo, aumento $10 \%$ e $9 \%$, entre um cenário e outro, contra um aumento de $15 \%$ e $14 \%$, no Método de Morgernstern \& Price. 
Nota-se que os valores de PR e $\beta$ obtidos pelo Método de Bishop Simplificado nas análises FOSM e Monte Carlo apresentaram grande consistência. O mesmo ocorre nas análises pelo Método Morgenstern \& Price, porém em menor grau.

Os valores de PR e $\beta$ obtidos pelo Método Phi-c Reduction no cenário pós construtivo, se mostram coerentes com aqueles obtidos pelo Método Morgernstern \& Price nas análises FOSM e Monte Carlo. Entretanto, no cenário pós dissipação de poropressão, a probabilidade de ruptura sofre redução substancial, destoando dos demais resultados.

Nota-se que o Método de Bishop Simplificado se mostrou o mais conservador, apresentando fatores de segurança menores e probabilidade de ruptura maiores em todos os cenários analisados pelo método FOSM.

A Figura 4-14 ilustra a comparação dos valores de PR e $\beta$, obtidos nos três diferentes métodos de cálculo de FS, pelos dois métodos probabilísticos empregados no estudo.

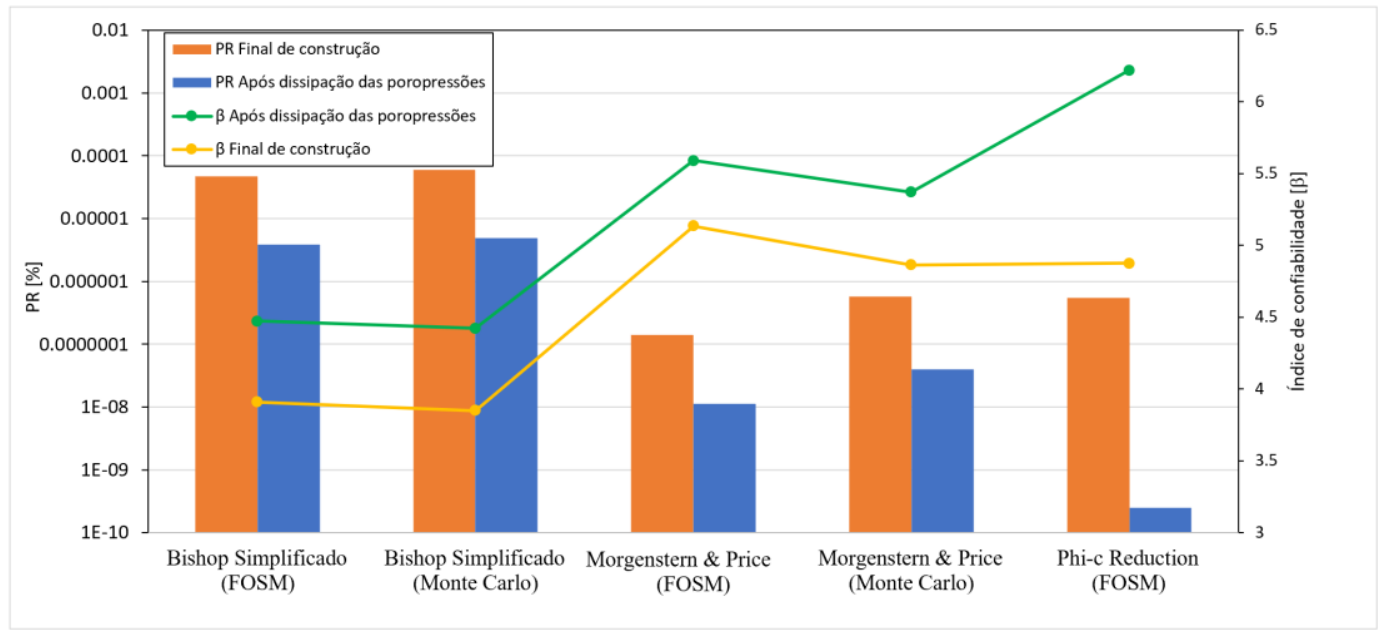

Figura 4-14 - Comparação das probabilidades de ruptura e índices de confiabilidade entre métodos 


\section{5 \\ Conclusões}

As análises pelo método FOSM permitiram identificar que a influência relativa dos parâmetros incertos na variância do fator de segurança muda após a dissipação dos excessos de poropressão na fundação. $O$ fenômeno, que foi observado nos três métodos de estabilidade adotados, ocorre devido à mudança de posição da superfície crítica de ruptura, após o aumento das tensões efetivas nas camadas antes afetadas pelo excesso de poropressão. O deslocamento das superfícies de ruptura para porções mais superficiais da fundação contribui para o aumento da influência relativa da coesão para a variância de FS.

No método FOSM, a participação relativa dos parâmetros para a variância de FS foi impactada pelo elevado grau de incerteza dos interceptos coesivos dos materiais SAC e SSG.

A definição de uma superfície de ruptura livre fez com que variações positivas (incrementais) nos parâmetros produzissem efeitos diferentes das variações negativas (decrementais), pois o algoritmo de busca altera a posição das superfícies de ruptura quando ocorrem variações de resistência nos materiais. A migração da superfície de ruptura se mostrou um fator determinante na influência dos parâmetros para a variância de FS no método FOSM.

A heterogeneidade do maciço e da fundação da barragem analisada pode ter contribuído para a frequente alteração de posição da superfície crítica de ruptura nas análises pelo método FOSM.

A discrepância observada na influência relativa dos parâmetros na variância de FS entre os métodos de equilíbrio limite e o método Phi-c Reduction, ressalta uma diferença relevante entre os métodos. O aumento da mobilização de resistência ao cisalhamento induzido pelas distorções no contato entre materiais com diferentes compressibilidades, induziu a formação de uma zona de fragilidade na qual se formam pontos plásticos durante o processo de redução dos parâmetros do método Phi-c Reduction. Esta plastificação gerou uma zona preferencial para formação das superfícies de ruptura críticas, que ocorrem em padrão progressivo. Tal fenômeno 
não pode ser reproduzido em análises de equilíbrio limite, pois estas não consideram taxas de mobilização de resistência diferentes ao longo das superfícies de ruptura.

Nas análises realizadas neste estudo, as diferenças observadas nos valores de PR entre os métodos de cálculo de FS foram maiores do que a diferença entre o cenário pós construtivo e pós dissipação de poropressão. Tal constatação não minimiza a importância do devido conhecimento das condições piezométricas de uma estrutura, mas reforça a importância que o método de cálculo pode ter sobre uma decisão em um projeto de engenharia. 


\section{6 Recomendações para Estudos Futuros}

Muitas das conclusões obtidas a partir do estudo de caso apresentado nesta dissertação se justificam pela opção feita pelo autor de considerar superfícies de ruptura livres. Dessa forma, a principal recomendação feita para pesquisas futuras é a avaliação das diferenças entre análises realizadas com superfícies de ruptura fixas e livres, em especial no caso de maciços heterogêneos, como o apresentado neste estudo. Posto isto, recomenda-se avaliação dos seguintes tópicos adicionais para estudos futuros.

- Uso de métodos numéricos para avaliação de segurança de barragens de rejeito;

- Aplicação de métodos probabilísticos a partir de campos de poropressão obtidos por métodos numéricos;

- Aplicação do método FOSM em avaliações de segurança de análises de tensão x deformação, como forma de avaliar a influência individual das incertezas no FS;

- Avaliação da influência do número de amostras adotado no Método de Monte Carlo para os valores de PR e $\beta$, em diferentes problemas geotécnicos;

- Estudo específico pelo método FOSM acerca da influência do uso de diferentes intervalos de variação de parâmetros, para estimativa das derivadas parciais de FS em relação aos parâmetros variáveis. Recomenda-se utilização de algoritmo de busca livre para as superfícies de ruptura. 


\section{7}

\section{Referências Bibliográficas}

ALBUQUERQUE FILHO, L.H. (2004). Avaliação do Comportamento Geotécnico de Barragens de Rejeitos de Minério de Ferro Através de Ensaios de Piezocone. Dissertação de Mestrado, Departamento de Engenharia Civil da Escola de Minas, Universidade Federal de Ouro Preto.

ANM. (2018). Ferro. Sumário Mineral Brasileiro. Agência Nacional de Mineração - ANM, 2018

BENZ, T. (2007). Small-strain Stiffness of Soils and its Numerical Consequences. Ph.D. Dissertation, University of Stuttgart.

BISHOP, A.W. (1955). The Use of the Slip Circle in the Stability Analysis of Slopes. Géotechnique, vol. 5 (1).

BITTAR, R. J. (2006). Caracterização Tecnológica de Rejeitos de Fosfato e Análises de Estabilidade Da Barragem de Rejeitos B5 da Bunge Fertilizantes S/A. Dissertação de Mestrado, Departamento de Engenharia Civil da Escola de Minas, Universidade Federal de Ouro Preto.

BRAGA, V. P. C. (2019). Análises Probabilísticas de Estabilidade de uma Barragem de Rejeito. Dissertação de Mestrado, Departamento de Engenharia Civil, PUC-Rio.

CARTER, J. P. (2006). Who Needs Constitutive Models?. Australian Geomechanics. 41. 1-27.

CHAKRABORTY, R. \& DEY, A. (2018). A Comparison of 1D and 2D Spatial. Variability in Probabilistic Slope Stability Analysis. ISGTI, Delhi, India.

CHOK, Y. H. et al. (2007). Effect of Spatial Variability on Reliability of Soil Slopes. Proceedings of the 10th Australia New Zealand Conference on Geomechanics Brisbane.

CHOK, Y. H. (2009). Modelling the Effects of Soil Variability and Vegetation on the Stability of Natural Slopes. PhD thesis, School of Civil, Environmental and Mining Engineering, University of Adelaide.

CORREA, S. M. B. B. (2003). Probabilidade e Estatística. $2^{a}$ edição, PUC Minas Virtual, Belo Horizonte.

CRAIG, R. F. (1974). Craig's Soil Mechanics. $7^{\text {th }}$ edition, Spon Press - Taylor $\&$ Francis Group. 
Dell'AVanZI, E. e SAYÃO, A.S.F.J. (1998). Avaliação da Probabilidade de Ruptura de Taludes. $11^{\circ}$ COBRAMSEG, ABMS, Brasília, vol. 2, pp. 12891295.

DELl'AVAnZI, E. (1995). Confiabilidade e Probabilidade em Análises de Estabilidade de Taludes. Dissertação de Mestrado, Departamento de Engenharia Civil, PUC-Rio.

DE OLIVEIRA, A. L. R. V. (2018). Avaliação da Segurança de um Quebra-mar Sobre Argila Mole. Dissertação de Mestrado, Departamento de Engenharia Civil, PUC-Rio.

DIXON-HARDY, D. W. \& Engels, J. M. (2007). Methods for the Disposal and Storage of Nine Tailings. Land Contamination \& Reclamation. 15. 301-317.

DUNCAN, J.M. e CHANG, C.Y. (1970). Nonlinear analysis of stress and strain in soil, Journal of the Soil Mechanics and Foundation Division. ASCE, pp. 1629-1653.

DUNCAN, J. M. (2000). Factors of Safety and Reliability. Journal of Geotechnical and Geoenvironmental Engineering. vol. 126 (4), pp. 307-316.

DUNCAN, J. M., WRIGHT S. G. \& BRANDON T. L. (2014). Soil Strength and Slope Stability. Second Edition, John Wiley \& Sons, Inc, New York, USA.

EL-RAMLY, H., MORGENSTERN, N.R. e CRUDEN, D.M. (2003). Reply to the Discussion by J. M. Duncan, M. Navin, and T. F. Wolff on "Probabilistic Slope Stability Analysis for Practice". Canadian Geotechnical Journal, vol. 40 (4), pp.851-855.

EVANS, M. J. \& ROSENTHAL, S. (2009). Probability and Statistics: The Science of Uncertainty. W.H. Freeman \& Company.

FARIAS, M.M. e ASSIS, A.P. (1998). Uma Comparação entre Métodos Probabilísticos Aplicados a Estabilidade de Taludes. $11^{\circ}$ COBRAMSEG, ABMS, Brasília, vol. 2, pp. 1305-1313.

FELLENIUS, W. (1936). Calculation of the Stability of Earth Dams.

Transactions 2nd Congress on Large Dams, Washington, D. C., USA, vol. 4, pp. 445-459.

FREITAS, M. A. C. (2011). Análise de Estabilidade de Taludes pelos Métodos de Morgenstern-Price e Correia. Dissertação de Mestrado, Faculdade de Engenharia do Porto.

GOOGLE EARTH. (2021). https://earth.google.com. Consulta realizada em $19 / 06 / 21$. 
GUEDES, M. C. S. (1997). Considerações sobre Análises Probabilísticas de Estabilidade de Taludes. Dissertação de Mestrado, Departamento de Engenharia Civil, PUC-Rio.

HARR, M. E. (1987). Reliability- Based Design in Civil Engineering. McGrawHill, Inc., U.S.A.

HICKS, M. A. \& SAMY, K. (2002). Influence of Heterogeneity on Undrained Clay Slope Stability. Manchester School of Engineering, University of Manchester, UK.

HURTADO, J. \& BARBAT, A. (1998). Monte Carlo Techniques in Computational Stochastic Mechanics. Archives of Computational Methods in Engineering. 5. 3-30. 10.1007/BF02736747.

JAKUBICK, A., MCKENNA, G., and ROBERTSON, A.M. (2003). Stabilisation of Tailings Deposits. International Experience. Mining and the Environment III, Sudbury. 25-28 May, pp. 1-9.

JANBU, N. (1963). Soil Compressibility as Determined by Oedometer and Triaxial Tests. Procedures ECSMFE, Wiesbaden, pp. 19-25.

KLOHN, E.J. (1981). The Development of Current Tailings Dam Design and Construction Methods. Design and Construction of Tailings Dams, Colorado School of Mines, Colorado, USA, p. 2-75.

KOITER, W. T. (1960). General Theorems for Elastic-plastic Solids. Sneddon \& Hill, eds, Progress in Solid Mechanics, North Holland Publishing Co.

Amsterdam, pp. 165-221

KONDNER, R.L. (1963). Hyperbolic Stress-Strain Response: Cohesive Soils. Journal of the Soil Mechanics and Foundations Division, 89, pp. 115-143.

KONDNER, R. L. \& ZELASKO, J. S. (1963). A Hyperbolic Stress Strain Formulation For Sands. Proceeding of the $2^{\text {nd }}$ Pan American Conference on Soil Mechanics and Foundation Engineering, Brazil.

KULHAWY, F. H. (1992). On the Evaluation of Soil Properties. Geotechnical Special Publication 31, ASCE, Reston, VA, pp. 95-115.

LACASSE, S. \& NADIM, F. (1996). Uncertainties in Characterizing Soil Properties. In Uncertainty in the Geologic Environment.

LACASSE, S. \& NADIM, F. (1997). Uncertainties in Characterizing Soil Properties. Publication No. 21, Norwegian Geotechnical Institute, Oslo, Norway, pp. 49-75.

LACASSE, S. \& NADIM, F. (2007). Geotechnical Analyses for Offshore Facilities. Georisk: Assessment and Management of Risk for Engineered Systems and Geohazards, pp. 21-42. 
LAMBE, T. W., \& WHITMAN, R. V. (1969). Soil Mechanics. John Wiley \& Sons.

LUZ, A.B., SAMPAIO, J.A., ALMEIDA, S.L.M. (2010). Tratamento de Minérios. 5a . Edição/Ed. Rio de Janeiro: CETEM. 965p.

MCKAY, M. D., BECKMAN, R. J. \& CONOVER W. J. (1979). Comparison of Three Methods for Selecting Values of Input Variables in the Analysis of Output from a Computer Code. Technometrics, 21:2, 239-245

METROPOLIS, N. e ULAM, S. (1949). The Monte Carlo Method. Journal of the American Statistical Association, vol. 44, pp. 335-341.

MORGENSTERN, N. R. and PRICE, V.E. (1965). The Analysis of the Stability of General Slip Surfaces. Geotechnique, vol. 15 (1), pp. 79-93.

NAYLOR, D. J., PANDE, G. N., SIMPSON B., \& TABB, R. (1981). Finite Elements in Geotechnical Engineering. Bell \& Bain Ltda., Glassgow, Great Britain.

OBRZUD. R. (2016). Constitutive Models for Practice. Disponível em http://www.zsoil.com/zsoil_course_notes/advancedmodels/ZSoilDay2016_Constitiutive_models_for_geotechnical_practice_v16.00EN.pdf

OLSSON, A., SANDBERG, G. \& DAHLBLOM, O. (2003). On Latin Hypercube Sampling for Structural Reliability Analysis. Division of Structural Mechanics, Lund University, Lund, Sweeden.

PHOON, K. K., \& KULHAWY, F. H. (1999). Characterization of

Geotechnical Variability. Canadian Geotechnical Journal, 36, 612-624.

PLAXIS (2020). Material Models Manual. Disponível em https://communities.bentley.com/products/geotech-analysis/w/plaxis-soilvisionwiki/46137/manuals---plaxis

ROMANEL C. (2018). Noções de Teoria da Plasticidade. Apostila do Curso de Modelos Constitutivos II da PUC-Rio, pp. 92-110.

ROSENBlUETH, R.Y. (1975). Point Estimates for Probability Moments. Proc. of the National Academy of Sciences, Mathematics Section, vol. 72 (10), p.p. 38123814.

ROWE, P. W. (1962). The stress dilatancy relations for static equilibrium of an assembly of particles in contact. Proceedings of Royal Society, London, Series A, 269, pp. 500-527.

SARMA, S. K. (1973). Stability Analysis of Embankments and Slopes. Géotechnique, No. 3, pp. 423-433 
SAYÃO, A. S. F. J., SANDRONI S. S., FONTOURA S. A. B. E RIBEIRO R. C. H. (2012). Considerations on Probability of Failure of Mine Slopes. Soils and Rocks, Volume 35, p.p. 31-37.

SCHANZ, T. (1998). Zur Modellierung des Mechanischen Verhaltens von Reibungsmaterialien.

SCHANZ, T., VERMEER, P. A. \& BONNIER P. G. (1999). Formulation \& Verification of the Hardening Soil Model. Beyond 2000 in Computational Geotechnics. First Edition.

SILVA, C. C. (2015). Análise de Estabilidade de um talude da Cava de Alegria Utilizando Abordagem Probabilística. Dissertação de Mestrado, NUGEO,

Universidade Federal de Ouro Preto.

SPENCER E. (1967). A Method of Analysis of the Stability of Embankment Assuming Inter-Slice Forces. Geotéchnique, vol. 17, p.p.11-26.

VANMARCKE, E. H. (1977a). Probabilistic Modeling od Soil Profiles. Journal of the Geotechnical Engineering Division, ASCE, vol 103.

VECCI, A. N. (2018). Análises Probabilísticas de um Talude de Mineração. Dissertação de Mestrado, Departamento de Engenharia Civil, PUC-Rio.

VERMEER, P. A., BORST, R. (1984). Non-Associated Plasticity for Soils, Concrete and Rock. Heron, 29.

VICK, S. G. (1990). Planning, Design, and Analysis of Tailings Dams. Bitech Publishers Ltd, Vancouver, B. C. Canada.

WACKERLY D. et al. (2007). Mathematical Statistics with Applications. $7^{\text {th }}$ Edition.

ZELGER, J. (2012). Calibration of 2D Pre-relaxation Factors in Tunnelling with 3D Finite Element Calculations. Master thesis, Graz University of Technology. 


\section{Apêndices}

\section{Apêndice A - Influência dos parâmetros no FS das análises FOSM}

Tabela A. 1 - Influência das variações incrementais e decrementais dos parâmetros no FS das análises FOSM pelos métodos de Bishop Simplificado e Morgenstern \& Price

\begin{tabular}{|c|c|c|c|c|c|}
\hline \multirow{2}{*}{ Cenário } & \multirow{2}{*}{ Análise } & \multicolumn{2}{|c|}{ Fator de Segurança } & \multicolumn{2}{|c|}{ Variação percentual de FS } \\
\hline & & $\begin{array}{c}\text { Bishop } \\
\text { Simplificado }\end{array}$ & $\begin{array}{c}\text { Morgenstern } \\
\text { \& Price }\end{array}$ & $\begin{array}{c}\text { Bishop } \\
\text { Simplificado }\end{array}$ & $\begin{array}{c}\text { Morgenstern } \\
\text { \& Price }\end{array}$ \\
\hline \multirow{13}{*}{$\begin{array}{c}\text { Pós } \\
\text { construtivo }\end{array}$} & $\mathrm{E}[\mathrm{FS}]$ & 1.517 & 1.751 & $0.00 \%$ & $0.00 \%$ \\
\hline & SAC - c' (+) & 1.524 & 1.762 & $0.43 \%$ & $0.61 \%$ \\
\hline & SAC $-\phi^{\prime}(+)$ & 1.556 & 1.798 & $2.38 \%$ & $2.61 \%$ \\
\hline & $S A C-\gamma_{n}(+)$ & 1.571 & 1.802 & $3.29 \%$ & $2.83 \%$ \\
\hline & SSG - c' (+) & 1.520 & 1.756 & $0.18 \%$ & $0.28 \%$ \\
\hline & SSG - $\phi^{\prime}(+)$ & 1.565 & 1.752 & $2.93 \%$ & $0.06 \%$ \\
\hline & SSG $-\gamma_{n}(+)$ & 1.535 & 1.752 & $1.10 \%$ & $0.06 \%$ \\
\hline & SAC - c' (-) & 1.510 & 1.745 & $-0.43 \%$ & $-0.33 \%$ \\
\hline & SAC - $\phi^{\prime}(-)$ & 1.475 & 1.692 & $-2.56 \%$ & $-3.28 \%$ \\
\hline & $S A C-\gamma_{n}(-)$ & 1.459 & 1.687 & $-3.54 \%$ & $-3.56 \%$ \\
\hline & SSG - c' (-) & 1.516 & 1.749 & $-0.06 \%$ & $-0.11 \%$ \\
\hline & SSG - $\phi^{\prime}(-)$ & 1.463 & 1.667 & $-3.29 \%$ & $-4.67 \%$ \\
\hline & $S S G-\gamma_{n}(-)$ & 1.494 & 1.706 & $-1.40 \%$ & $-2.50 \%$ \\
\hline \multirow{13}{*}{$\begin{array}{c}\text { Pós } \\
\text { dissipação de } \\
\text { poropressão }\end{array}$} & $\mathrm{E}[\mathrm{FS}]$ & 1.640 & 1.800 & $0.00 \%$ & $0.00 \%$ \\
\hline & SAC $-c^{\prime}(+)$ & 1.650 & 1.803 & $0.61 \%$ & $0.17 \%$ \\
\hline & SAC $-\phi^{\prime}(+)$ & 1.666 & 1.816 & $1.59 \%$ & $0.89 \%$ \\
\hline & $S A C-\gamma_{n}(+)$ & 1.683 & 1.841 & $2.62 \%$ & $2.28 \%$ \\
\hline & SSG - c' (+) & 1.652 & 1.811 & $0.73 \%$ & $0.61 \%$ \\
\hline & SSG - $\phi^{\prime}(+)$ & 1.650 & 1.816 & $0.61 \%$ & $0.89 \%$ \\
\hline & $S S G-\gamma_{n}(+)$ & 1.655 & 1.815 & $0.91 \%$ & $0.83 \%$ \\
\hline & SAC $-c^{\prime}(-)$ & 1.641 & 1.799 & $0.06 \%$ & $-0.06 \%$ \\
\hline & SAC $-\phi^{\prime}(-)$ & 1.593 & 1.749 & $-2.87 \%$ & $-2.83 \%$ \\
\hline & $S A C-\gamma_{n}(-)$ & 1.587 & 1.754 & $-3.23 \%$ & $-2.56 \%$ \\
\hline & SSG - $C^{\prime}(-)$ & 1.639 & 1.794 & $-0.06 \%$ & $-0.33 \%$ \\
\hline & SSG - $\phi^{\prime}(-)$ & 1.562 & 1.718 & $-4.76 \%$ & $-4.56 \%$ \\
\hline & SSG $-\gamma_{n}(-)$ & 1.564 & 1.729 & $-4.63 \%$ & $-3.94 \%$ \\
\hline
\end{tabular}


Tabela A. 2 - Influência das variações incrementais e decrementais dos parâmetros no FS das análises FOSM pelo método Phi-c Reduction

\begin{tabular}{|c|c|c|c|}
\hline \multirow{2}{*}{ Cenário } & \multirow{2}{*}{ Análise } & Fator de Segurança & $\begin{array}{c}\text { Variação } \\
\text { percentual de FS }\end{array}$ \\
\hline & & Phi-c Reduction & Phi-c Reduction \\
\hline \multirow{13}{*}{$\begin{array}{c}\text { Pós } \\
\text { construtivo }\end{array}$} & $\mathrm{E}[\mathrm{FS}]$ & 1.867 & $0.00 \%$ \\
\hline & $S A C-c^{\prime}(+)$ & 1.871 & $0.21 \%$ \\
\hline & SAC $-\phi^{\prime}(+)$ & 1.917 & $2.68 \%$ \\
\hline & $S A C-\gamma_{n}(+)$ & 1.871 & $0.21 \%$ \\
\hline & SSG - c $c^{\prime}(+)$ & 1.87 & $0.16 \%$ \\
\hline & SSG - $\phi^{\prime}(+)$ & 1.888 & $1.12 \%$ \\
\hline & $S S G-\gamma_{n}(+)$ & 1.882 & $0.80 \%$ \\
\hline & $S A C-C^{\prime}(-)$ & 1.862 & $-0.27 \%$ \\
\hline & SAC $-\phi^{\prime}(-)$ & 1.803 & $-3.43 \%$ \\
\hline & $S A C-\gamma_{n}(-)$ & 1.852 & $-0.80 \%$ \\
\hline & SSG - c' (-) & 1.863 & $-0.21 \%$ \\
\hline & SSG - $\phi^{\prime}(-)$ & 1.775 & $-4.93 \%$ \\
\hline & $S S G-\gamma_{n}(-)$ & 1.840 & $-1.45 \%$ \\
\hline \multirow{13}{*}{$\begin{array}{c}\text { Pós } \\
\text { dissipação } \\
\text { de } \\
\text { poropressão }\end{array}$} & $E[F S]$ & 1.662 & $0.00 \%$ \\
\hline & SAC $-c^{\prime}(+)$ & 1.666 & $0.24 \%$ \\
\hline & SAC $-\phi^{\prime}(+)$ & 1.698 & $2.17 \%$ \\
\hline & $S A C-\gamma_{n}(+)$ & 1.667 & $0.30 \%$ \\
\hline & SSG $-c^{\prime}(+)$ & 1.665 & $0.18 \%$ \\
\hline & SSG - $\phi^{\prime}(+)$ & 1.728 & $3.97 \%$ \\
\hline & SSG $-\gamma_{n}(+)$ & 1.674 & $0.72 \%$ \\
\hline & $S A C-c^{\prime}(-)$ & 1.658 & $-0.24 \%$ \\
\hline & $S A C-\phi^{\prime}(-)$ & 1.616 & $-2.77 \%$ \\
\hline & $S A C-\gamma_{n}(-)$ & 1.646 & $-0.96 \%$ \\
\hline & SSG - c' (-) & 1.656 & $-0.36 \%$ \\
\hline & SSG - $\phi^{\prime}(-)$ & 1.574 & $-5.29 \%$ \\
\hline & $S S G-\gamma_{n}(-)$ & 1.633 & $-1.74 \%$ \\
\hline
\end{tabular}




\section{Apêndice B - Resultados das análises pelo método FOSM}

Tabela B. 1 - Resultados das análises FOSM pelo método de Bishop

Simplificado no cenário pós construtivo

\begin{tabular}{|c|c|c|c|c|c|c|}
\hline \multicolumn{7}{|c|}{ Bishop Simplificado - Cenário pós construtivo } \\
\hline Variável & $\bar{x}$ & $\bar{x}+\delta x$ & $\bar{x}-\delta x$ & $\partial \mathbf{F S} / \partial \mathbf{x i}$ & $\mathbf{V}(\mathbf{x})$ & $\mathbf{V}_{\text {rel }}(\mathrm{FS})$ \\
\hline$c^{\prime} \mathrm{SAC}(\mathrm{kPa})$ & 20,1 & 22,11 & 18,09 & 0.0035 & 110.0401 & 0.001348 \\
\hline$\phi^{\prime} \operatorname{SAC}\left({ }^{\circ}\right)$ & 24,42 & 26,86 & 21,98 & 0.0166 & 22.1841 & 0.006113 \\
\hline$\gamma_{n} \mathrm{SAC}\left(\mathrm{kN} / \mathrm{m}^{3}\right)$ & 16,92 & 18,61 & 15,23 & 0.0331 & 3.3856 & 0.003709 \\
\hline$c^{\prime} \mathrm{SSG}(\mathrm{kPa})$ & 9,22 & 10,14 & 8,30 & 0.0022 & 154.0081 & 0.000745 \\
\hline$\phi^{\prime}$ SSG $\left(^{\circ}\right)$ & 28,16 & 30,98 & 25,34 & 0.0181 & 9.9856 & 0.003271 \\
\hline$\gamma_{n} \operatorname{SSG}\left(\mathrm{kN} / \mathrm{m}^{3}\right)$ & 17,53 & 19,28 & 15,78 & 0.026 & 3.4225 & 0.002314 \\
\hline & & & & & $E[F S]$ & 1,517 \\
\hline & & & & & $\mathrm{V}[\mathrm{FS}]$ & 0.017501 \\
\hline & & & & & $\sigma[\mathrm{FS}]$ & 0.13229 \\
\hline & & & & & $\beta$ & 3.908071 \\
\hline & & & & & PR & 4.65E-05 \\
\hline
\end{tabular}

Tabela B. 2 - Resultados das análises FOSM pelo método de Morgenstern \& Price no cenário pós construtivo

\begin{tabular}{ccccccc}
\hline \multicolumn{7}{c}{ Morgenstern \& Price - Cenário pós construtivo } \\
\hline Variável & $\overline{\boldsymbol{x}}$ & $\overline{\boldsymbol{x}}+\boldsymbol{\delta} \boldsymbol{x}$ & $\overline{\boldsymbol{x}}-\boldsymbol{\delta} \boldsymbol{x}$ & $\boldsymbol{\partial \mathbf { F S }} / \boldsymbol{\partial \mathbf { x i }}$ & $\mathbf{V}(\mathbf{x})$ & $\mathbf{V}_{\text {rel }}(\mathbf{F S})$ \\
\hline$c^{\prime} \mathrm{SAC}(\mathrm{kPa})$ & 20,1 & 22,11 & 18,09 & 0.0042 & 110.0401 & 0.001941 \\
\hline$\phi^{\prime} \mathrm{SAC}\left({ }^{\circ}\right)$ & 24,42 & 26,86 & 21,98 & 0.0217 & 22.1841 & 0.010446 \\
\hline$\gamma_{n} \mathrm{SAC}\left(\mathrm{kN} / \mathrm{m}^{3}\right)$ & 16,92 & 18,61 & 15,23 & 0.034 & 3.3856 & 0.003914 \\
\hline$c^{\prime} \mathrm{SSG}(\mathrm{kPa})$ & 9,22 & 10,14 & 8,30 & 0.0038 & 154.0081 & 0.002224 \\
\hline$\phi^{\prime} \mathrm{SSG}\left(^{\circ}\right)$ & 28,16 & 30,98 & 25,34 & 0.0151 & 9.9856 & 0.002277 \\
\hline$\gamma_{n} \mathrm{SSG}\left(\mathrm{kN} / \mathrm{m}^{3}\right)$ & 17,53 & 19,28 & 15,78 & 0.0131 & 3.4225 & 0.000587 \\
\hline & & & & & $\mathrm{E}[\mathrm{FS}]$ & 1,751 \\
& & & & & $\mathrm{~V}[\mathrm{FS}]$ & 0.021389 \\
& & & & & $\sigma \mathrm{FS}]$ & 0.14625 \\
& & & & & $\beta$ & 5.135031 \\
& & & & & & $1.41 \mathrm{E}-07$
\end{tabular}


Tabela B. 3 - Resultados das análises FOSM pelo método Phi-c Reduction no cenário pós construtivo

\begin{tabular}{|c|c|c|c|c|c|c|}
\hline \multicolumn{7}{|c|}{ Phi-c Reduction - Cenário pós construtivo } \\
\hline Variável & $\bar{x}$ & $\bar{x}+\delta x$ & $\bar{x}-\delta x$ & $\partial \mathbf{F S} / \partial \mathbf{x i}$ & $\mathbf{V}(\mathbf{x})$ & $\mathrm{V}_{\text {rel }}(\mathrm{FS})$ \\
\hline$c^{\prime} \mathrm{SAC}(\mathrm{kPa})$ & 20,1 & 22,11 & 18,09 & 0.002 & 110.0401 & 0.00044 \\
\hline$\phi^{\prime} \operatorname{SAC}\left({ }^{\circ}\right)$ & 24,42 & 26,86 & 21,98 & 0.0168 & 22.1841 & 0.006261 \\
\hline$\gamma_{n} \mathrm{SAC}\left(\mathrm{kN} / \mathrm{m}^{3}\right)$ & 16,92 & 18,61 & 15,23 & 0.0062 & 3.3856 & 0.00013 \\
\hline$c^{\prime} \mathrm{SSG}(\mathrm{kPa})$ & 9,22 & 10,14 & 8,30 & 0.0049 & 154.0081 & 0.003698 \\
\hline$\phi^{\prime}$ SSG $\left(^{\circ}\right)$ & 28,16 & 30,98 & 25,34 & 0.0273 & 9.9856 & 0.007442 \\
\hline \multirow[t]{6}{*}{$\gamma_{n} \mathrm{SSG}\left(\mathrm{kN} / \mathrm{m}^{3}\right)$} & 17,53 & 19,28 & 15,78 & 0.0117 & 3.4225 & 0.000469 \\
\hline & & & & & $E[F S]$ & 1,662 \\
\hline & & & & & $\mathrm{V}[\mathrm{FS}]$ & 0.01844 \\
\hline & & & & & $\sigma[\mathrm{FS}]$ & 0.135794 \\
\hline & & & & & $\beta$ & 4.875039 \\
\hline & & & & & PR & $5.44 \mathrm{E}-07$ \\
\hline
\end{tabular}

Tabela B. 4 - Resultados das análises FOSM pelo método de Bishop

Simplificado no cenário pós dissipação de poropressão

\begin{tabular}{|c|c|c|c|c|c|c|}
\hline \multicolumn{7}{|c|}{ Bishop Simplificado - Cenário pós dissipação de poropressão } \\
\hline Variável & & & & $\partial \mathbf{F S} / \partial \mathbf{x i}$ & $\mathbf{V}(\mathbf{x})$ & $\mathbf{V}_{\text {rel }}(\mathrm{FS})$ \\
\hline$c^{\prime} \mathrm{SAC}(\mathrm{kPa})$ & 20,1 & 22,11 & 18,09 & 0,0022 & 110,0401 & 0,000533 \\
\hline$\phi^{\prime} \operatorname{SAC}\left({ }^{\circ}\right)$ & 24,42 & 26,86 & 21,98 & 0,0149 & 22,1841 & 0,004925 \\
\hline$\gamma_{n} \mathrm{SAC}\left(\mathrm{kN} / \mathrm{m}^{3}\right)$ & 16,92 & 18,61 & 15,23 & 0,0284 & 3,3856 & 0,002731 \\
\hline$c^{\prime} \mathrm{SSG}(\mathrm{kPa})$ & 9,22 & 10,14 & 8,30 & 0,007 & 154,0081 & 0,007546 \\
\hline$\phi^{\prime}$ SSG $\left({ }^{\circ}\right)$ & 28,16 & 30,98 & 25,34 & 0,0156 & 9,9856 & 0,00243 \\
\hline \multirow[t]{6}{*}{$\gamma_{n}$ SSG $\left(\mathrm{kN} / \mathrm{m}^{3}\right)$} & 17,53 & 19,28 & 15,78 & 0,026 & 3,4225 & 0,002314 \\
\hline & & & & & $\mathrm{E}[\mathrm{FS}]$ & 1,640 \\
\hline & & & & & $\mathrm{V}[\mathrm{FS}]$ & 0,020478 \\
\hline & & & & & $\sigma[\mathrm{FS}]$ & 0,143103 \\
\hline & & & & & $\beta$ & 4,472302 \\
\hline & & & & & PR & 3,87E-06 \\
\hline
\end{tabular}


Tabela B. 5 - Resultados das análises FOSM pelo método de Morgenstern \& Price no cenário pós dissipação de poropressão

\begin{tabular}{|c|c|c|c|c|c|c|}
\hline \multicolumn{7}{|c|}{ Morgenstern \& Price - Cenário pós dissipação de poropressão } \\
\hline Variável & & & & $\partial \mathbf{F S} / \partial \mathbf{x i}$ & $\mathbf{V}(\mathbf{x})$ & $\mathrm{V}_{\text {rel }}(\mathrm{FS})$ \\
\hline$c^{\prime} \mathrm{SAC}(\mathrm{kPa})$ & 20,1 & 22,11 & 18,09 & 0,001 & 110,0401 & 0,00011 \\
\hline$\phi^{\prime} \operatorname{SAC}\left({ }^{\circ}\right)$ & 24,42 & 26,86 & 21,98 & 0,0137 & 22,1841 & 0,004164 \\
\hline$\gamma_{n} \mathrm{SAC}\left(\mathrm{kN} / \mathrm{m}^{3}\right)$ & 16,92 & 18,61 & 15,23 & 0,0257 & 3,3856 & 0,002236 \\
\hline$c^{\prime}$ SSG (kPa) & 9,22 & 10,14 & 8,30 & 0,0092 & 154,0081 & 0,013035 \\
\hline$\phi^{\prime} \operatorname{SSG}\left({ }^{\circ}\right)$ & 28,16 & 30,98 & 25,34 & 0,0174 & 9,9856 & 0,003023 \\
\hline \multirow[t]{6}{*}{$\gamma_{n} \operatorname{SSG}\left(\mathrm{kN} / \mathrm{m}^{3}\right)$} & 17,53 & 19,28 & 15,78 & 0,0245 & 3,4225 & 0,002054 \\
\hline & & & & & $\mathrm{E}[\mathrm{FS}]$ & 1,800 \\
\hline & & & & & $\mathrm{V}[\mathrm{FS}]$ & 0,024623 \\
\hline & & & & & $\sigma[\mathrm{FS}]$ & 0,156916 \\
\hline & & & & & $\beta$ & 5,590378 \\
\hline & & & & & PR & $1,13 \mathrm{E}-08$ \\
\hline
\end{tabular}

Tabela B. 6 - Resultados das análises FOSM pelo método Phi-c Reduction no cenário pós dissipação de poropressão

\begin{tabular}{|c|c|c|c|c|c|c|}
\hline \multicolumn{7}{|c|}{ Phi-c Reduction - Cenário pós dissipação de poropressão } \\
\hline Variável & & & & $\partial \mathbf{F S} / \partial \mathbf{x i}$ & $\mathbf{V}(\mathbf{x})$ & $V_{\text {rel }}(\mathrm{FS})$ \\
\hline$c^{\prime} \mathrm{SAC}(\mathrm{kPa})$ & 20,1 & 22,11 & 18,09 & 0,0022 & 110,0401 & 0,000533 \\
\hline$\phi^{\prime} \mathrm{SAC}\left({ }^{\circ}\right)$ & 24,42 & 26,86 & 21,98 & 0,0233 & 22,1841 & 0,012044 \\
\hline$\gamma_{n} \mathrm{SAC}\left(\mathrm{kN} / \mathrm{m}^{3}\right)$ & 16,92 & 18,61 & 15,23 & 0,0056 & 3,3856 & 0,000106 \\
\hline$c^{\prime} \mathrm{SSG}(\mathrm{kPa})$ & 9,22 & 10,14 & 8,30 & 0,0038 & 154,0081 & 0,002224 \\
\hline$\phi^{\prime}$ SSG $\left(^{\circ}\right)$ & 28,16 & 30,98 & 25,34 & 0,0201 & 9,9856 & 0,004034 \\
\hline$\gamma_{n} \mathrm{SSG}\left(\mathrm{kN} / \mathrm{m}^{3}\right)$ & 17,53 & 19,28 & 15,78 & 0,012 & 3,4225 & 0,000493 \\
\hline & & & & & $E[F S]$ & 1,867 \\
\hline & & & & & $\mathrm{V}[\mathrm{FS}]$ & 0,019433 \\
\hline & & & & & $\sigma[\mathrm{FS}]$ & 0,139403 \\
\hline & & & & & $\beta$ & 6,219363 \\
\hline & & & & & PR & $2,5 \mathrm{E}-10$ \\
\hline
\end{tabular}

